\title{
ADT-OH exhibits anti-metastatic activity on malignant melanoma through inhibition of FAK/Paxillin signaling pathways
}

\section{Fangfang Cai}

Nanjing University

Huangru Xu

Nanjing University

Shihui Yu

Nanjing University

Ping Li

Nanjing University

Yanyan Lu

Nanjing University

Jia Chen

Nanjing University

Zhiqian Bi

Nanjing University

Huisong Sun

Nanjing University

Jian Cheng

Soochow University

Hongqin Zhuang

Nanjing University

Zi-Chun Hua ( $\square$ hzc1117@nju.edu.cn )

Nanjing University

\section{Research}

Keywords: ADT-OH, melanoma, EMT, tumor metastasis, FAK

Posted Date: November 5th, 2020

DOI: https://doi.org/10.21203/rs.3.rs-100300/v1 
License: (c) (i) This work is licensed under a Creative Commons Attribution 4.0 International License. Read Full License 


\section{Abstract}

Background: Melanoma is a highly aggressive cancer, and its high metastasis results in a high lethality. Hydrogen sulfide $\left(\mathrm{H}_{2} \mathrm{~S}\right)$ is now widely recognized as the third endogenous gas delivery substance and may play a key role in cancer biological processes. The present study was designed to evaluate the antimetastatic effect of $\mathrm{H}_{2} \mathrm{~S}$-donor ADT-OH on melanoma cells and the underlying mechanism.

Methods: Firstly, the effect of ADT-OH on the migration of melanoma cells was explored in vivo by the mouse footpad injection model and the mouse tail vein metastasis model. Tumor xenograft growth and tumor tissue H\&E analyses were also measured in vivo. Then, the migration inhibitory effect and the underlying mechanism of ADT-OH on B16F10, B16F1 and A375 melanoma cell lines were evaluated by wound healing, transwell, western blot and immunofluorescence analyses.

Results: Our data showed that ADT-OH inhibited the migration and invasion of melanoma cells significantly in vivo in three different animal models. Further research showed that ADT-OH significantly suppressed the migratory, invasive and adhesive properties of A375 and B16F10 cells as measured by the wound-healing and transwell assays. Mechanistically, ADT-OH treatment suppressed the EMT processes and reduced the enzymatic activity of FAK and Paxillin. Moreover, abnormal CSE/CBS and AKT signaling pathways in A375 and B16F10 cells were notably observed following ADT-OH treatment. Additionally, ADT-OH at higher concentration significantly inhibited the proliferation of highly metastatic melanoma A375 and B16F10 cells.

Conclusions: Our results suggest that ADT-OH exerts anti-metastasis activity in melanoma cells by suppressing the EMT process through the CSE/CBS and FAK signaling pathways, and it might be used as an agent against metastatic melanoma in future.

\section{Background}

Melanoma is the deadliest and most aggressive form of skin cancer. According to epidemiological data, 132,000 new cases of melanoma and 50,000 melanoma-related deaths are diagnosed worldwide each year (1). Over the last 10 years, rates for new melanoma of the skin cases have been rising on average $1.5 \%$ each year. If melanoma is resected before metastasis, the 5 -year survival rate is about $98 \%$. However, if transfer is allowed, the rate is only $10-15 \%$ (2). Unfortunately, metastatic melanoma responds poorly to current available therapeutic agents. And so far, there is no clinically effective drugs for metastatic melanoma. Therefore, new and effective compounds are urgently needed to effectively inhibit the metastatic ability of melanoma cells and prevent the metastasis of tumor cells.

Hydrogen sulfide $\left(\mathrm{H}_{2} \mathrm{~S}\right)$ is the third gas signal molecule other than carbon dioxide and nitric oxide that plays important roles in cancer biological processes, such as angiogenesis (3), oxidative stress (4), cell cycle $(5)$ and cell apoptosis $(6,7) . \mathrm{H}_{2} \mathrm{~S}$ is also endogenously produced by several enzymes, including cystathionine $\beta$-synthase (CBS), cystathionine $\gamma$-lyase (CSE), the tandem enzymes cysteine 
aminotransferase (CAT) and 3-mercaptopyruvate sulfurtransferase (3-MST) (8). Nevertheless, overexpression of $\mathrm{H}_{2} \mathrm{~S}$-generating enzymes or treatment with relatively high concentrations of $\mathrm{H}_{2} \mathrm{~S}$ donors, such as DATS, GYY4137 and ATB-346, exhibits a better anti-cancer effect on various kinds of tumors including lung cancer, liver cancer, prostate cancer and other cancers. This anti-cancer effect is mainly through the following ways: inducing tumor cell death by increasing uncontrolled intracellular acidification (9); inducing apoptosis by inhibiting the NF-KB pathway and STAT3 $(5,7,10)$; triggering cell cycle arrest by inhibiting Cyclin D1 (11). It has also been reported that hydrogen sulfide could inhibit human breast cancer invasion and epithelial-mesenchymal transition (EMT) by reducing p38 mitogenactivated protein kinase phosphorylation (12). However, the detailed mechanism of $\mathrm{H}_{2} \mathrm{~S}$-mediated antimetastatic effect on melanoma has not been clarified so far, and further clarification is needed.

We have made considerable research on the anti-tumor effect and mechanism of $\mathrm{H}_{2} \mathrm{~S}$ and its donor ADT$\mathrm{OH}$, which show that the anti-tumor effect of hydrogen sulfide donor is efficient with low toxicity. ADT-OH significantly inhibited the proliferation of a variety of tumor cells, such as A549, H446, H1299, HepG2, HCT-116 and MDA-MB-231, especially melanoma cells B16F10 and A375. Interestingly, ADT-OH was found to significantly inhibit melanoma cell migration and its molecular mechanism has also been elucidated in this study.

\section{Materials And Methods}

\section{Plasmids, Cell lines and Reagents}

The encoding sequence of mouse FAK was amplified from cDNA of B16F10 cells and cloned into pRK5Flag vector. The promoter sequence of human and mouse FAK was amplified and cloned into pGL3 reporter vector just as the previous article (13). Actinomycin D (Act D) was purchased from Sigma. B16F10 and B16F1 (murine melanoma cells), A375 (human melanoma cells) and MEF (murine embryonic fibroblast cells) were purchased from American Type Culture Collection (ATCC, USA) or maintained in our laboratory. All cells were cultured at $37^{\circ} \mathrm{C}$ in $5 \% \mathrm{CO}_{2}$ in a humidified atmosphere in Dulbecco's modified Eagle's media (DMEM, Gibco, Shanghai, China) with 10\% fetal bovine serum (FBS, Gibco, Australia), penicillin (100 IU/ml) and streptomycin $(100 \mu \mathrm{g} / \mathrm{ml})$.

\section{Real-time quantitative PCR assay}

Total RNA was extracted with TRIzol reagent (Invitrogen, USA) following the manufacturer's instructions. Quantitative real-time PCR was performed using reverse transcription kit (Takara, Japan) and SYBR Green PCR Master Mix (Roche, Germany). The primers were listed in Supplementary Table S1. Data were analyzed by StepOne 2.1 software (Applied Biosystems, USA) according to the manufacturer's specifications, and were normalized using $\beta$-actin.

\section{Protein extraction and immunoblotting}


Cells were collected and homogenized with whole cell lysate prepared with RIPA lysis buffer (Santa Cruz Biotechnology) containing protease inhibitors, PMSF and orthovanadate. After 30 minutes of incubation on ice, the whole-cell extract was pelleted in an Eppendorf microcentrifuge and centrifuged at 12,000 rpm for 10 minutes at $4{ }^{\circ} \mathrm{C}$. Supernatants were collected and protein concentration was determined by the BioRad protein assay method (Bio-Rad, Hercules, CA). Proteins were separated by SDS-PAGE and transferred onto nitrocellulose membranes that were blocked with $5 \%$ non-fat milk in TBS containing $0.1 \%$ Tween-20, and incubated with primary antibodies: p-FAK, FAK, Akt, p-Akt (Ser 473), Paxillin, E-cadherin, N-cadherin, Vimentin (Cell Signaling Technology, Beverly, MA, USA), $\beta$-actin (ABGENT, San Diego, USA). Secondary antibodies were coupled to horseradish peroxidase, and were goat anti-rabbit or goat anti-mouse. All experiments were done in triplicate and performed at least three times independently.

\section{LC-MS/MS analysis and bioinformatics analysis}

The LC-MS/MS analysis was performed as previously described (13). Briefly, after collecting the cells and obtaining the lysate, the peptide was purified using a Strata-XC18 column, and then the obtained peptide was labeled with the iTRAQ Reagent-8 plex Multiplex Kit (AB Sciex U.K. Limited) according to the manufacturer's instructions. The samples and labeled markers in this article were as follows: the samples of MEF negative control cells were labeled with iTRAQ tag 115, the samples of MEF ADT-OH $(2 \mu \mathrm{M}, 15$ min)-treated cells were labeled with iTRAQ tag 117, the samples of MEF ADT-OH $(2 \mu \mathrm{M}, 2 \mathrm{~h})$-treated cells were labeled with iTRAQ tag 118, the samples of MEF ADT-OH (50 $\mu \mathrm{M}, 15 \mathrm{~min})$-treated cells were labeled with iTRAQ tag 119 the samples of MEF ADT-OH $(50 \mu \mathrm{M}, 2 \mathrm{~h})$-treated cells were labeled with iTRAQ tag 121. All the labeled samples were mixed in equal amounts and then fractionated using a Durashell C18 (5 $\mu \mathrm{m}, 100 \AA, 4.6 \times 250 \mathrm{~mm}$ ) though high-performance liquid chromatography (HPLC) system (Thermo DINOEX Ultimate 3000 BioRS). Then the Triple TOF 5600 System (AB SCIEX, Concord, ON) was used for data acquisition, and ProteinPilot Software 5.0 (AB SCIEX) was used for protein identification and iTRAQ relative quantification. High abundance $(>1.5$-fold, $p<0.05)$ and low abundance $(<0.67$-fold, $p<0.05)$ proteins were used to identify differentially expressed proteins (DEPs). Finally, MetaCore ${ }^{\mathrm{TM}}$ version 5.4 (GeneGo, St. Joseph, MI) was used to further analyze the identified differentially expressed proteins through pathway analysis.

\section{Cell cycle, cell apoptosis and cellular reactive oxygen species (ROS) levels analysis}

B16F10, B16F1 and A375 cells were treated with different concentrations of ADT-OH $(0,6.3,25,100 \mu \mathrm{M})$ for $24 \mathrm{~h}$. For cell cycle analysis, cells were fixed overnight at $4{ }^{\circ} \mathrm{C}$ using $70 \%$ pre-chilled ethanol $(1 \mathrm{~mL})$. After PI staining, cells were analyzed on a FACSCalibur flow cytometer with CellQuest software (BD Biosciences, CA, USA). For the detection of apoptosis, the treated cells were incubated with enhanced green fluorescent protein-coupled annexin V (BD Pharmingen, San Diego, CA, USA) according to the manufacturer's instructions, and then analyzed by flow cytometry (BD Biosciences, California, USA). For the detection of ROS, the cells treated with the above drugs were resuspended in serum-free DMEM medium containing $10 \mu \mathrm{M} \mathrm{MDCFH-DA}$ and incubated at $37^{\circ} \mathrm{C}$ in the dark for 30 minutes. After collecting and washing the cells, $400 \mu \mathrm{L}$ of single cell suspension was analyzed using a FACSCalibur flow 
cytometer with CellQuest software (BD Biosciences, CA, USA). The level of intracellular reactive oxygen species was determined based on the fluorescence intensity of the FL1 channel.

\section{Luciferase reporter assay}

B16F10, B16F1 and A375 cells were cotransfected with pGL3-basic, FAK-promoter luciferase (pGL3-FAK) and control pRL-SV40 reporter for $24 \mathrm{~h}$. Luciferase activities were measured consecutively by using DualLuciferase assays (Promega, USA). All measurements were normalized for Renilla luciferase activity to correct the variations in transfection efficiencies.

\section{Cell proliferation assay}

CCK8 assay was used to measure cell proliferation. Cells in the exponential growth phase were seeded into a 96-well plate at a density of 5000 cells per well. The cells were incubated with ADT-OH $(0.8-100 \mu \mathrm{M})$ for $24 \mathrm{~h}$ before adding $10 \mu \mathrm{l}$ of CCK8 (Sigma, Milan, Italy), and cell viability was measured by using a microplate spectrophotometer (Titertek Mul-tiskan MCC / 340) equipped with a $450 \mathrm{~nm}$ filter. Each experiment was performed in quadruplicate and repeated at least three times.

\section{Cell migration assay}

The cell migration assay was performed using transwell inserts $(8.0 \mathrm{~mm}$ pore size, Millipore, Billerica, MA, USA). The cells were starved for $12 \mathrm{~h}$ prior to the experiment. Cells were then harvested and resuspended in a cell suspension diluted to $5 \times 10^{5}$ cells / mL with serum-free DMEM containing $1 \%$ BSA. $200 \mu \mathrm{L}$ of cell suspension were pipetted into the upper chamber, and the lower chamber was filled with $600 \mu \mathrm{L}$ of $10 \%$ FBS supplemented medium. After incubation at $37^{\circ} \mathrm{C}$ for $10 \mathrm{~h}$ or $16 \mathrm{~h}$, cells on the upper surface of the membrane were removed. The migrant cells attached to the lower surface were fixed in $4 \%$ paraformaldehyde at room temperature for $30 \mathrm{~min}$, and stained for $30 \mathrm{~min}$ with a solution containing $1 \%$ crystal violet and $2 \%$ ethanol in $100 \mathrm{mM}$ borate buffer ( $\mathrm{pH} 9.0)$. The number of cells migrating to the lower surface of the membrane was photographed in five fields under a microscope with a magnification of $\times 100$. The chamber was then purged with $33 \% \mathrm{HAC}(100 \mu \mathrm{L})$. After the crystal violet was completely dissolved and the cells were evenly distributed in the HAC solution, the assay was performed at $570 \mathrm{~nm}$ using a microplate reader (TECNA, Switzerland) and quantitative analysis was performed using GraphPad Prism 8.0 software.

\section{Wound-healing assay}

Cells were plated in 6-well culture plates to form cell monolayer (near $90 \%$ confluence). A sterile P-200 micropipette was used to scrape off the cells to make wounds. Then the wells were washed three times with PBS to remove non-adherent cells. The progress of wound closure was monitored with $\mathrm{a} \times 10$ microphotographs taken by the light microscope (Carl Zeiss Axioplan 2) at the beginning and the end of the experiments after washing with PBS. Image $\mathrm{J}$ software was used to calculate the scratch area of the melanoma cells treated with or without $\mathrm{ADT}-\mathrm{OH}$ at $\mathrm{O} \mathrm{h}$ and $24 \mathrm{~h}$, and then the migration rates were 
calculated using the following formula $₫$ Migration rate $=(\mathrm{S} 1-\mathrm{S} 2) / \mathrm{S} 1$, where $\mathrm{S} 1$ represents the scratch area at $0 \mathrm{~h}$; $\mathrm{S} 2$ represents the scratch area at $24 \mathrm{~h}$.

\section{Colony-forming assay}

Colony-forming assay was performed as previously described $(14,15)$. Briefly, about 300 cells in log phase were plated into $60 \mathrm{~mm}$ tissue culture Petri-dish (Greiner) in triplicate with $3 \mathrm{~mL}$ of culture medium and grown at $37^{\circ} \mathrm{C}$ with $5 \% \mathrm{CO}_{2} .48 \mathrm{~h}$ later, cells were rinsed with fresh medium, and ADT-OH was added at different concentrations $(0,3.2,6.3,12.5,25,50 \mu \mathrm{M})$. After incubation for $48 \mathrm{~h}$, the cells were washed twice with PBS and then incubated in drug-free medium. The medium was changed every 5 days. After culturing for additional 10-14 days, the medium was discarded and each dish was washed twice with PBS carefully. The cells were fixed with methanol for $15 \mathrm{~min}$ and stained with a 1:10 dilution of Giemsa regent (Merck, Germany) for 10 min. Any grouping of cells containing 30 or more cells was counted as a colony. Colony numbers were determined from triplicate plates. Colony growth was related to the control value without any treatment.

\section{Immunofluorescence assay (IFA)}

The immunofluorescence assay was performed as previously described (16). B16F10, B16F1 and A375 cells were treated with $\mathrm{ADT}-\mathrm{OH}$ at different concentrations. After $48 \mathrm{~h}$, cells were harvested and immunostained with anti-E-cadherin and vimentin antibody, respectively. The cells were then incubated with Alexa Fluor 488-labeled (\#A21202, Thermo Fisher Scientific Inc.) and Alexa Fluor 594-labeled (\#A21207, Thermo Fisher Scientific Inc.) secondary antibody for $1 \mathrm{~h}$ at room temperature. After the cell nucleus was counterstained with DAPI, images were obtained using the ZEN 2009 Light Edition software (Carl Zeiss) through an inverted Zeiss LSM710 confocal microscope (40x lens) (Carl Zeiss).

\section{Development of mouse tail vein injection model}

B16F10 and A375 cells $\left(2 \times 10^{6}\right)$ suspended in $200 \mu \mathrm{L}$ of PBS were injected into the tail vein of the C57BL/ 6 mice or nude mice. Beginning on the second day, the mice were administered with vehicle, 17.5 $\mathrm{mg} / \mathrm{kg} \mathrm{ADT-OH}, 37.5 \mathrm{mg} / \mathrm{kg}$ ADT-OH, 75 mg/kg ADT-OH, 1.4 mg/kg NaHS, 2.8 mg/kg NaHS and 5.6 $\mathrm{mg} / \mathrm{kg} \mathrm{NaHS}$ five times a week for a total of 3 weeks with at least 8 mice per group. The mice were then repeatedly imaged for metastatic tumor spreading to distant organs. At the end of study, mice were euthanized and the lungs and livers were harvested, fixed in 10\% formalin, and paraffin embedded for pathological examination of H\&E slides.

\section{In vivo footpad injection model}

B16F10 cells $\left(2 \times 10^{5}\right.$ cells in $50 \mu$ PBS) were implanted into the right hind footpads of C57BL/ 6 mice using a Hamilton syringe and 25-gauge needle. The detailed treatment was described in Fig. 1b. All mice were euthanized 21 days after tumor inoculation in order to assess the number of spontaneous metastases in the lungs. The following formula was used to measure and calculate the volume of the 
tumor in the sole of the foot: $0.5236 \times L 1 \times(L 2)^{2}$, where $L 1$ is the long axis of the tumor and $L 2$ is the short axis of the tumor.

\section{H\&E assays}

In a parallel animal assay (totally three groups, and three mice per group), the tumor establishment and drug treatment are the same as described above. On the $21^{\text {th }}$ day, mice were euthanized. Tumors were collected, fixed with $4 \%$ formaldehyde and then embedded in paraffin. Tissue sections (5 $\mu$ m in thickness) were prepared according to standard protocols for hematoxylin/eosin (H\&E) staining. Apoptotic cells in tumor sections (two sections per mouse, three mice in total) were visualized by the TUNEL technique according to the manufacturer's instruction (Merck).

\section{Statistical analysis}

Data were presented as means \pm SD. Comparisons within groups were done with a $t$-test with repeated measures; $p$-values indicated in figures are $<0.05(*),<0.01(* *)$, and $<0.001(* * *)$.

\section{Results}

\section{ADT-OH inhibits melanoma invasion in vivo}

$\mathrm{H}_{2} \mathrm{~S}$ is produced in mammalian cells by three major enzymes, including CSE, CBS, and 3-MST. Numerous studies have shown that expression of these enzymes has changed in various types of cancer cell processes, especially CSE and CBS $(3,17-19)$. According to Oncomine, an online cancer transcriptome database, CSE and CBS were observed to be overexpressed in human skin cutaneous melanoma (SKCM). In addition, Kaplan-Meier survival analysis of SKCM patients showed that cases with higher expression of CSE or CBS exhibited poorer overall survival (Fig. 1a). Furthermore, we found that the overall survival rate of patients exhibiting high CSE and CBS expression with lung adenocarcinoma, acute myeloid leukemia, bladder urothelial carcinoma, and adrenocortical carcinoma is also significantly reduced based on The Cancer Genome Atlas (TCGA) datasets (Fig. 1a, Supplementary Fig. S1 and Supplementary Fig. S2). In our study, after treatment with ADT-OH, the protein level of CBS and CSE in melanoma cells was found to be significantly down-regulated (Supplementary Fig. S3). Taken together, these results discover that $\mathrm{H}_{2} \mathrm{~S}$ plays a vital role in the molecular biological characteristics of cancer, which may be a potential drug target for treatment of poor prognosis. Therefore, the palm transfer model was implemented. As is shown in Fig. $1 \mathrm{~b}$ and c, intraplantar injection of mouse melanoma cells ( $5 \times 10^{5}$ cells in $\left.20 \mu \mathrm{l}\right)$ into C57BL/ 6 mice led to time-dependent tumor growth in a hind paw, showing a 3 to 4-fold increase in paw volume 3 weeks after melanoma cell implantation. After treatment with $\mathrm{ADT}-\mathrm{OH}$, the paw volume of melanoma-bearing mice was reduced from $252.128 \mathrm{~mm}^{3}$ to $105.2557 \mathrm{~mm}^{3}$. Moreover, H\&E staining analysis showed that ADT-OH treatment significantly reduced the melanoma nodules in the lungs of mice, especially when treated with a dose of $37.5 \mathrm{mg} / \mathrm{kg}$ (Fig. 1d). Furthermore, mice passive lung metastasis model was also established to investigate the effects of ADT-OH on melanoma cancer metastasis in vivo (Fig. 2a). Lung 
metastasis nodules were found in the lungs and counted macroscopically (Fig. 2b). Compared with control group, the lung metastasis was restrained in $\mathrm{ADT}-\mathrm{OH}$ - and NaHS-treated groups, especially in the ADT-OH (37.5 mg/kg)-treated group. Likewise, H\&E staining results in Fig. $2 \mathrm{c}$ showed that ADT-OH and $\mathrm{NaHS}$ treatment could significantly decrease lung metastases of B16F10 cells and reduce lung nodule volume. We also performed the same experiment on female BALB/c nude mice using A375 cells. As shown in Fig. $2 \mathrm{~d}$ and e, lung metastases of $\mathrm{A} 375$ cells and lung nodule volumes were markedly decreased after ADT-OH treatment. Taken together, our study suggests that ADT-OH could inhibit the migration and invasion of melanoma cells significantly in vivo.

\section{ADT-OH suppresses melanoma cell migration and invasion in vitro}

Migration is an essential step in tumor cell metastasis process. Since effective therapeutics against metastatic melanoma are absent in the clinical practice, we assessed the anti-migration effect of ADT-OH on the metastatic melanoma cells A375 and B16F10. The wound-healing assay showed that A375, B16F10 and B16F1 cells displayed high migrated capabilities as indicated by being able to completely heal the wound scratch in the absence of ADT-OH (Fig. 3). However, ADT-OH significantly inhibited the activity of migration of melanoma A375, B16F10 and B16F1 cells in a dose-dependent manner.

\section{ADT-OH inhibits melanoma cell invasion in vitro}

In addition, tumor cell invasion is a vital step in the cancer metastasis process. Cell invasion was usually examined by Matrigel-coated transwell chambers assay. To investigate whether ADT-OH can suppress the invasion of $\mathrm{A} 375, \mathrm{~B} 16 \mathrm{~F} 10$ and $\mathrm{B} 16 \mathrm{~F} 1$ cells, we performed an invasion assay following $\mathrm{ADT}-\mathrm{OH}$ treatment. In the absence of ADT-OH (control group), A375, B16F10 and B16F1 cells showed highly invasion capabilities by being able to completely penetrate the Matrigel-coated filters (Fig. 4a-C). However, the invasion capability of A375, B16F10 and B16F1 cells were effectively suppressed by ADT-OH in a dosedependent manner (Fig. 4a-c). To further visualize the effect of ADT-OH on the actin cytoskeletons of melanoma cells, a phalloidin immunofluorescence staining assay was performed. Elevated ADT-OH concentration obviously inhibited filopodia production and spear elongation, especially at a concentration of $100 \mu \mathrm{M}$ (Fig. 4d-f). Taken together, these data indicate that ADT-OH might reduce the migration and invasion capability of melanoma cells.

\section{ADT-OH inhibits cell migration by regulating FAK signaling pathway}

To further explore the specific role of ADT-OH on cell migration and which signaling pathway it might be involved in, we performed high throughput proteomic approach to compare protein expressions between ADT-OH-treated and -untreated cell lines. There are 2217 differential proteins in all groups were screened by a $t$-test (Additional file 3 ). The MetaCore ${ }^{\mathrm{TM}}$ pathway mapping tool clustered the differential networks from DEPs results, among which the cell adhesion and migration pathway show a high score (Fig. 5a and b). Moreover, as is shown in Supplementary Fig. S4, the intracellular protein changes under the action of $2 \mu \mathrm{M}$ and $50 \mu \mathrm{M}$ ADT-OH are quite different, of which only 165 proteins have the same changes. Next, further analysis of the process network of the two groups found that the $2 \mu \mathrm{M}$ group is more related to 
tumor metastasis. As shown in Supplementary Fig. S4C, the fourth cell pathway under $2 \mu \mathrm{M}$ ADT-OH treatment is cell adhesion. It is well known that the FAK signaling pathway plays a crucial role in the metastasis and invasion of a variety of tumor cells (20-22). Here, we found that FAK is involved in multiple signaling pathways including cell migration following ADT-OH treatment (Fig. $5 c$ and d). As we can see in Fig. 5d, ADT-OH might directly affect cell migration through the PTEN/FAK/Paxillin pathway. Therefore, the changes in protein and mRNA levels in this signaling pathway after ADT-OH treatment were next detected by Western blotting and GPCR analyses. As shown in Fig. 6a and b, both total FAK and its phosphorylation level were greatly decreased in response to ADT-OH treatment in melanoma cells. After ADT-OH treatment, the protein level of Paxillin, the downstream response protein of FAK, was also significantly reduced. In addition, tumor cells with EMT phenotype changes are often involved in the loss of epithelial properties and acquisition of mesenchymal characteristics, exhibiting enhanced motility, and invasive abilities. To determine whether the anti-metastatic activity of ADT-OH also involves the regulation of EMT, typical markers of EMT including E-cadherin, N-cadherin and Vimentin were next detected using Western blot assay. The results showed that ADT-OH reversed EMT changes in A375 and B16F10 cells, causing the re-induction of E-cadherin and the re-inhibition of $\mathrm{N}$-cadherin and Vimentin expression as compared to the control in a dose-dependent manner, indicating that ADT-OH has inhibitory effects on melanoma cell EMT (Fig. 6a-b, Supplementary Fig. S5 and Supplementary Fig. S6).

Furthermore, the change pattern in mRNA levels of FAK, Paxillin, E-cadherin and N-cadherin was similar to that in their protein levels (Supplementary Fig. S7). Immunofluorescence assay was also performed to show that ADT-OH-treated melanoma cells exhibited suppressed epithelial markers, E-cadherin, and overexpressed mesenchymal markers, vimentin, in comparison with the control (Fig. 6c, d).

\section{ADT-OH affected the protein level of FAK mainly through decreasing the stability of FAK.}

As is shown in Fig. 7a, ADT-OH significantly reduces the FAK mRNA levels in B16F10, B16F1 and A375 cells. To explore the mechanism of ADT-OH on FAK, we constructed the FAK luciferase reporter gene plasmid and performed experiments in B16F10 melanoma cells. The detection of dual luciferase reporter gene showed that ADT-OH had no effect on the transcriptional activity of FAK promoter (Fig. 7b). However, mRNA stability experiments showed that ADT-OH significantly reduced the stability of FAK mRNA (Fig. 7c). Therefore, we speculate that ADT-OH might inhibit cell migration by reducing the level of FAK $m R N A$ and then reducing its protein expression level.

Then, we further determined whether FAK overexpression could reverse the inhibitory effect of ADT-OH on melanoma migration. B16F10 cells were used for transfection of FAK-overexpression vector (Fig. 8). We found that FAK mRNA and protein expression levels increased significantly in the transfected cells (Fig. $8 \mathrm{a}, \mathrm{b})$. Compared with negatively transfected cells, overexpression of FAK significantly promoted the protein and mRNA expression of N-Cadherin and Vimentin. In contrast to the cells that were not treated with ADT-OH or NaHS, the expression levels of Vimentin and N-Cadherin significantly increased and FAK, p-AKT, and AKT significantly decreased in B16F10 cells after ADT-OH or NaHS treatment, along with the microvilli and pseudopodia; however, these effects and phenotype were significantly abolished after overexpression of FAK (Fig. 8a-c). As shown in Fig. 8c, the level of F-actin in melanoma cells was 
decreased, the cell structure was disorganized, and the cell morphology became round after treatment with ADT-OH in control cells. However, cells overexpressing FAK showed increased levels of F-actin protein, and the cells elongated and grew fusiform, and the barbed ends of the cells were more prominent. After $\mathrm{NaHS}$ or ADT-OH treatment, this phenotype of melanoma cells did not change obviously. These results indicate that, by reducing FAK expression, ADT-OH significantly inhibited the EMT process of melanoma, while this ADT-OH-induced effect was significantly reversed after FAK overexpression. The migrational potency of cells is inhibited once the EMT process is suppressed in melanoma cells. The results of transwell experiment further showed that the migration ability of B16F10 cells was significantly inhibited under ADT-OH treatment, but it was restored after overexpression of FAK (Fig. 8d).

\section{$\mathrm{ADT}-\mathrm{OH}$ inhibits the viability of $\mathrm{A} 375$ and B16F10 cells in vitro}

To determine whether ADT-OH exhibits cytotoxicity, we next analyzed the inhibitory effects of ADT-OH on the proliferation of A375, B16F10, and MEF cells by CCK-8 assay. As shown in Supplementary Fig. S7, ADT-OH inhibited the viability of A375 cells and B16F10 cells in both a time- and concentration-dependent manner, but had a slight effect on MEF. After pretreatment with ADT-OH for $24 \mathrm{~h}, \mathrm{ADT}$-OH exhibited an $\mathrm{IC}_{50}$ value of $11.67 \mu \mathrm{M}$ against $\mathrm{A} 375$ cells and an $\mathrm{IC}_{50}$ value of $5.653 \mu \mathrm{M}$ against B16F10 cells, respectively, while the $\mathrm{IC}_{50}$ value against MEF cells was $32.37 \mu \mathrm{M}$. Furthermore, we found that $0-6.4 \mu \mathrm{M}$ of ADT-OH had no obvious inhibitory effects on the viability of A375 cells, B16F10 cells and MEF cells (Supplementary Fig. S8). Besides, CCK8 assay showed that ADT-OH could also significantly inhibit the proliferation of a variety of tumor cells in addition to melanoma (Supplementary Fig. S9). Next, the longterm cell viability of ADT-OH-treated melanoma cells and control cells were tested by colony formation assay (Supplementary Fig. S10). The results showed that ADT-OH significantly inhibited the colony formation capacity of melanoma cells. Moreover, we studied whether ADT-OH had any effect on B16F10, B16F1 and A375 cell cycle. As shown in Supplementary Fig. S10, ADT-OH arrested the tumor cells in the G2/M phase, while the effect of NaHS treatment on cell cycle was not significant. Analysis of apoptosis further confirmed that ADT-OH promoted apoptosis of B16F10, B16F1 and A375 cells (Supplementary Fig. S11). Additionally, ADT-OH also increased the content of ROS in melanoma cells to further promote tumor cell death (Supplementary Fig. S12). These results indicate that higher concentrations of ADT-OH can not only inhibit the migration of melanoma cells, but also inhibit the cell activity by inhibiting the melanoma cycle and proliferation, thereby achieving a more effective treatment of melanoma.

\section{Discussion}

Melanoma is a kind of highly aggressive cancer and the metastasis accounts for the majority of patient deaths. Many cancer patients exhibit metastasis by the time of diagnosis. Cancer metastasis is a complicated process that involves multiple sequential and interlinked steps including detachment, migration, invasion, and adhesion (23). Until now, effective drugs against melanoma metastasis are absent in clinical practice. Nowadays, various $\mathrm{H}_{2} \mathrm{~S}$ donors including ADT-OH have been confirmed to inhibit proliferation and development of melanoma. There is an increasing number of research studies focused on elucidating the molecular mechanisms of $\mathrm{H}_{2} \mathrm{~S}$ 's anti-cancer effects, and several critical 
signaling pathways have been reported to be influenced by $\mathrm{H}_{2} \mathrm{~S}$ donors' treatment. The multiple functional effects of $\mathrm{H}_{2} \mathrm{~S}$ administration in cancer cells involve the induction of apoptosis, the inhibition of proliferation and the prevention of metastasis and tumor angiogenesis $(10,11,24-26)$. But unfortunately, none of the $\mathrm{H}_{2} \mathrm{~S}$ donors could be approved for the treatment of melanoma metastasis. Therefore, $\mathrm{H}_{2} \mathrm{~S}$ donors gaining insights into the mechanisms of inhibition melanoma metastasis will provide new therapeutics for metastasis of melanoma. In addition, the slow-releasing $\mathrm{H}_{2} \mathrm{~S}$ donor 5-(4hydroxyphenyl)-3H-1,2-dithiocyclopentene-3-thione (ADT-OH) is known as potent therapeutics with chemopreventive and cytoprotective properties due to its 3H-1,2-dithiole-3-thione group (dithiolethiones), which is also one of the most widely used moiety for synthesizing slow-releasing organic hydrogen sulfide donors $(24,27)$. Previously, we have found that ADT-OH is a potential anti-tumor agent by enhancing FADD-dependent extrinsic apoptosis of melanoma cells (16). Here, we further broaden the potential anti-tumor effect of ADT-OH by demonstrating its ability in inhibiting melanoma metastasis both in vitro and in vivo.

A375 is a human melanoma cell line while B16F10 is a mouse melanoma cell line. In the current study, these two cell lines were selected to investigate whether ADT-OH's anti-metastasis effect have species selectivity. We firstly found that ADT-OH significantly inhibited melanoma cell migration in vivo by the palm transfer model and mice passive lung metastasis models. Similarly, ADT-OH significantly suppressed migration, invasion, and adhesion in vitro. Further research found that ADT-OH inhibited the proliferation of melanoma cells A375 and B16F10, but exhibited little toxicity to normal cell MEF. Interestingly, proteomics data showed that low concentrations of ADT-OH are more related to tumor migration, while high concentrations of ADT-OH can more affect cell apoptosis and survival. Moreover, next results showed that ADT-OH at low concentration (such as $6.3 \mu \mathrm{M}$ ) can significantly inhibit the metastasis of melanoma cells, but cannot cause melanoma cell apoptosis, indicating that the inhibition of tumor cell migration caused by ADT-OH at lower concentrations is not achieved by promoting tumor cell apoptosis.

EMT is a critical cellular phenomenon regulating tumor metastasis, which is characterized by tumor cells losing typical epithelial traits including cell polarity and cell-cell adhesion, and the acquisition of the mesenchymal characteristics (28). Intriguingly, EMT is involved in cancer-related mortality by implicating critical processes, including cell migration and invasion. Currently, many studies have confirmed that EMT exerts a determinant role in the progression and metastasis of tumors (28-31). In this study, we observed that ADT-OH could obviously increase levels of the epithelial marker (e.g., E-cadherin), and decrease levels of mesenchymal markers (e.g., N-cadherin and Vimentin) in both A375 and B16F10 cells. These findings suggest that ADT-OH negatively regulates EMT, and significantly attenuates cell migration, invasion, and adhesion in vitro. Recently, lots of investigations have revealed that $\mathrm{H}_{2} \mathrm{~S}$ suppressed the EMT process induced by TGF- $\beta 1$ in A549 cells and HK-2 cells $(26,32)$. The anti-metastasis effect of ADT$\mathrm{OH}$ on melanoma cells in our study are thus consistent with these reported works. 
FA kinase (FAK) is a nonreceptor tyrosine kinase that participates in FA complex formation. Its dysregulation is found in various types of cancer in relation to tumor metastasis (33-36). Paxillin, which is a structural protein of the FA complex, also contributes to metastasis (37). FAK is a key regulator of integrin-mediated adhesion, which can be auto-phosphorylated at Tyr-397 upon recruitment of this kinase to FA sites following the binding of the transmembrane integrin receptor to ECM. An activated FAK provides both signal transduction and scaffolding functions. Paxillin is an important FA-associated cytoskeletal adaptor protein that provides a docking site for FAK. In turn, FAK can phosphorylate paxillin at Tyr-118 to regulate its function. Phosphorylation of both proteins is required for FA formation, cell motility, and metastasis. Previous researches have demonstrated that $\mathrm{H}_{2} \mathrm{~S}$ and $\mathrm{H}_{2} \mathrm{~S}$ donors covalently react with functional proteins to influence several signaling pathways, including the EGF, NF-KB, MAPK, $\mathrm{PI} 3 \mathrm{~K} / \mathrm{Akt}$ and integrin pathways $(32,38,39)$. However, the role of ADT-OH in melanoma cell adhesion as well as the involvement of FAK or paxillin in this biological process remains largely unknown. Therefore, targeted inhibition for FAK signaling pathways has been considered as promising strategies for the treatment of melanoma metastasis. In this study, $\mathrm{ADT}-\mathrm{OH}$ treatment decreased the phosphorylation of FAK in a dose-dependent manner in both A375 and B16F10 cells. In contrast, overexpression of FAK could reverse the effects and restore the phenotype exerted by ADT-OH in melanoma cells, suggesting a critical role of FAK signaling pathway in ADT-OH-induced inhibitory effect on cell migration.

Furthermore, ADT-OH also decreased the expression of CSE and CBS, which further elucidated the mechanism of ADT-OH inhibiting melanoma migration. We thus speculated that the inhibition of ADT-OH on melanoma metastasis may, in part, be attributed to its ability in inhibiting the CSE/CBS and FAK/Paxillin pathways. To the best of our knowledge, this is the first time to demonstrate the antimetastasis mechanism of ADT-OH on melanoma cells.

\section{Conclusion}

Taken together, our results imply that ADT-OH exhibits a potent anti-metastasis effect in vitro and in vivo through inhibition of CSE/CBS and FAK/Paxillin signaling pathways, leading to the suppression of EMT (Supplementary Fig. S13). Besides, our findings may provide a new development of therapies for the inhibition of melanoma metastasis. Moreover, ADT-OH shows reduced cytotoxicity in normal human cells (e.g., MEF and 2B cells). Therefore, novel ADT-OH derivatives should be developed to improve its efficacy and stability through a structure-activity relationship study. Further studies are needed to determine the full mechanism and potential of ADT-OH in anti-metastasis of melanoma. High throughput screening analyses, such as a microarray experiment, can also be conducted to assess the potential biomarkers that are affected by the treatment of ADT-OH.

\section{Abbreviations}

$\mathrm{H}_{2} \mathrm{~S}$ : hydrogen sulfide; ADT-OH: 5-(4-hydroxyphenyl)-3H-1,2-ithiocyclopentene-3-thione; CBS: cystathionine $\beta$-synthase; CSE: cystathionine $\beta$-lyase; CAT: cysteine aminotransferase; 3-MST: 3-mercaptopyruvate 
sulfurtransferase; NF-кB: nuclear factor-кB; EMT: epithelial-mesenchymal transition; Act D: Actinomycin D; FAK: Focal Adhesion Kinase; UVM: uveal melanoma; SKCM: skin cutaneous melanoma

\section{Declarations}

\section{Ethics approval and consent to participate}

Animal welfare and experimental procedures were performed in strict accordance with high standard animal welfare and other related ethical regulations approved by Nanjing University.

\section{Consent for publication}

Not applicable.

\section{Availability of data and material}

All data generated or analyzed during this study are included in this published article.

\section{Competing interests}

The authors declare no conflicts of interest.

\section{Funding}

This study was supported by grants from the Chinese National Natural Sciences Foundation (81773099 and 81630092), the National Key R\&D Program of China (2017YFA0506000), Jiangsu Province Natural Sciences Foundation (BK20192005 and BK20171202) and the program B for Outstanding PhD candidate of Nanjing University (202001B051).

\section{Author contributions}

$\mathrm{ZCH}, \mathrm{HZ}$ and $\mathrm{JC}$ designed the outline of the paper. $\mathrm{HZ}$ revised this manuscript. $\mathrm{FC}$ and $\mathrm{HX}$ contributed equally to this work. FC and $\mathrm{HX}$ performed most of the experiments in this study. FC wrote the manuscript and prepared the figures. SY, PL, YL, JC, ZB and HS helped with the cell related experiments. SY and PL helped with the experiments using animals. All authors have read and approved the final version of this manuscript.

\section{Acknowledgements}

Not applicable.

\section{References}

1. Geller AC, Clapp RW, Sober AJ, Gonsalves L, Mueller L, Christiansen CL, et al. Melanoma epidemic: an analysis of six decades of data from the Connecticut Tumor Registry. Journal of clinical oncology : 
official journal of the American Society of Clinical Oncology. 2013;31(33):4172-8.

2. Palrasu M, Knapinska AM, Diez J, Smith L, LaVoi T, Giulianotti M, et al. A Novel Probe for Spliceosomal Proteins that Induces Autophagy and Death of Melanoma Cells Reveals New Targets for Melanoma Drug Discovery. Cellular physiology and biochemistry : international journal of experimental cellular physiology, biochemistry, and pharmacology. 2019;53(4):656-86.

3. Szabo C, Coletta C, Chao C, Modis K, Szczesny B, Papapetropoulos A, et al. Tumor-derived hydrogen sulfide, produced by cystathionine-beta-synthase, stimulates bioenergetics, cell proliferation, and angiogenesis in colon cancer. Proceedings of the National Academy of Sciences of the United States of America. 2013;110(30):12474-9.

4. Arribillaga L, Dotor J, Basagoiti M, Riezu-Boj JI, Borras-Cuesta F, Lasarte JJ, et al. Therapeutic effect of a peptide inhibitor of TGF-beta on pulmonary fibrosis. Cytokine. 2011;53(3):327-33.

5. Lu S, Gao Y, Huang X, Wang X. GYY4137, a hydrogen sulfide (H(2)S) donor, shows potent antihepatocellular carcinoma activity through blocking the STAT3 pathway. International journal of oncology. 2014;44(4):1259-67.

6. Murata T, Sato T, Kamoda T, Moriyama H, Kumazawa Y, Hanada N. Differential susceptibility to hydrogen sulfide-induced apoptosis between PHLDA1-overexpressing oral cancer cell lines and oral keratinocytes: role of PHLDA1 as an apoptosis suppressor. Experimental cell research. 2014;320(2):247-57.

7. Panza E, De Cicco P, Armogida C, Scognamiglio G, Gigantino V, Botti G, et al. Role of the cystathionine gamma lyase/hydrogen sulfide pathway in human melanoma progression. Pigment cell \& melanoma research. 2015;28(1):61-72.

8. Kashfi K, Olson KR. Biology and therapeutic potential of hydrogen sulfide and hydrogen sulfidereleasing chimeras. Biochemical pharmacology. 2013;85(5):689-703.

9. Lee ZW, Teo XY, Tay EY, Tan CH, Hagen T, Moore PK, et al. Utilizing hydrogen sulfide as a novel anticancer agent by targeting cancer glycolysis and $\mathrm{pH}$ imbalance. British journal of pharmacology. 2014;171(18):4322-36.

10. De Cicco P, Panza E, Ercolano G, Armogida C, Sessa G, Pirozzi G, et al. ATB-346, a novel hydrogen sulfide-releasing anti-inflammatory drug, induces apoptosis of human melanoma cells and inhibits melanoma development in vivo. Pharmacological research. 2016;114:67-73.

11. Lee ZW, Zhou J, Chen CS, Zhao Y, Tan CH, Li L, et al. The slow-releasing hydrogen sulfide donor, GYY4137, exhibits novel anti-cancer effects in vitro and in vivo. PloS one. 2011;6(6):e21077.

12. Lv M, Li Y, Ji MH, Zhuang M, Tang JH. Inhibition of invasion and epithelial-mesenchymal transition of human breast cancer cells by hydrogen sulfide through decreased phospho-p38 expression. Molecular medicine reports. 2014;10(1):341-6.

13. Jiang W, Cai F, Xu H, Lu Y, Chen J, Liu J, et al. Extracellular signal regulated kinase 5 promotes cell migration, invasion and lung metastasis in a FAK-dependent manner. Protein Cell. 2020.

14. Cai F, Chen M, Zha D, Zhang P, Zhang X, Cao N, et al. Curcumol potentiates celecoxib-induced growth inhibition and apoptosis in human non-small cell lung cancer. Oncotarget. 2017;8(70):115526-45. 
15. Jiang W, Jin G, Cai F, Chen X, Cao N, Zhang X, et al. Extracellular signal-regulated kinase 5 increases radioresistance of lung cancer cells by enhancing the DNA damage response. Exp Mol Med. 2019;51(2):1-20.

16. Cai F, Xu H, Cao N, Zhang X, Liu J, Lu Y, et al. ADT-OH, a hydrogen sulfide-releasing donor, induces apoptosis and inhibits the development of melanoma in vivo by upregulating FADD. Cell death \& disease. 2020;11(1):33.

17. Guo H, Gai JW, Wang Y, Jin HF, Du JB, Jin J. Characterization of hydrogen sulfide and its synthases, cystathionine beta-synthase and cystathionine gamma-lyase, in human prostatic tissue and cells. Urology. 2012;79(2):483 e1-5.

18. Zhang L, Qi Q, Yang J, Sun D, Li C, Xue Y, et al. An Anticancer Role of Hydrogen Sulfide in Human Gastric Cancer Cells. Oxidative medicine and cellular longevity. 2015;2015:636410.

19. Jurkowska H, Placha W, Nagahara N, Wrobel M. The expression and activity of cystathioninegamma-lyase and 3-mercaptopyruvate sulfurtransferase in human neoplastic cell lines. Amino acids. 2011;41(1):151-8.

20. Cheng Y, Gao XH, Li XJ, Cao QH, Zhao DD, Zhou JR, et al. Depression promotes prostate cancer invasion and metastasis via a sympathetic-cAMP-FAK signaling pathway. Oncogene. 2018;37(22):2953-66.

21. Li R, Wang Y, Zhang X, Feng M, Ma J, Li J, et al. Exosome-mediated secretion of LOXL4 promotes hepatocellular carcinoma cell invasion and metastasis. Molecular cancer. 2019;18(1):18.

22. Jiang WG, Sanders AJ, Katoh M, Ungefroren $H$, Gieseler F, Prince $M$, et al. Tissue invasion and metastasis: Molecular, biological and clinical perspectives. Semin Cancer Biol. 2015;35 Suppl:S244S75.

23. Pal M. Tumor metastasis suppressor functions of Ets transcription factor through integrin beta3mediated signaling pathway. Journal of cellular physiology. 2019;234(11):20266-74.

24. Yang CT, Chen L, Xu S, Day JJ, Li X, Xian M. Recent Development of Hydrogen Sulfide Releasing/Stimulating Reagents and Their Potential Applications in Cancer and Glycometabolic Disorders. Frontiers in pharmacology. 2017;8:664.

25. Chattopadhyay M, Kodela R, Nath N, Barsegian A, Boring D, Kashfi K. Hydrogen sulfide-releasing aspirin suppresses NF-kappaB signaling in estrogen receptor negative breast cancer cells in vitro and in vivo. Biochemical pharmacology. 2012;83(6):723-32.

26. Bai YW, Ye MJ, Yang DL, Yu MP, Zhou CF, Shen T. Hydrogen sulfide attenuates paraquat-induced epithelial-mesenchymal transition of human alveolar epithelial cells through regulating transforming growth factor-beta1/Smad2/3 signaling pathway. Journal of applied toxicology : JAT. 2019;39(3):432-40.

27. Hasegawa U, Tateishi N, Uyama H, van der Vlies AJ. Hydrolysis-Sensitive Dithiolethione Prodrug Micelles. Macromolecular bioscience. 2015;15(11):1512-22.

28. Aiello NM, Kang Y. Context-dependent EMT programs in cancer metastasis. The Journal of experimental medicine. 2019;216(5):1016-26. 
29. Tulchinsky E, Demidov O, Kriajevska M, Barlev NA, Imyanitov E. EMT: A mechanism for escape from EGFR-targeted therapy in lung cancer. Biochimica et biophysica acta Reviews on cancer. 2019;1871(1):29-39.

30. He X, Xue M, Jiang S, Li W, Yu J, Xiang S. Fucoidan Promotes Apoptosis and Inhibits EMT of Breast Cancer Cells. Biological \& pharmaceutical bulletin. 2019;42(3):442-7.

31. Cho ES, Kang HE, Kim NH, Yook JI. Therapeutic implications of cancer epithelial-mesenchymal transition (EMT). Archives of pharmacal research. 2019;42(1):14-24.

32. Liao CC, Chen YH, Lin F, Qi YF. Hydrogen sulfide inhibits transforming growth factor beta-1 induced bronchial epithelial-mesenchymal transition. Chinese medical journal. 2015;128(23):3247-50.

33. Miyazaki T, Kato H, Nakajima M, Sohda M, Fukai Y, Masuda N, et al. FAK overexpression is correlated with tumour invasiveness and lymph node metastasis in oesophageal squamous cell carcinoma. British journal of cancer. 2003;89(1):140-5.

34. Zaidel-Bar R, Itzkovitz S, Ma'ayan A, lyengar R, Geiger B. Functional atlas of the integrin adhesome. Nature cell biology. 2007;9(8):858-67.

35. Lahlou H, Sanguin-Gendreau V, Zuo D, Cardiff RD, McLean GW, Frame MC, et al. Mammary epithelialspecific disruption of the focal adhesion kinase blocks mammary tumor progression. Proceedings of the National Academy of Sciences of the United States of America. 2007;104(51):20302-7.

36. Yu HG, Nam JO, Miller NL, Tanjoni I, Walsh C, Shi L, et al. p190RhoGEF (Rgnef) promotes colon carcinoma tumor progression via interaction with focal adhesion kinase. Cancer research. 2011;71(2):360-70.

37. Deakin NO, Turner CE. Distinct roles for paxillin and Hic-5 in regulating breast cancer cell morphology, invasion, and metastasis. Molecular biology of the cell. 2011;22(3):327-41.

38. Fang LP, Lin Q, Tang CS, Liu XM. Hydrogen sulfide attenuates epithelial-mesenchymal transition of human alveolar epithelial cells. Pharmacological research. 2010;61(4):298-305.

39. Cheng S, Lu Y, Li Y, Gao L, Shen H, Song K. Hydrogen sulfide inhibits epithelial-mesenchymal transition in peritoneal mesothelial cells. Scientific reports. 2018;8(1):5863.

\section{Supplementary Information}

Additional file 1: Supplementary Table S1. The primers of selected genes for real time PCR.

Additional file 2ロSupplementary Figure S1. The levels of CBS gene associated with the prognosis of patients with different cancers. Supplementary Figure S2. The levels of CSE gene associated with the prognosis of patients with different cancers. Supplementary Figure S3. The effect of ADT-OH on CBS and CES expression levels in B16F10 melanoma cells in vivo and in vitro. (A) The tumor is harvested and used for CBS and CSE staining; original magnification is 400 times. (B) Western blot analysis of CSE and CBS in B16F10 cells treated with ADT-OH (24 h) at different concentration. (C) Statistical analysis of (B) by Image J. Western blot analysis of CSE and CBS in B16F10 cells. ${ }^{*} P<0.05, * \star P<0.01,{ }^{\star} * \star P<0.005$, compared with the control group. Supplementary Figure $\$ 4$. Proteomics analysis of proteins differentially 
expressed in ADT-OH-treated cells. (A) Venn diagram of $2 \mathrm{mM}$ and $50 \mathrm{mM}$ ADT-OH (15min) groups. (B-C) The protein network associated with cell adhesion and migration is differentially expressed in MEF cells treated with ADT-OH. Supplementary Figure S5. Statistical analysis of Figure 6A by Image J. Western blot analysis of p-FAK, FAK, Paxillin, p-AKT, AKT, E-Cadherin, N-Cadherin and Vimentin in B16F10 cells. ${ }^{*} P<$ $0.05, * \star P<0.01, * \star \star P<0.005$, compared with the control group. Supplementary Figure S6. Statistical analysis of Figure 6B by Image J. Western blot analysis of p-FAK, FAK, Paxillin, p-AKT, AKT, E-Cadherin, N-

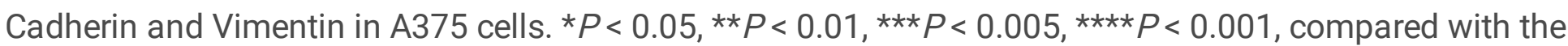
control group. Supplementary Figure S7. The FAK, Paxillin, E-Cadherin and N-Cadherin mRNA levels of B16F10 and A375 cells were detected by qPCR analysis after ADT-OH $(25 \mu \mathrm{M})$ treatment for $1 \mathrm{~h}$ and $6 \mathrm{~h}$ respectively. ${ }^{\star} P<0.05, * \star P<0.01, * \star \star P<0.005$. Data are expressed as mean \pm SD of three independent experiments. Supplementary Figure S8. ADT-OH inhibits the viability of A375 and B16F10 cells in vitro. A375, B16F10 melanoma cells and MEF normal cells were incubated with increasing concentrations of

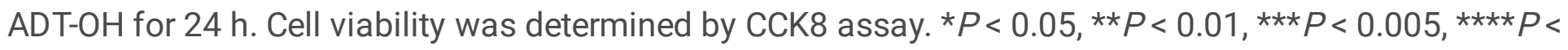
0.001 compared with vehicle group. Supplementary Figure S9. ADT-OH inhibits tumor cell proliferation. F1(B16F1), A375, A549, H446, HCT-116, MDA231(MDA-MB-231), H1299, and HepG2 cells were incubated with increasing concentrations of ADT-OH for $24 \mathrm{~h}$. Cell viability was determined by MTT assay. ${ }^{*}<0.05$, ${ }^{*} P<0.01,{ }^{*} * P<0.005, * \star \star \star P<0.001$, compared with the vehicle group. Supplementary Figure S10. ADT$\mathrm{OH}$ inhibits tumor cell proliferation. Colony formation ability of A375 cells treated with ADT-OH (3.2-50 $\mu \mathrm{M})$. The experiments were repeated three times $(\mathrm{n}=3)$; representative data are shown. Data are represented as mean \pm SD. ${ }^{\star} P<0.05,{ }^{*} P<0.01$. Supplementary Figure $S 11$. ADT-OH inhibits the viability of melanoma cells in vitro. (A) B16F10, B16F1 and A375 cells were treated with different concentrations of $\operatorname{ADT}-\mathrm{OH}(0,6.3,25,100 \mu \mathrm{M})$ for $24 \mathrm{~h}$. The cell cycle distribution (G0/G1, G2/M and S) was determined by flow cytometry. (B) Representative FACS analysis and quantitative analysis of Annexin $\mathrm{V}$ and propidium iodide $(\mathrm{PI})$ staining after $\mathrm{ADT}-\mathrm{OH}$ treatment at different concentration in B16F10, B16F1 and A375 cells. ${ }^{*} P<0.05,{ }^{*} P<<0.01,{ }^{*} * P<0.005$. Data are expressed as mean $\pm S D$ of three independent experiments. Supplementary Figure S12. ROS production. The ROS concentration was determined in B16F10 and A375 cells following treatment with ADT-OH $(12.5 \mu \mathrm{M}, 25 \mu \mathrm{M}$ and $50 \mu \mathrm{M})$ for 24 hours. Data

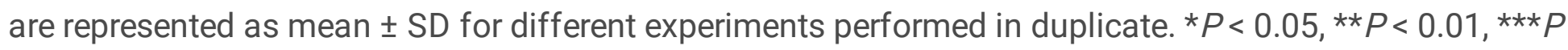
$<0.005$ compared with the vehicle group. Supplementary Figure S13. A proposed signaling pathway by which ADT-OH inhibits melanoma metastasis.

\section{Additional file 3: The raw data for differential proteomics analysis.}

\section{Figures}


Figure 1

a
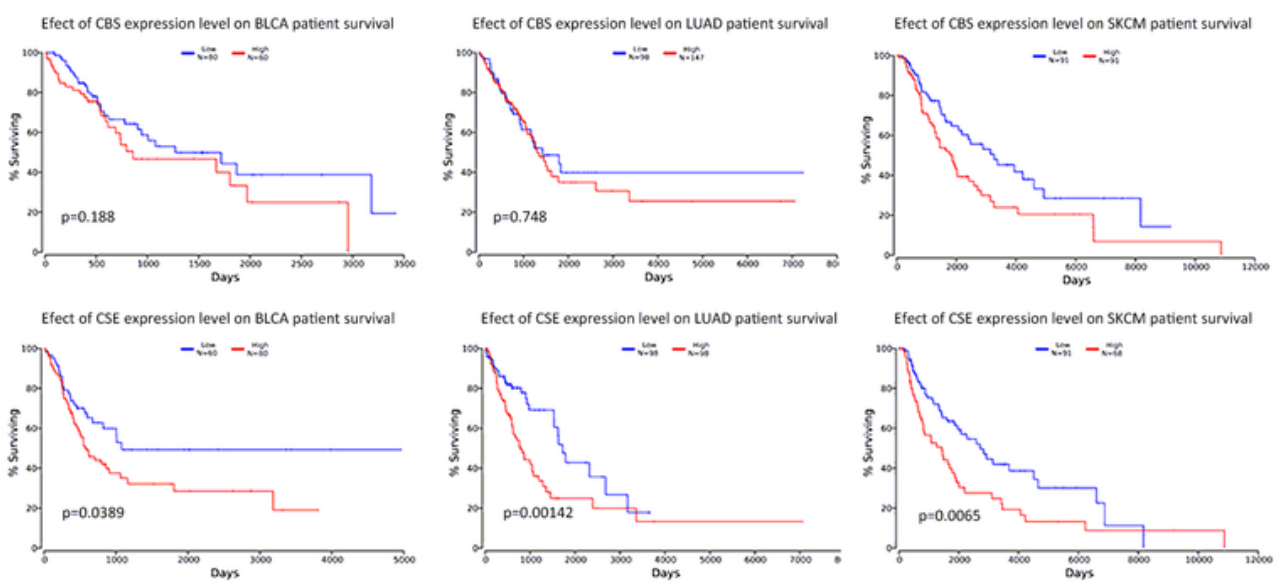

b
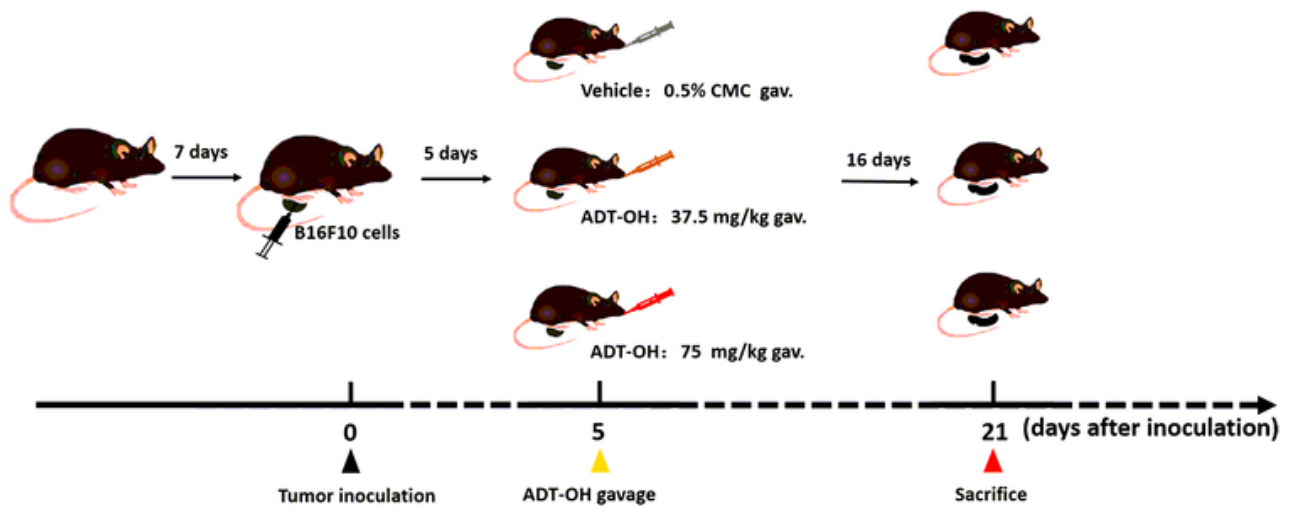

C

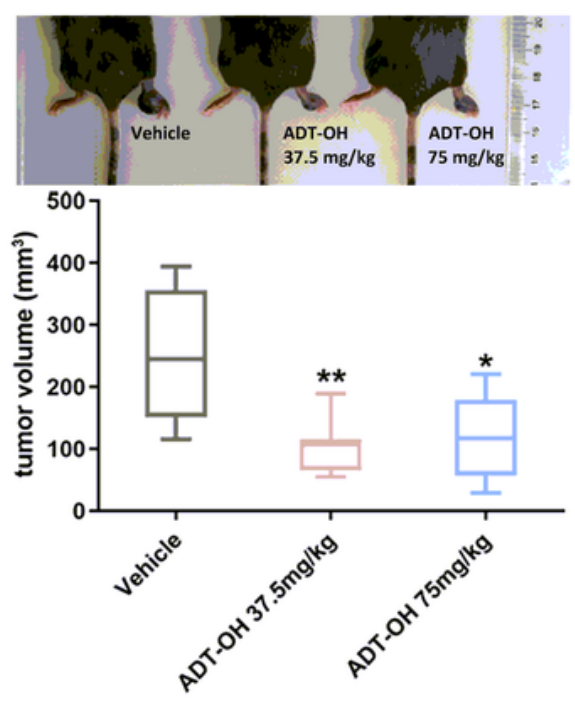

d

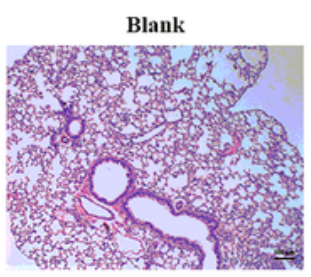

ADT-OH $37.5 \mathrm{mg} / \mathrm{kg}$

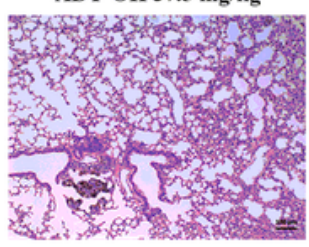

Vehicle

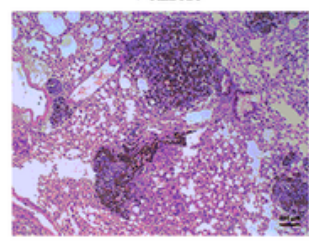

ADT-OH 75 mg/kg

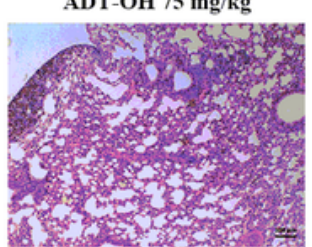

\section{Figure 1}

ADT-OH inhibits melanoma invasion in vivo in the palm transfer model. a The level of the CBS and CSE genes are associated with the prognosis of patients with different cancers (bladder urothelial carcinoma, lung adenocarcinoma and skin cutaneous melanoma). Kaplan-Meier curves for recurrence-free survival were created using a Kaplan-Meier plotter (www.kmplot.com), in which bladder urothelial carcinoma, lung adenocarcinoma and skin cutaneous melanoma patients were classified according to high and low 
CBS/CSE gene expression. The hazard ratio (with 95\% confidence interval) and the log rank $p$ value were calculated. b Animal treatment methods. c Representative imaging of Footpad model mice and the tumor volume at the footpad of each group at the end of the experiment. Data are represented as mean \pm SD. ${ }^{*} p$ $<0.05, * * p<0.01$. d Representative H\&E tissue staining of lungs in footpad model mice.

\section{Figure 1}

a
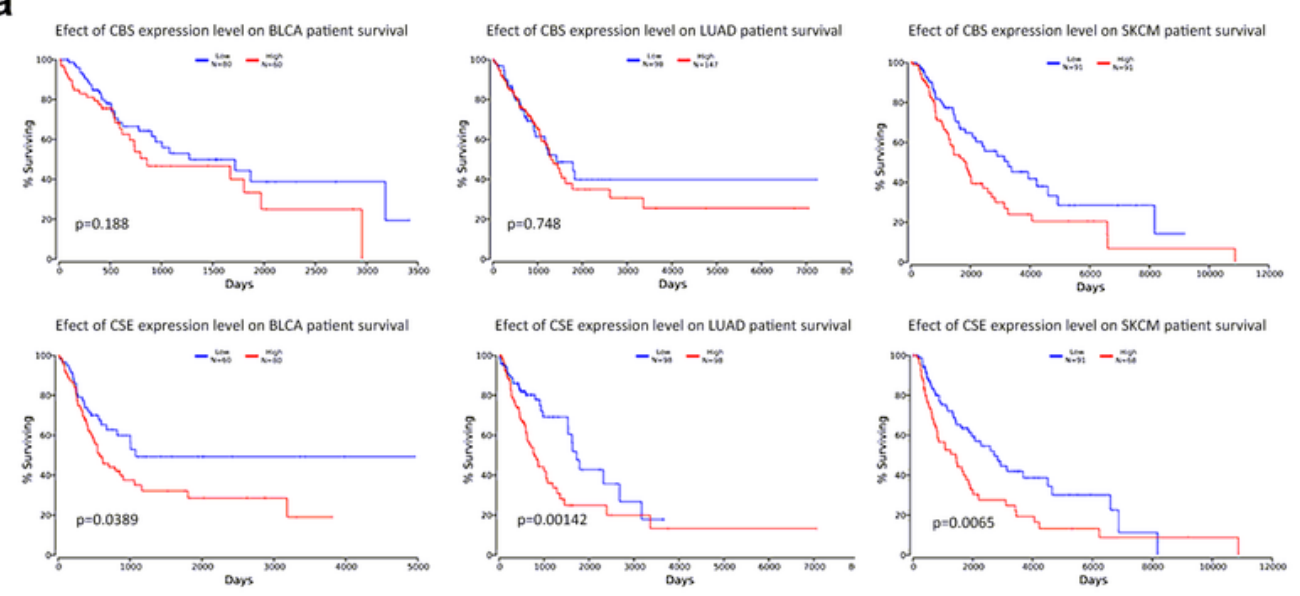

b

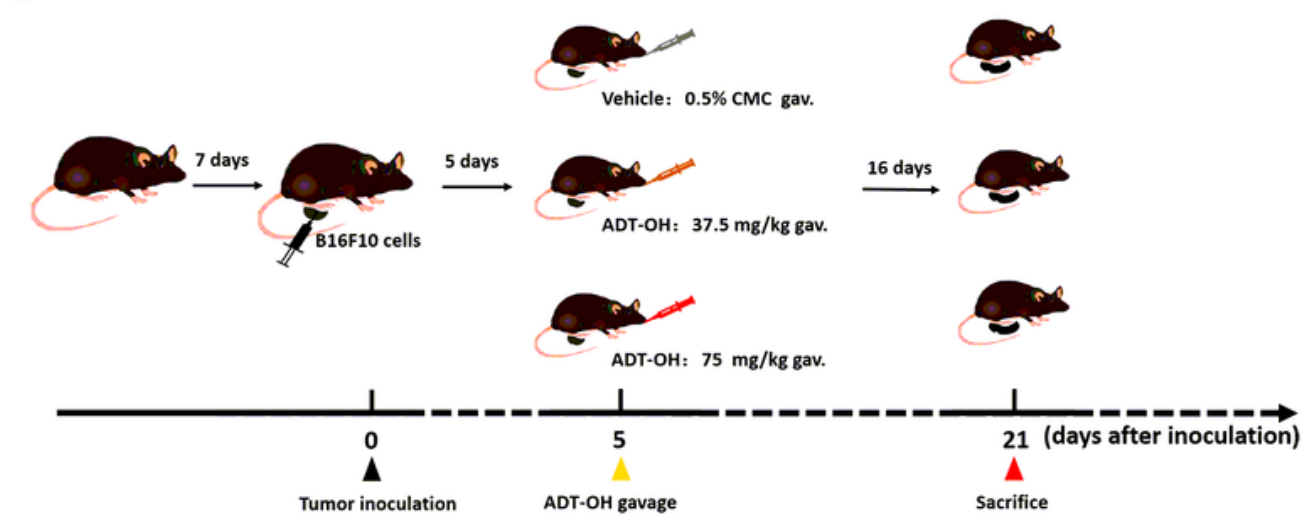

C

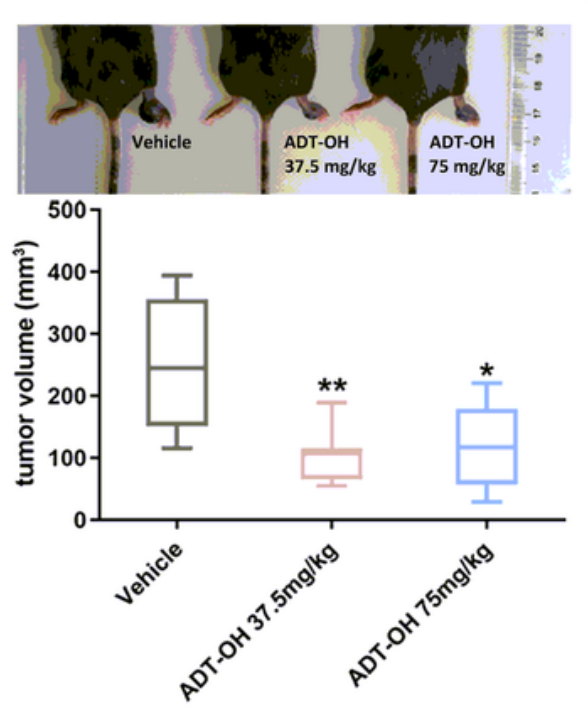

d

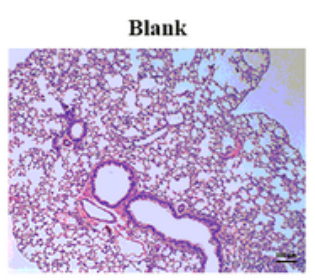

ADT-OH $37.5 \mathrm{mg} / \mathrm{kg}$

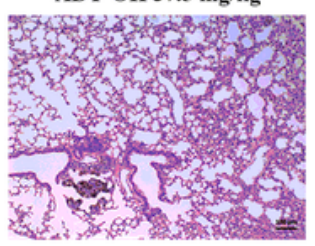

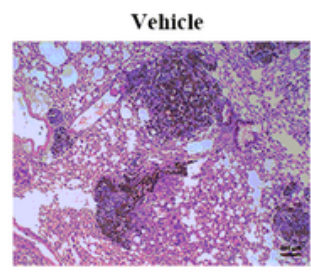

ADT-OH 75 mg/kg

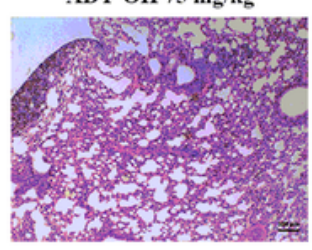

Figure 1 
ADT-OH inhibits melanoma invasion in vivo in the palm transfer model. a The level of the CBS and CSE genes are associated with the prognosis of patients with different cancers (bladder urothelial carcinoma, lung adenocarcinoma and skin cutaneous melanoma). Kaplan-Meier curves for recurrence-free survival were created using a Kaplan-Meier plotter (www.kmplot.com), in which bladder urothelial carcinoma, lung adenocarcinoma and skin cutaneous melanoma patients were classified according to high and low CBS/CSE gene expression. The hazard ratio (with 95\% confidence interval) and the log rank $p$ value were calculated. b Animal treatment methods. c Representative imaging of Footpad model mice and the tumor volume at the footpad of each group at the end of the experiment. Data are represented as mean \pm SD. ${ }^{*} p$ $<0.05,{ }^{*} p<0.01$. $d$ Representative H\&E tissue staining of lungs in footpad model mice. 
Figure 1

a
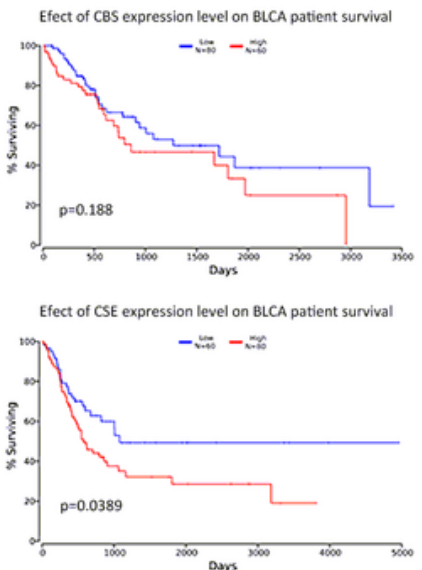

b
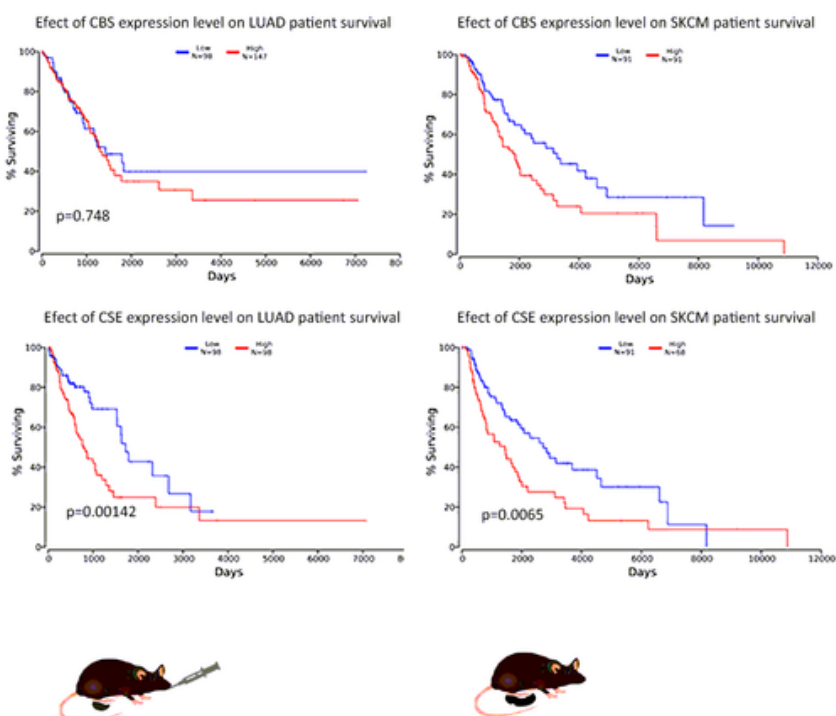

Vehicle: $0.5 \% \mathrm{CMC}$ gav.

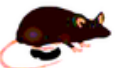

$\stackrel{16 \text { days }}{\longrightarrow}$
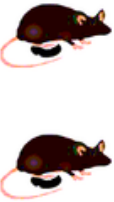

ADT-OH: $75 \mathrm{mg} / \mathrm{kg} \mathrm{gav}$

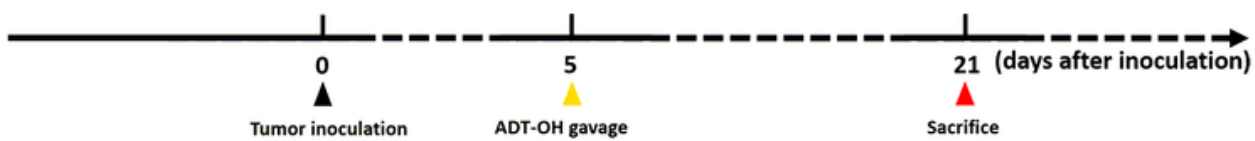

d

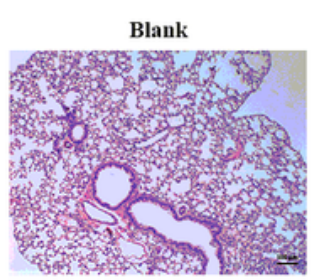

ADT-OH 37.5 mg/kg

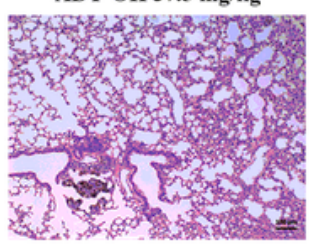

Vehicle

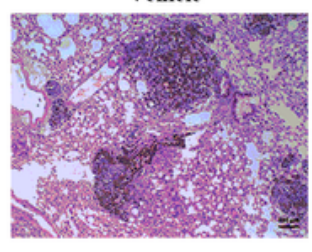

ADT-OH 75 mg/kg

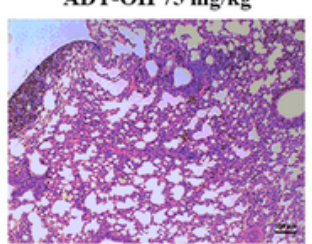

\section{Figure 1}

ADT-OH inhibits melanoma invasion in vivo in the palm transfer model. a The level of the CBS and CSE genes are associated with the prognosis of patients with different cancers (bladder urothelial carcinoma, lung adenocarcinoma and skin cutaneous melanoma). Kaplan-Meier curves for recurrence-free survival were created using a Kaplan-Meier plotter (www.kmplot.com), in which bladder urothelial carcinoma, lung adenocarcinoma and skin cutaneous melanoma patients were classified according to high and low 
CBS/CSE gene expression. The hazard ratio (with 95\% confidence interval) and the log rank $\mathrm{p}$ value were calculated. b Animal treatment methods. c Representative imaging of Footpad model mice and the tumor volume at the footpad of each group at the end of the experiment. Data are represented as mean \pm SD. * $p$ $<0.05,{ }^{* *} p<0.01$. d Representative H\&E tissue staining of lungs in footpad model mice.

Figure 2

a

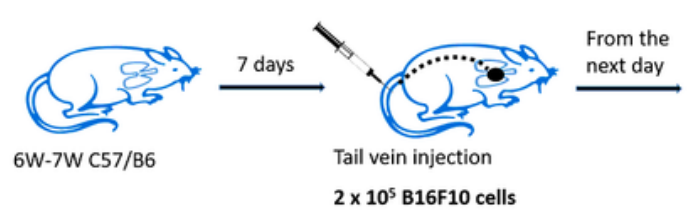

Vehicle: $0.5 \% \mathrm{CMC}$ gav.

ADT-OH: $18.75 \mathrm{mg} / \mathrm{kg}$ gav.

ADT-OH: $37.5 \mathrm{mg} / \mathrm{kg}$ gav.

ADT-OH: $75 \mathrm{mg} / \mathrm{kg}$ gav.

15 days

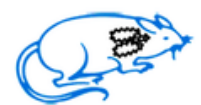

NaHS: $1.4 \mathrm{mg} / \mathrm{kg}$ gav.

NaHS: $2.8 \mathrm{mg} / \mathrm{kg}$ gav.

NaHS: $5.6 \mathrm{mg} / \mathrm{kg}$ gav. b

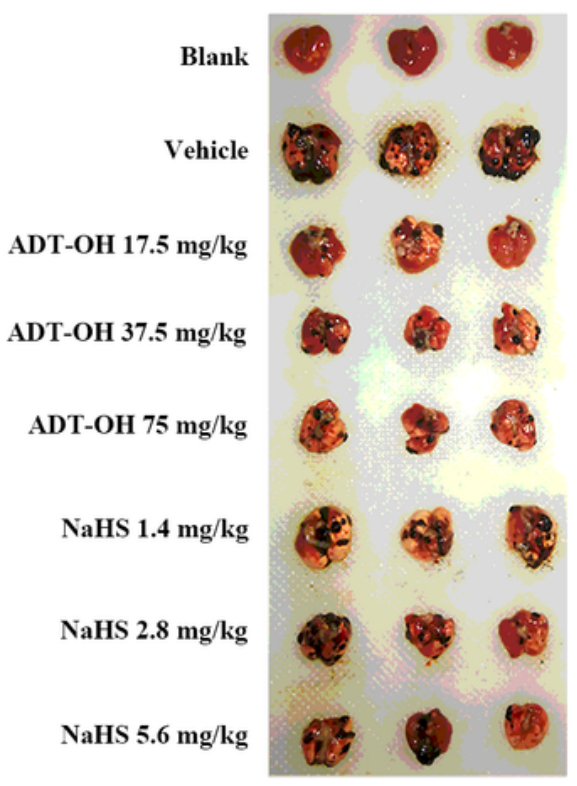

d

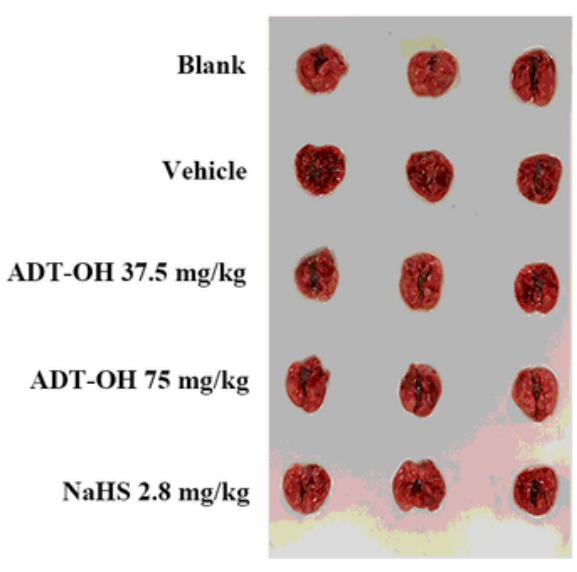

C

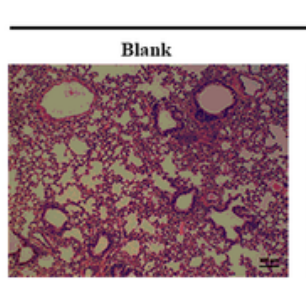

B16F10 cells

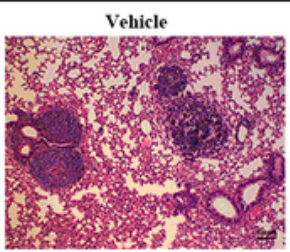

ADT-OH $18.75 \mathrm{mg} / \mathrm{kg}$

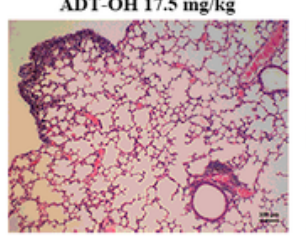

NaHS $1.4 \mathrm{mg} / \mathrm{kg}$
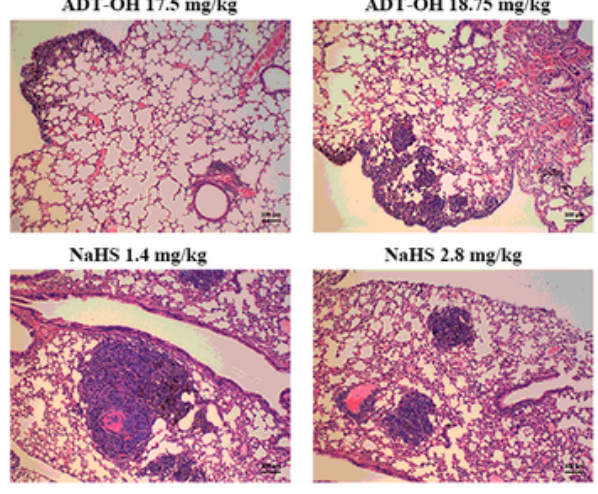

NaHS $2.8 \mathrm{mg} / \mathrm{kg}$
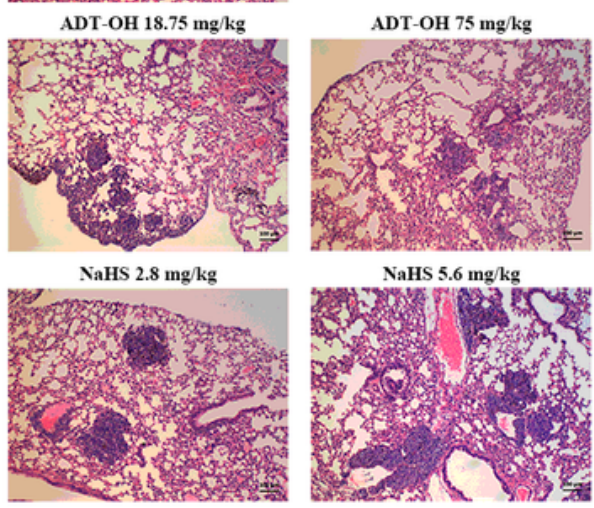

NaHS $5.6 \mathrm{mg} / \mathrm{kg}$

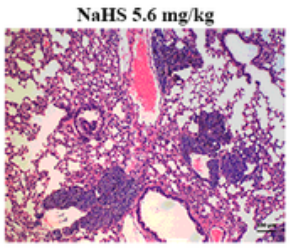

e

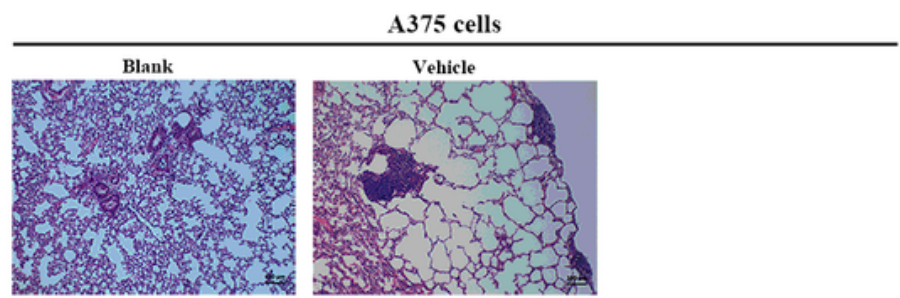

ADT-OH 75 mg/kg

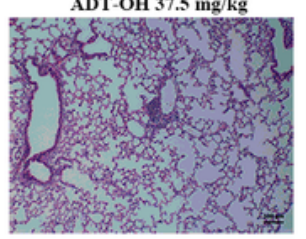

NaHS $2.8 \mathrm{mg} / \mathrm{kg}$

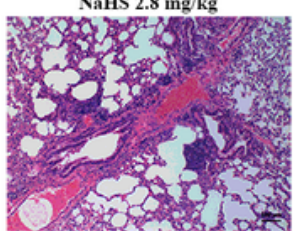

Figure 2 
ADT-OH inhibits melanoma invasion in vivo in mice tail vein injection model. a Animal treatment methods. b Representative lung imaging of mice after tail vein injection with B16F10 cells for 3 weeks. C $\mathrm{H} \& \mathrm{E}$ stained lung sections. The representative images showed lung tumor distribution of the lung metastasis model mice treated with vehicle, $17.5 \mathrm{mg} / \mathrm{kg} \mathrm{ADT-OH,} 37.5 \mathrm{mg} / \mathrm{kg} \mathrm{ADT-OH}, 75 \mathrm{mg} / \mathrm{kg}$ ADT-OH, $1.4 \mathrm{mg} / \mathrm{kg} \mathrm{NaHS}, 2.8 \mathrm{mg} / \mathrm{kg} \mathrm{NaHS}$ and $5.6 \mathrm{mg} / \mathrm{kg} \mathrm{NaHS}$. Scale bars, $100 \mu \mathrm{m}$. d-e Representative lung imaging (d) and H\&E tissue staining (e) of mice injected with A375 cells in the tail vein. The lung metastasis model mice were treated with vehicle, $37.5 \mathrm{mg} / \mathrm{kg}$ ADT-OH, $75 \mathrm{mg} / \mathrm{kg} \mathrm{ADT-OH}$ and $2.8 \mathrm{mg} / \mathrm{kg}$ NaHS for 3 weeks. Scale bars, $100 \mu \mathrm{m}$. 


\section{Figure 2}

a

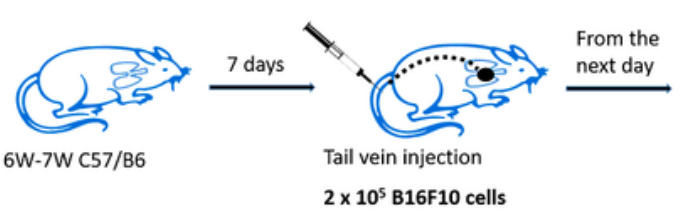

Vehicle: $0.5 \% \mathrm{CMC}$ gav.

ADT-OH: $18.75 \mathrm{mg} / \mathrm{kg}$ gav.

ADT-OH: $37.5 \mathrm{mg} / \mathrm{kg}$ gav.

ADT-OH: $75 \mathrm{mg} / \mathrm{kg}$ gav.

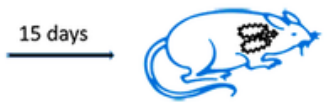

NaHS: $1.4 \mathrm{mg} / \mathrm{kg}$ gav.

直 NaHS: $2.8 \mathrm{mg} / \mathrm{kg}$ gav.

直 NaHS: $5.6 \mathrm{mg} / \mathrm{kg}$ gav. b

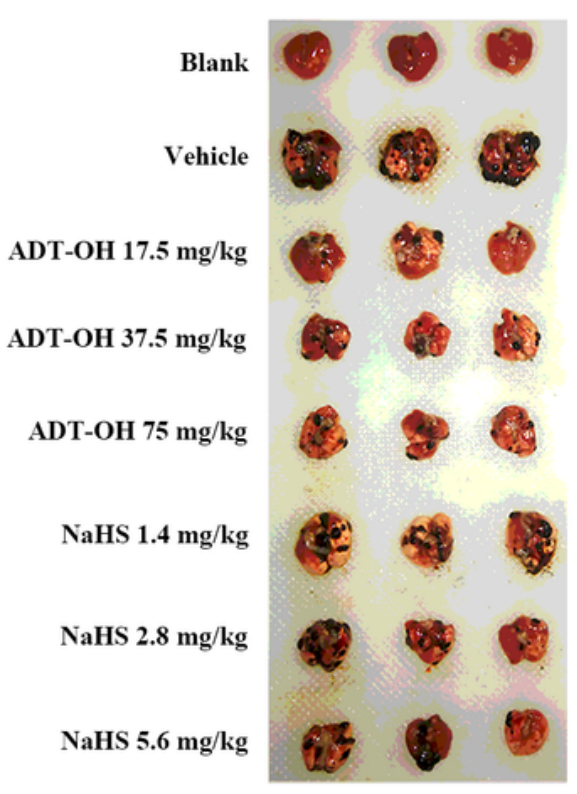

d

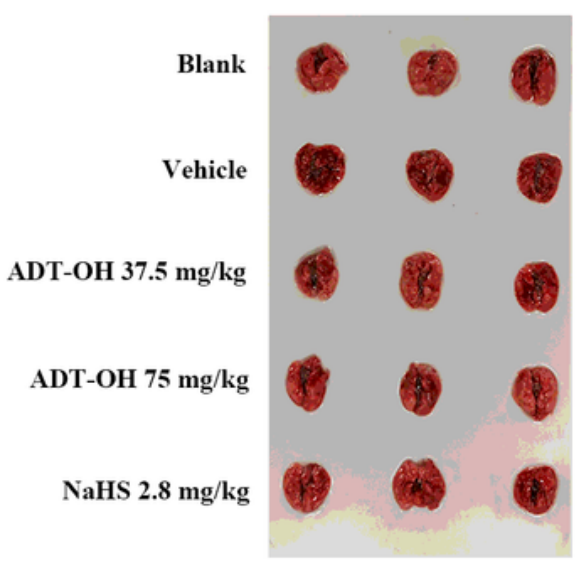

C

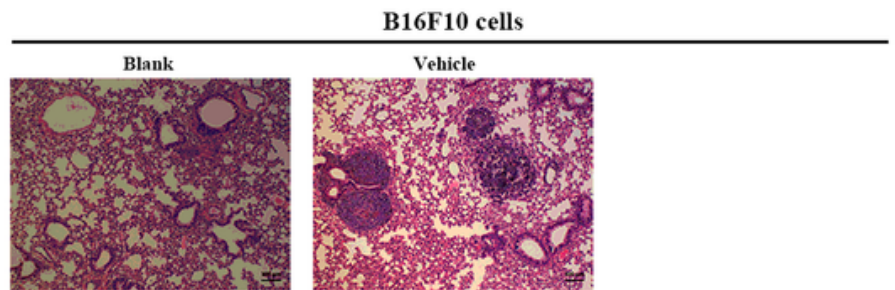

ADT-OH $17.5 \mathrm{mg} / \mathrm{kg}$

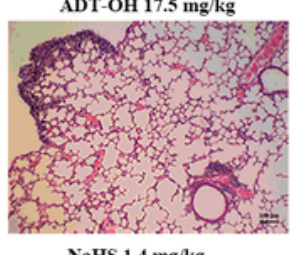

ADT-OH $18.75 \mathrm{mg} / \mathrm{kg}$

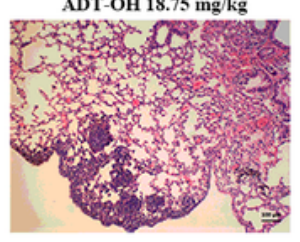

NaHS $2.8 \mathrm{mg} / \mathrm{kg}$
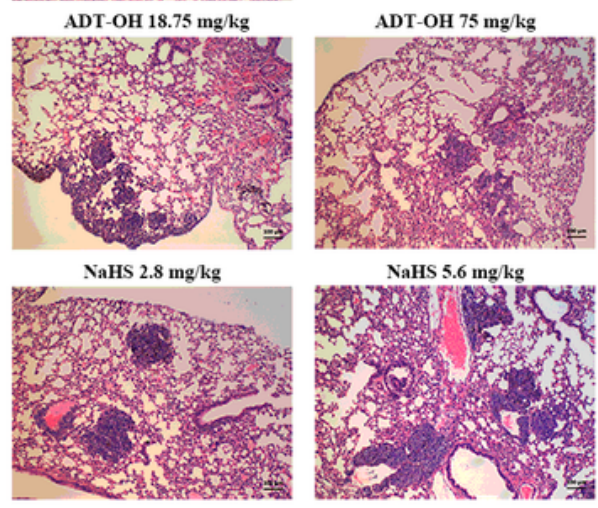

NaHS $5.6 \mathrm{mg} / \mathrm{kg}$

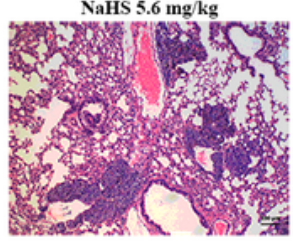

e

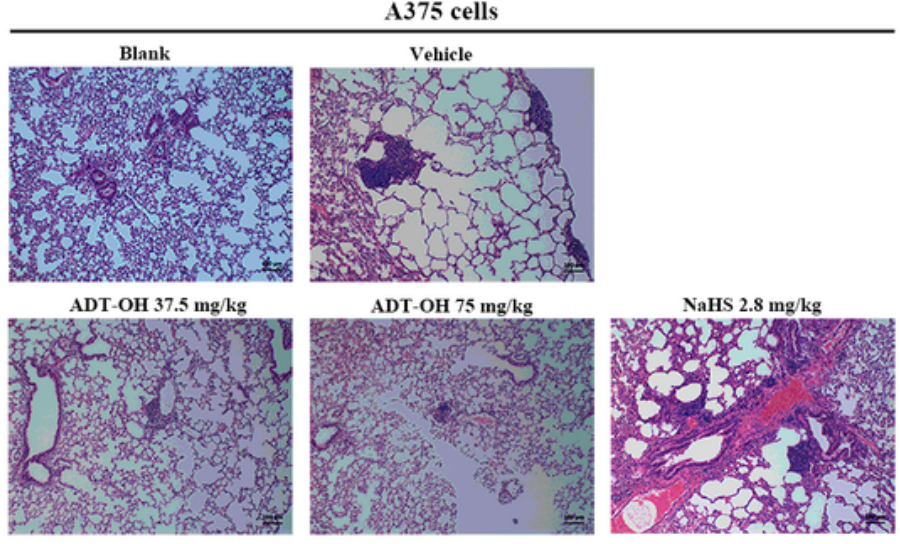

\section{Figure 2}

ADT-OH inhibits melanoma invasion in vivo in mice tail vein injection model. a Animal treatment methods. b Representative lung imaging of mice after tail vein injection with B16F10 cells for 3 weeks. $\mathrm{C}$ H\&E stained lung sections. The representative images showed lung tumor distribution of the lung metastasis model mice treated with vehicle, $17.5 \mathrm{mg} / \mathrm{kg} \mathrm{ADT-OH,} 37.5 \mathrm{mg} / \mathrm{kg} \mathrm{ADT-OH,} 75 \mathrm{mg} / \mathrm{kg} \mathrm{ADT-OH}$, $1.4 \mathrm{mg} / \mathrm{kg} \mathrm{NaHS}, 2.8 \mathrm{mg} / \mathrm{kg}$ NaHS and $5.6 \mathrm{mg} / \mathrm{kg}$ NaHS. Scale bars, 100 m. d-e Representative lung 
imaging (d) and H\&E tissue staining (e) of mice injected with A375 cells in the tail vein. The lung metastasis model mice were treated with vehicle, $37.5 \mathrm{mg} / \mathrm{kg} \mathrm{ADT-OH}, 75 \mathrm{mg} / \mathrm{kg}$ ADT-OH and $2.8 \mathrm{mg} / \mathrm{kg}$ NaHS for 3 weeks. Scale bars, $100 \mu \mathrm{m}$.

\section{Figure 2}

a

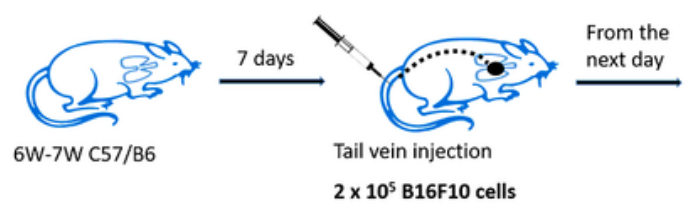

Vehicle: $0.5 \% \mathrm{CMC}$ gav.

ADT-OH: $18.75 \mathrm{mg} / \mathrm{kg}$ gav.

ADT-OH: $37.5 \mathrm{mg} / \mathrm{kg}$ gav.

ADT-OH: $75 \mathrm{mg} / \mathrm{kg}$ gav.

15 days

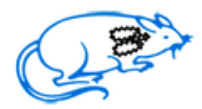

NaHS: $1.4 \mathrm{mg} / \mathrm{kg}$ gav.

NaHS: $2.8 \mathrm{mg} / \mathrm{kg}$ gav.

直 NaHS: $5.6 \mathrm{mg} / \mathrm{kg}$ gav. b

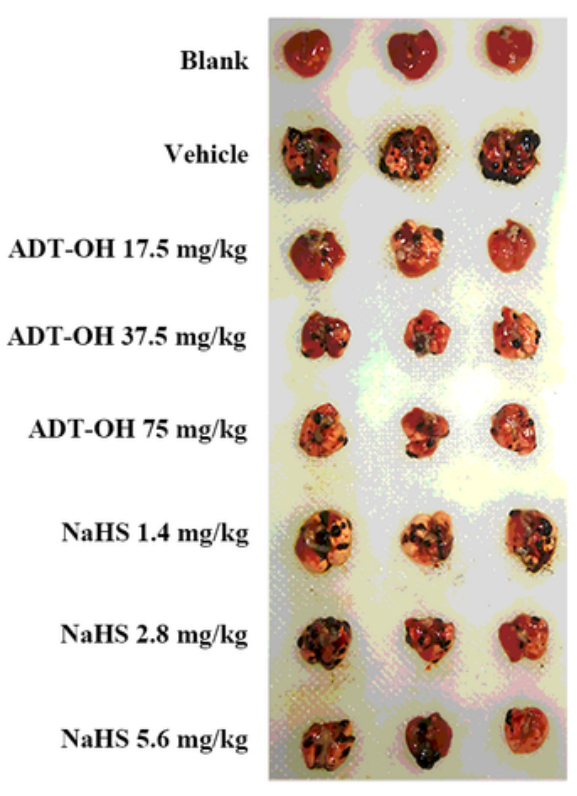

d

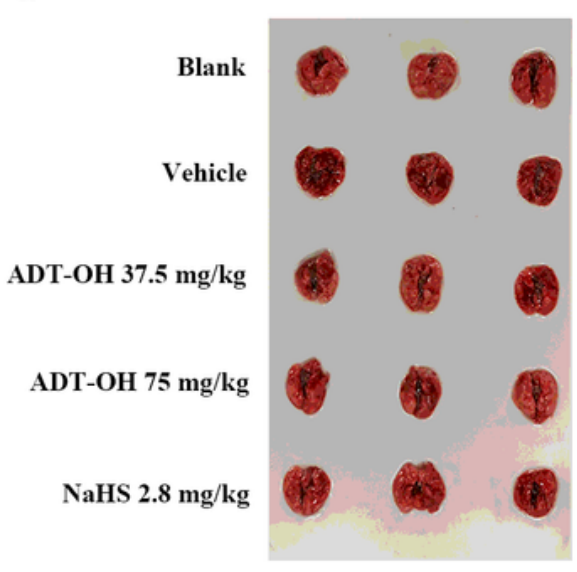

C

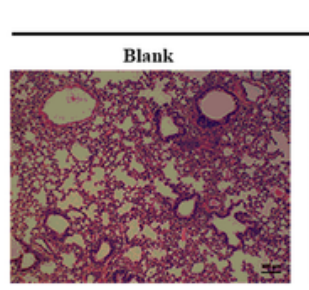

ADT-OH $17.5 \mathrm{mg} / \mathrm{kg}$

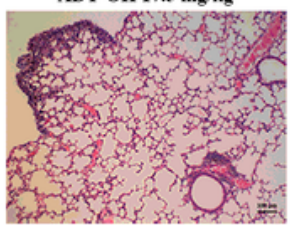

NaHS $1.4 \mathrm{mg} / \mathrm{kg}$

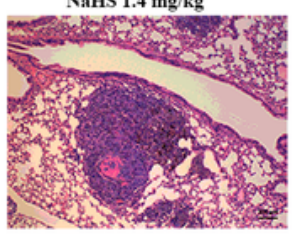

B16F10 cells

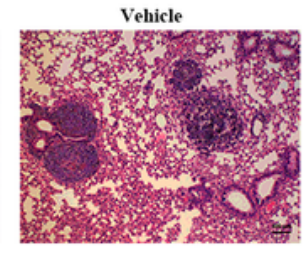

ADT-OH $18.75 \mathrm{mg} / \mathrm{kg}$

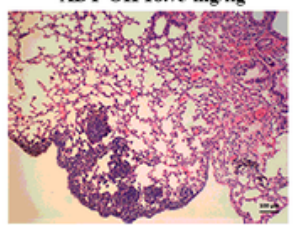

NaHS $2.8 \mathrm{mg} / \mathrm{kg}$
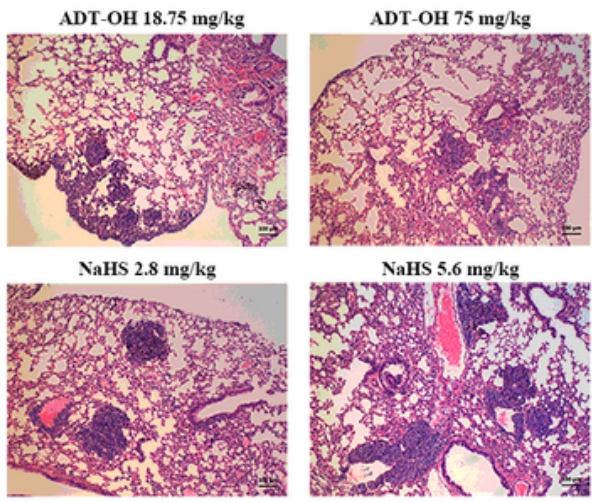

NaHS $5.6 \mathrm{mg} / \mathrm{kg}$

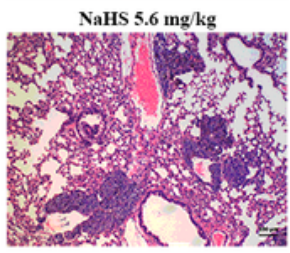

e
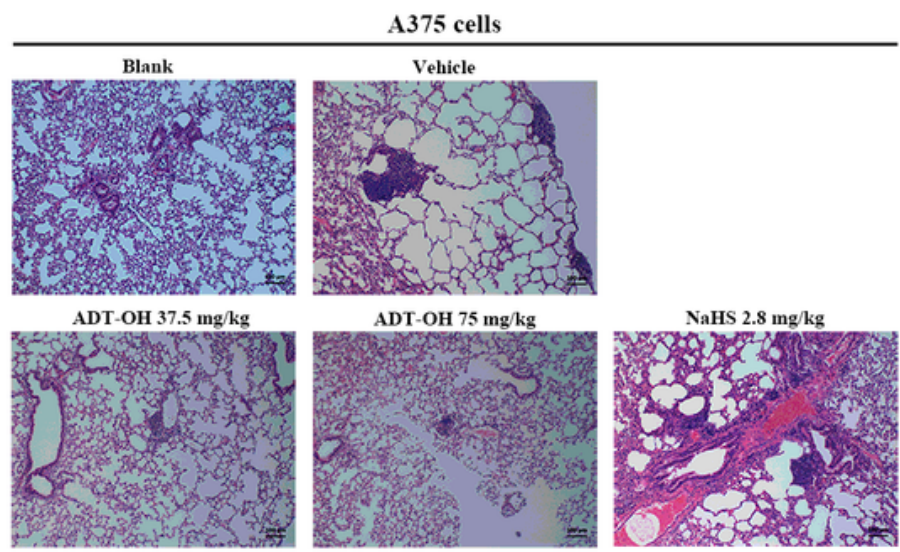

NaHS $2.8 \mathrm{mg} / \mathrm{kg}$

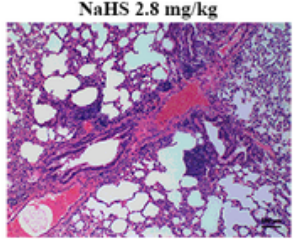

Figure 2

ADT-OH inhibits melanoma invasion in vivo in mice tail vein injection model. a Animal treatment methods. b Representative lung imaging of mice after tail vein injection with B16F10 cells for 3 weeks. c 
H\&E stained lung sections. The representative images showed lung tumor distribution of the lung metastasis model mice treated with vehicle, $17.5 \mathrm{mg} / \mathrm{kg} \mathrm{ADT-OH,} 37.5 \mathrm{mg} / \mathrm{kg}$ ADT-OH, $75 \mathrm{mg} / \mathrm{kg}$ ADT-OH, $1.4 \mathrm{mg} / \mathrm{kg} \mathrm{NaHS}, 2.8 \mathrm{mg} / \mathrm{kg} \mathrm{NaHS}$ and $5.6 \mathrm{mg} / \mathrm{kg} \mathrm{NaHS}$. Scale bars, $100 \mu \mathrm{m}$. d-e Representative lung imaging (d) and H\&E tissue staining (e) of mice injected with A375 cells in the tail vein. The lung metastasis model mice were treated with vehicle, $37.5 \mathrm{mg} / \mathrm{kg} \mathrm{ADT-OH,} 75 \mathrm{mg} / \mathrm{kg} \mathrm{ADT-OH}$ and $2.8 \mathrm{mg} / \mathrm{kg}$ NaHS for 3 weeks. Scale bars, $100 \mu \mathrm{m}$.

\section{Figure 3}

a

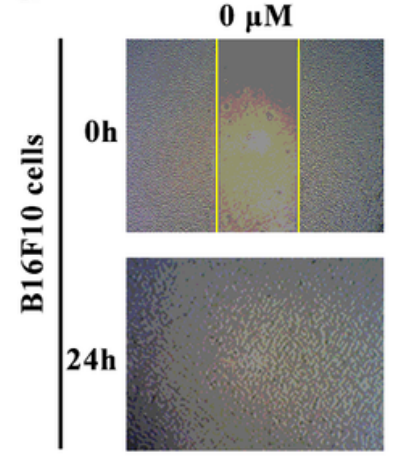

b

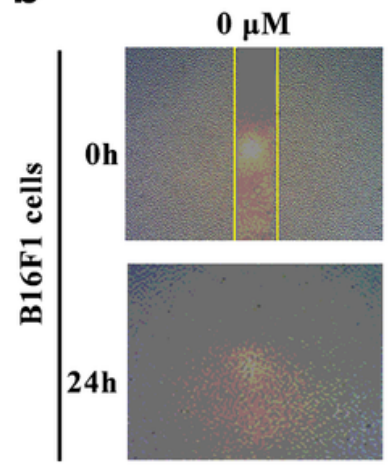

C

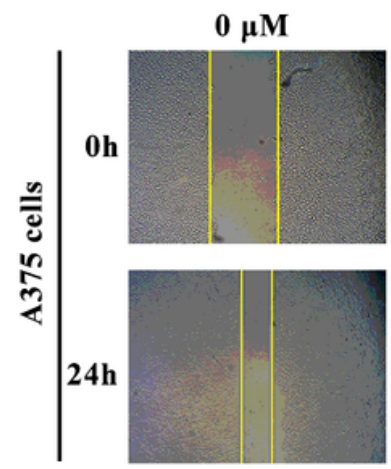

$6.3 \mu \mathrm{M}$
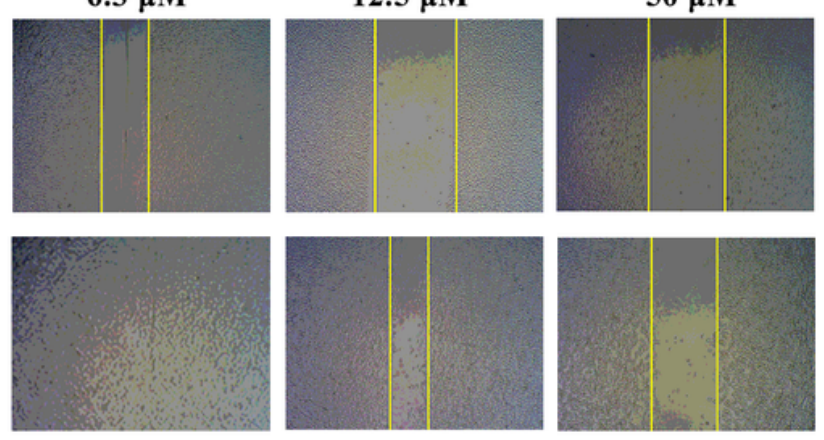

$12.5 \mu \mathrm{M}$
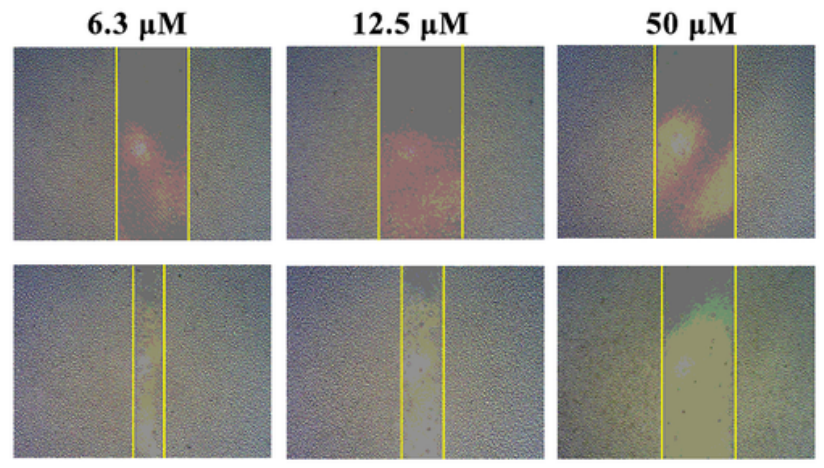

f
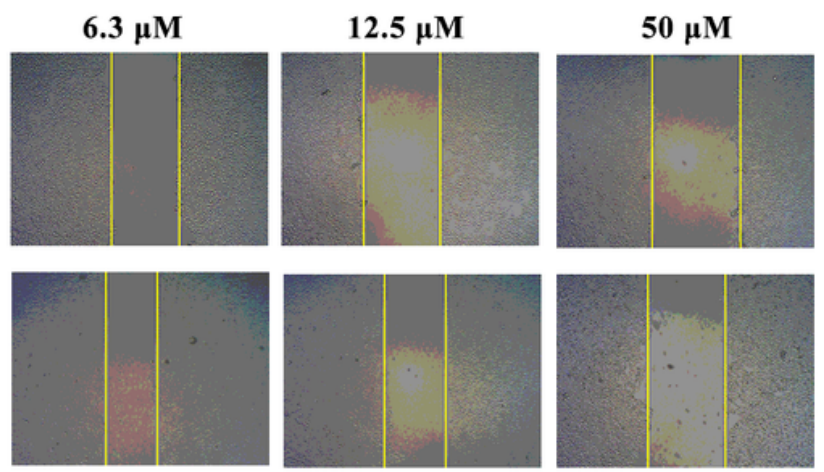

e

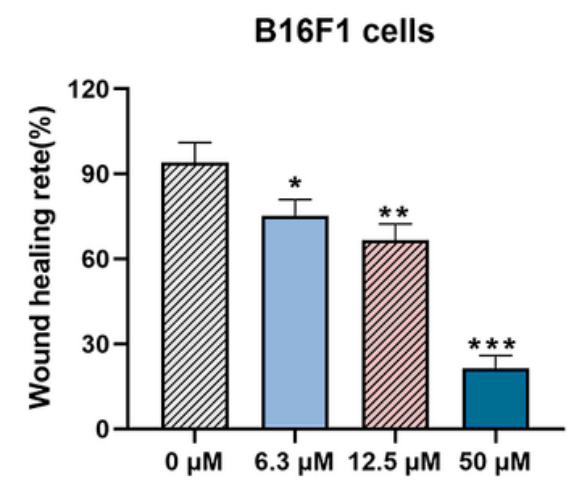

d

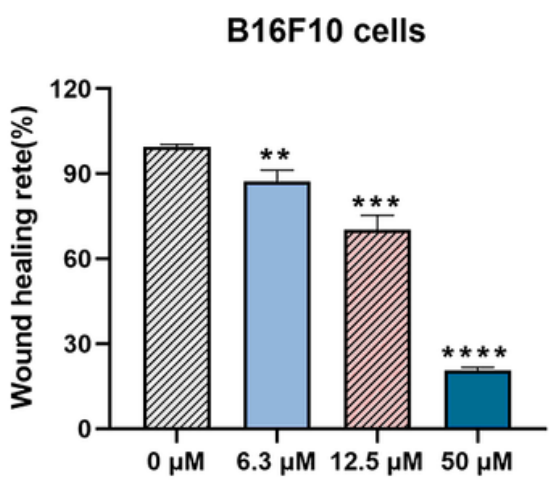

A375 cells

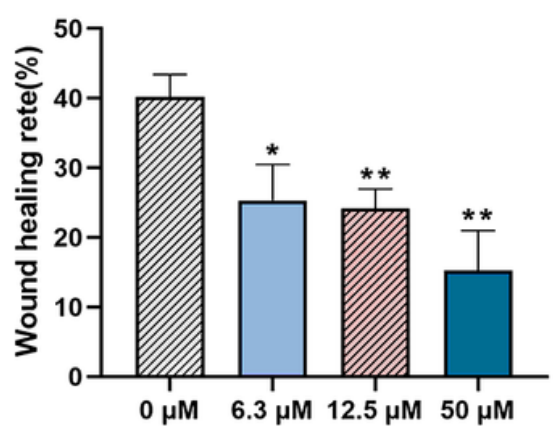

Figure 3

ADT-OH suppresses melanoma cells migration in vitro. a-c Melanoma cell line B16F10, B16F1 and A375 cell line were seeded into 6-well plates at $2 \times 105$ cells / well. After incubation with ADT-OH at 0 (Control), 
$6.3,12.5,100 \mu \mathrm{M}$ for $24 \mathrm{~h}$, the effect of $\mathrm{ADT}-\mathrm{OH}$ on cell migration was measured by wound-healing assay; original magnification $40 \times$. d-f The migration rates of B16F10, B16F1 and A375 cells were calculated by the formula shown in Materials and Methods. Data are presented as mean \pm SD of three independent experiments; ${ }^{*} p<0.05, * * p<0.01,{ }^{* *} p<0.005$ compared with vehicle group.

\section{Figure 3}

a

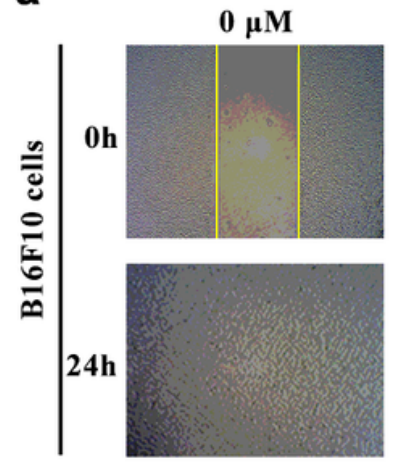

b

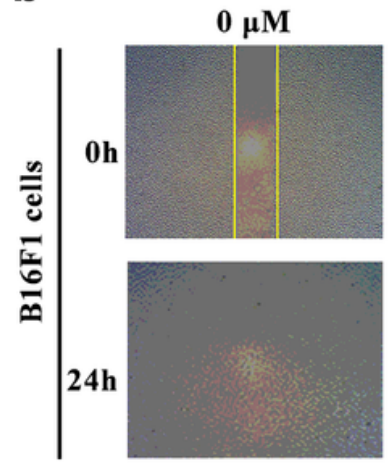

C

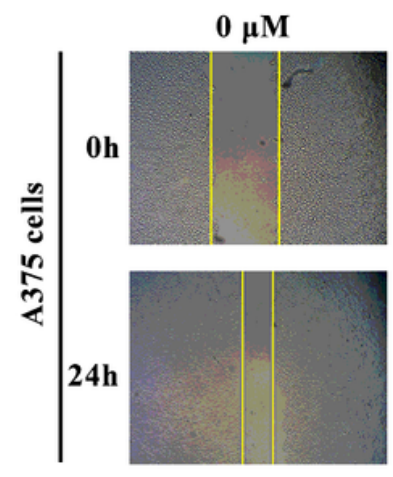

$6.3 \mu \mathrm{M}$
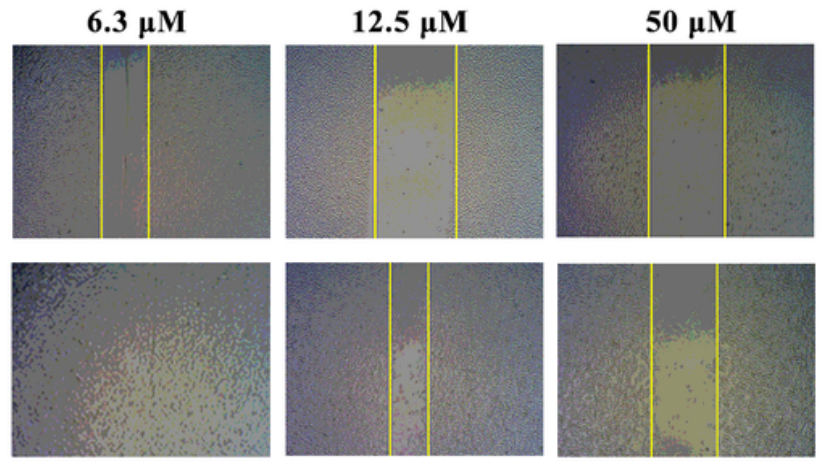

$12.5 \mu \mathrm{M}$
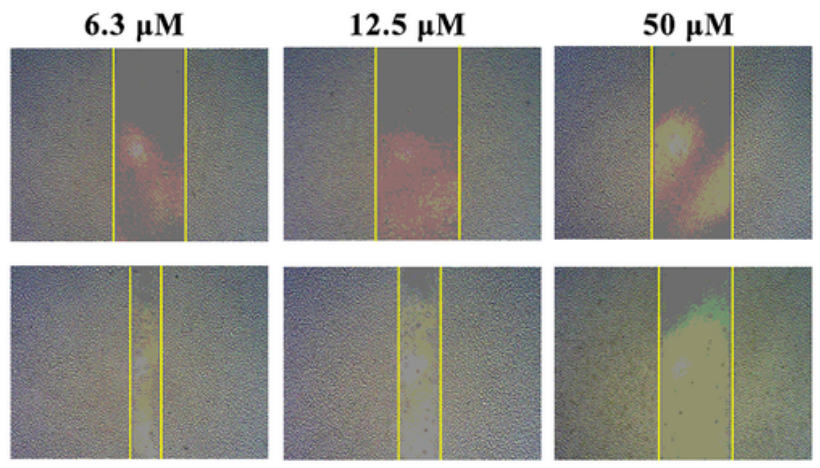

$12.5 \mu \mathrm{M}$

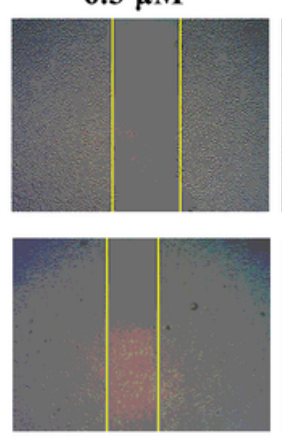

$\mathbf{5 0} \mu \mathrm{M}$

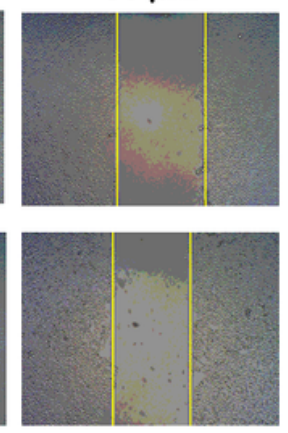

d

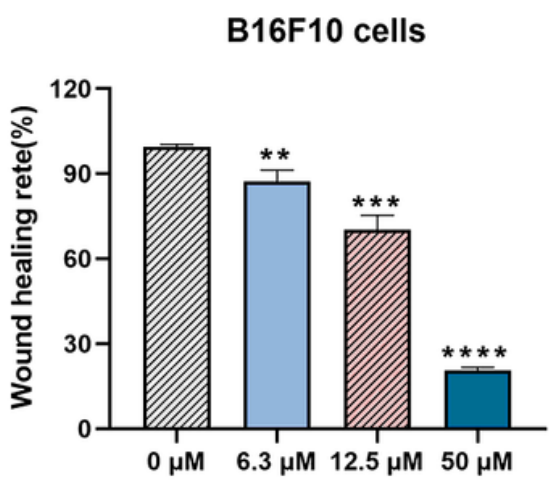

e

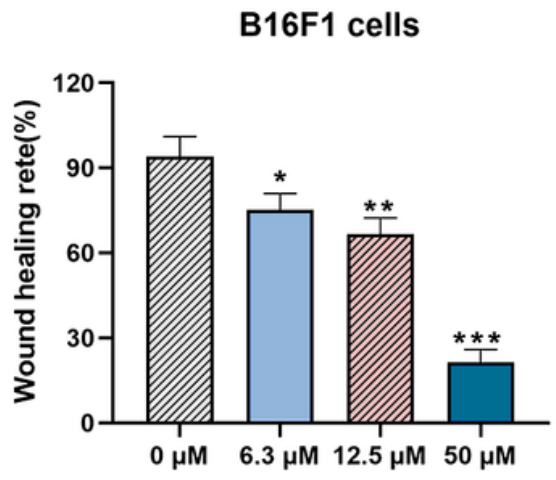

f
A375 cells

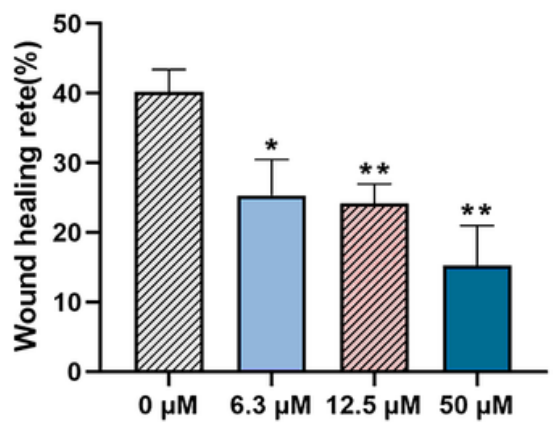

Figure 3

ADT-OH suppresses melanoma cells migration in vitro. a-c Melanoma cell line B16F10, B16F1 and A375 cell line were seeded into 6-well plates at $2 \times 105$ cells / well. After incubation with ADT-OH at 0 (Control), $6.3,12.5,100 \mu \mathrm{M}$ for $24 \mathrm{~h}$, the effect of $\mathrm{ADT}-\mathrm{OH}$ on cell migration was measured by wound-healing assay; original magnification $40 \times$. d-f The migration rates of B16F10, B16F1 and A375 cells were calculated by 
the formula shown in Materials and Methods. Data are presented as mean \pm SD of three independent experiments; ${ }^{*} p<0.05,{ }^{*} p<0.01, * * * p<0.005$ compared with vehicle group.

\section{Figure 3}

a
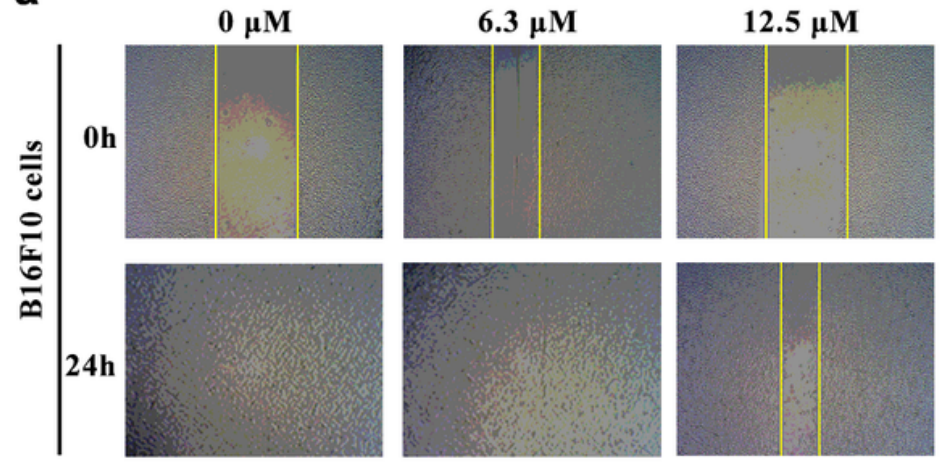

b
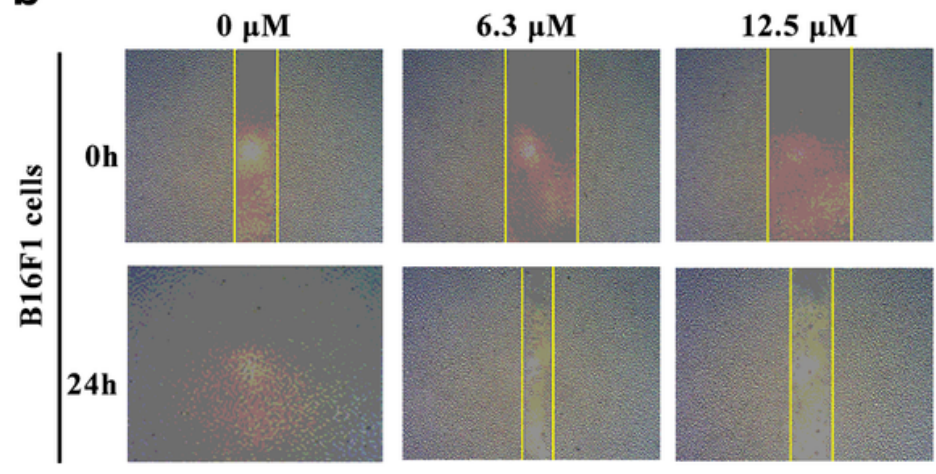

C

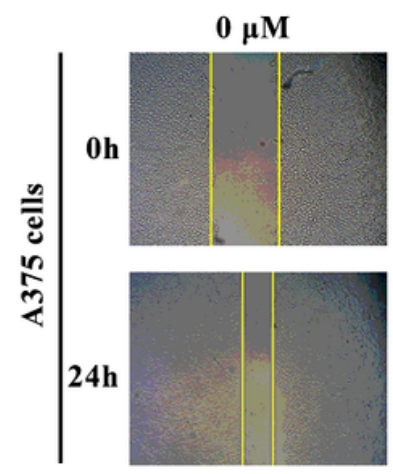

$6.3 \mu \mathrm{M}$
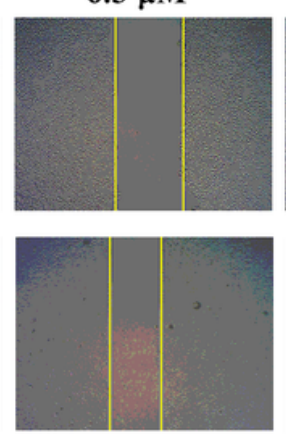

$12.5 \mu \mathrm{M}$
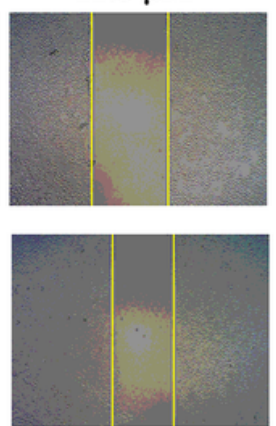
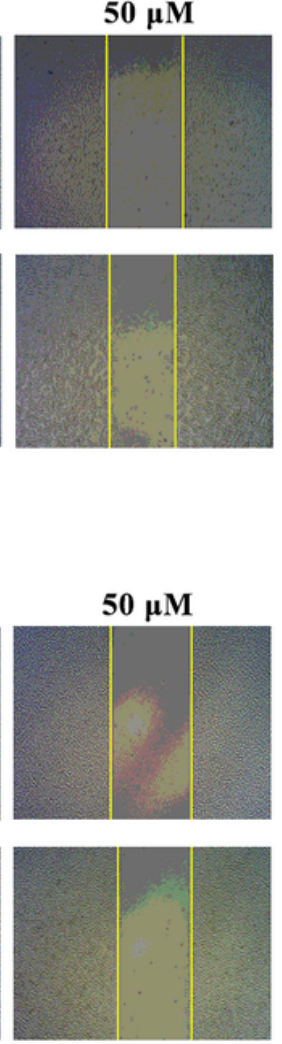

d

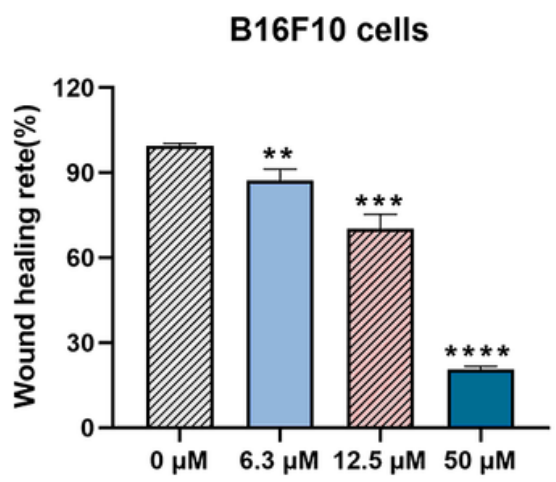

e

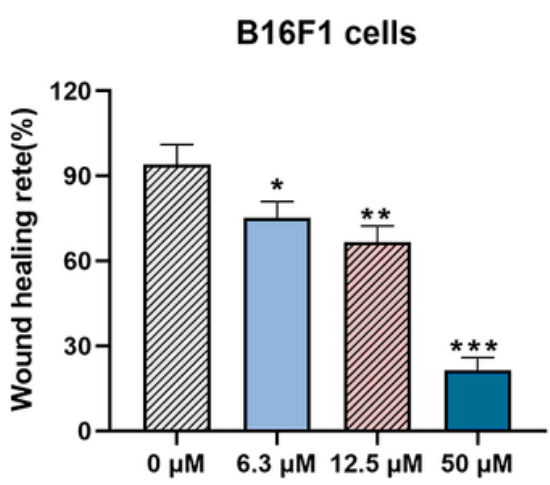

f $50 \mu M$
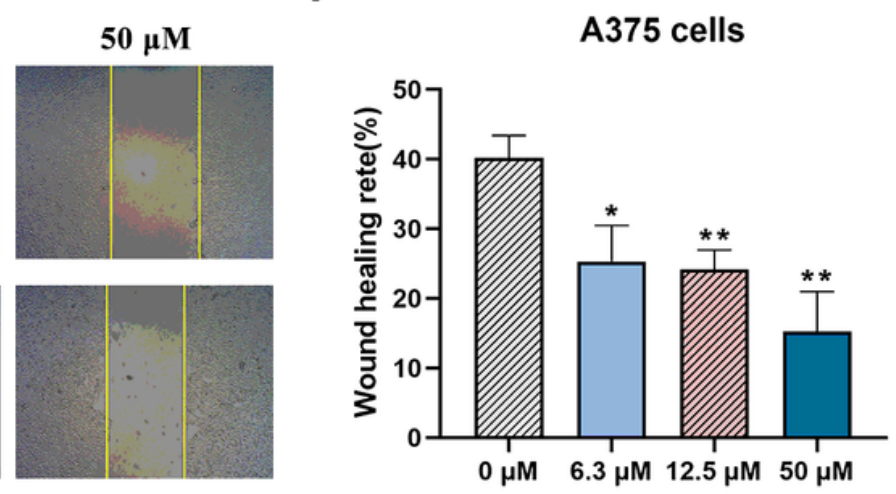

\section{Figure 3}

ADT-OH suppresses melanoma cells migration in vitro. a-c Melanoma cell line B16F10, B16F1 and A375 cell line were seeded into 6-well plates at $2 \times 105$ cells / well. After incubation with ADT-OH at 0 (Control), $6.3,12.5,100 \mu \mathrm{M}$ for $24 \mathrm{~h}$, the effect of $\mathrm{ADT}-\mathrm{OH}$ on cell migration was measured by wound-healing assay; original magnification $40 \times$. d-f The migration rates of B16F10, B16F1 and A375 cells were calculated by the formula shown in Materials and Methods. Data are presented as mean \pm SD of three independent experiments; ${ }^{\star} p<0.05,{ }^{*} p<0.01,{ }^{\star \star *} p<0.005$ compared with vehicle group. 


\section{Figure 4}

a

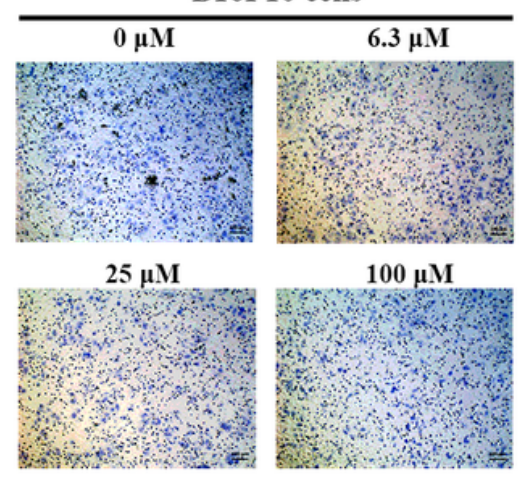

B16F10 cells

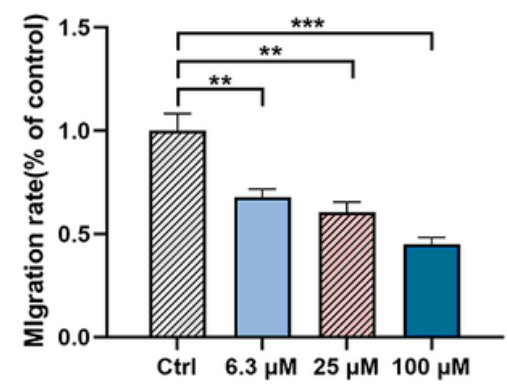

d

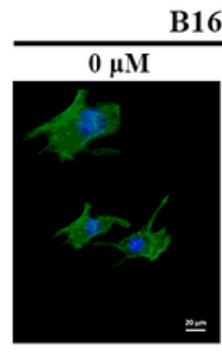

$25 \mu \mathrm{M}$

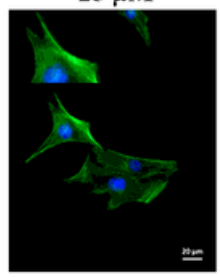

b

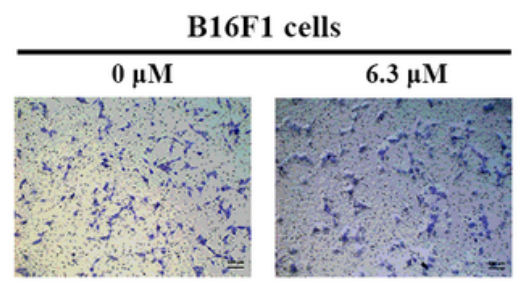

$25 \mu \mathrm{M}$

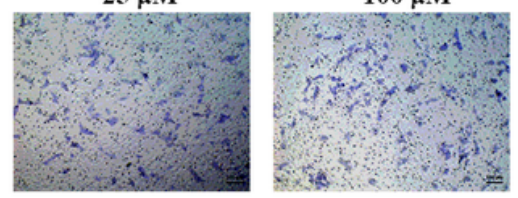

B16F1 cells

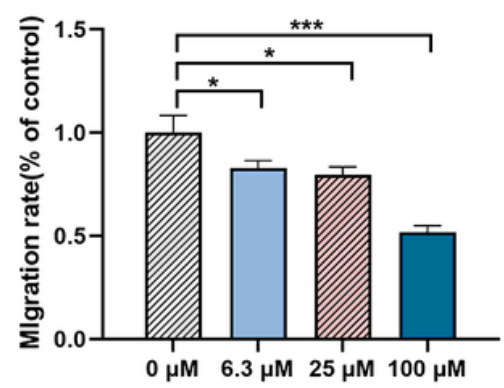

e

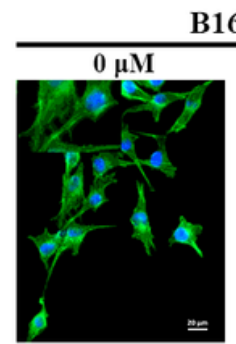

$25 \mu \mathrm{M}$

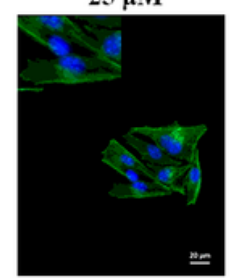

C

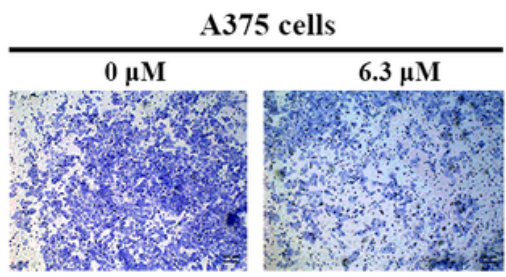

$25 \mu \mathrm{M}$

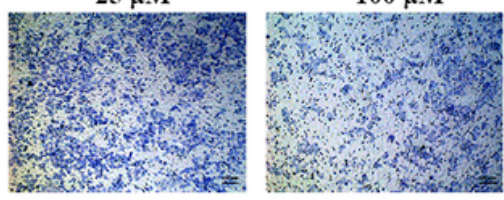

A375 cells

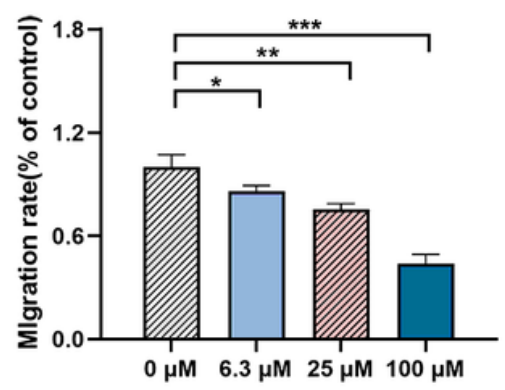

f

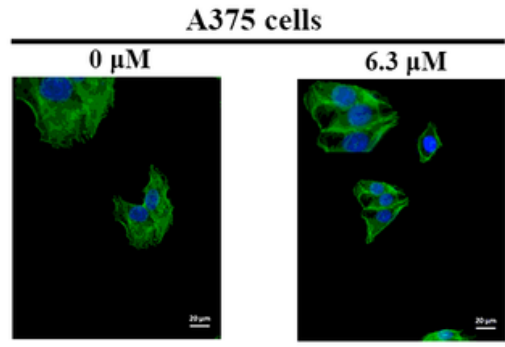

$25 \mu \mathrm{M}$

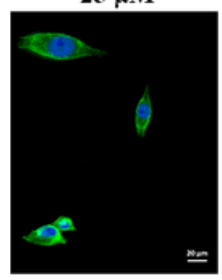

$100 \mu \mathrm{M}$

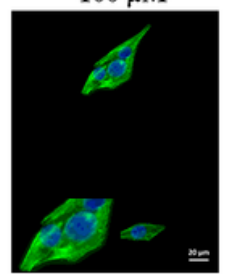

\section{Figure 4}

ADT-OH inhibits melanoma cells invasion in vitro. a-c Summary of results from the transwell invasion assay. After $12 \mathrm{~h}$ of incubation with or without $\mathrm{ADT}-\mathrm{OH}$, the cells that migrated to the lower chamber were fixed, stained, and counted using a light microscope. Four random fields per filter were scanned for the presence of cells on the lower side of the membrane. The panels of the upper figures show the images obtained by cell invasion assay in B16F10, B16F1 and A375 cells. All experiments were performed thrice in triplicate. The data are presented as the mean $\pm S D$. ${ }^{\star} p<0.05$, ${ }^{\star \star} p<0.01$, ${ }^{\star \star \star} p<0.005$ compared with vehicle group. d-f Representative images of F-actin immunofluorescence in B16F10, B16F1 and A375 cells. Scale bars correspond to $20 \mu \mathrm{m}$. 


\section{Figure 4}

a

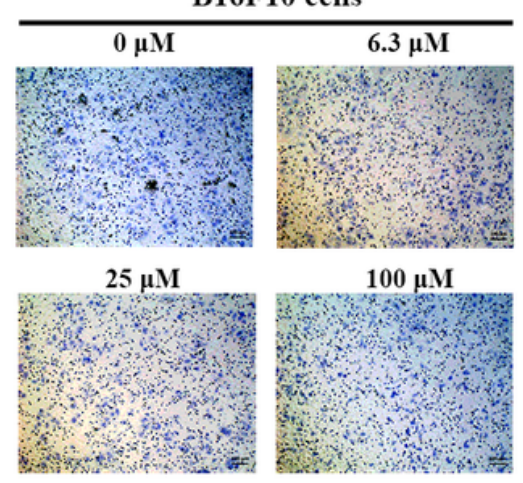

B16F10 cells

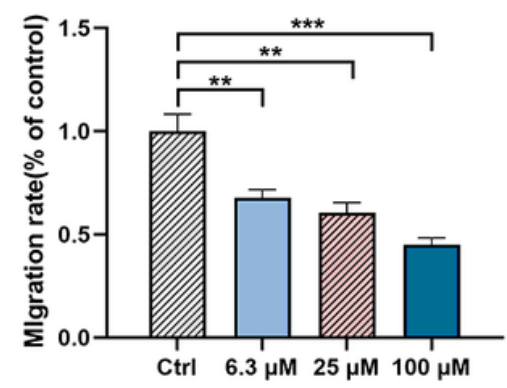

d

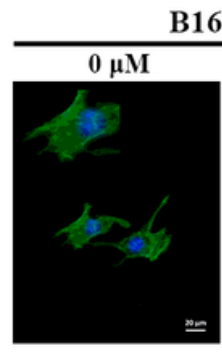

$25 \mu \mathrm{M}$

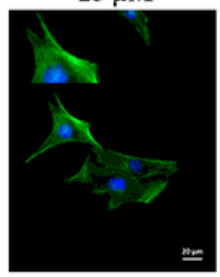

b

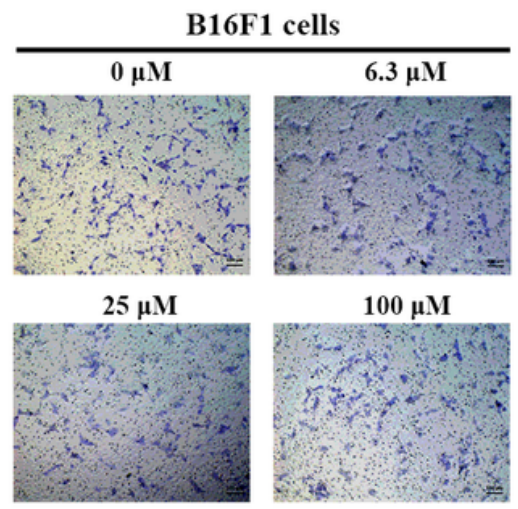

B16F1 cells

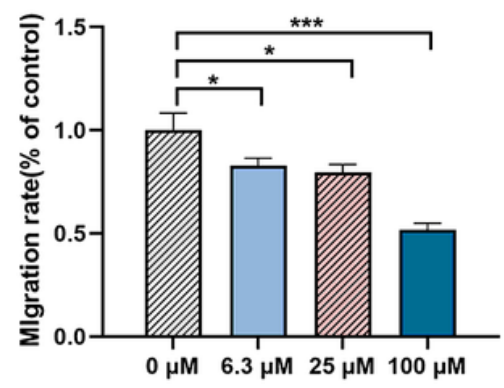

e

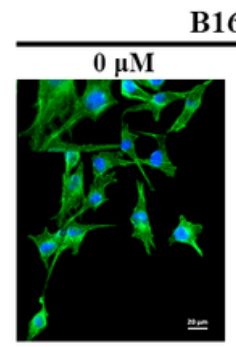

$25 \mu \mathrm{M}$

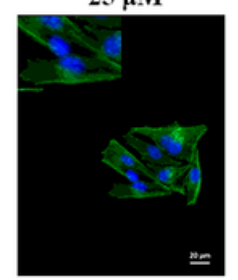

C

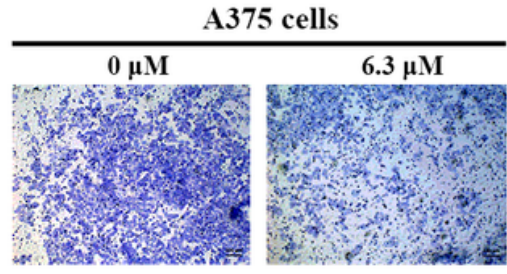

$25 \mu \mathrm{M}$

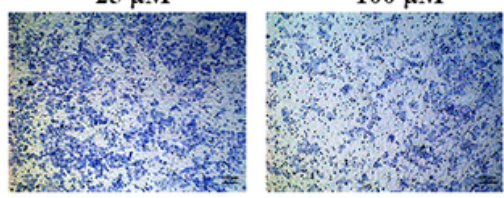

A375 cells

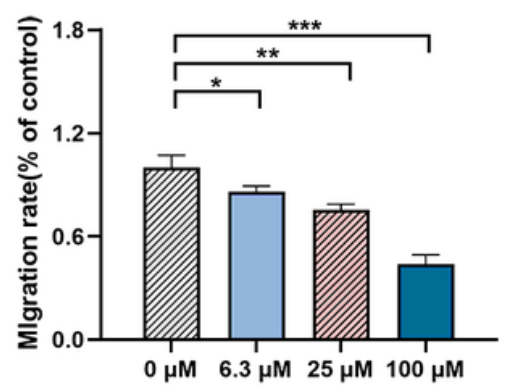

f

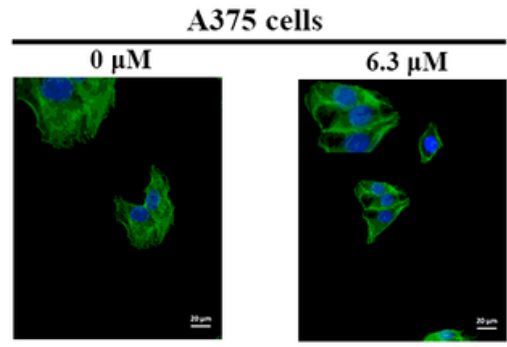

$25 \mu \mathrm{M}$

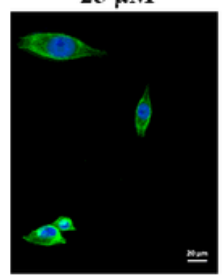

$100 \mu \mathrm{M}$

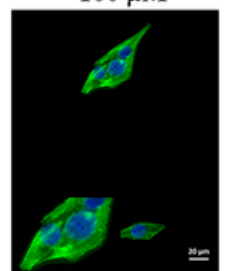

\section{Figure 4}

ADT-OH inhibits melanoma cells invasion in vitro. a-c Summary of results from the transwell invasion assay. After $12 \mathrm{~h}$ of incubation with or without ADT-OH, the cells that migrated to the lower chamber were fixed, stained, and counted using a light microscope. Four random fields per filter were scanned for the presence of cells on the lower side of the membrane. The panels of the upper figures show the images obtained by cell invasion assay in B16F10, B16F1 and A375 cells. All experiments were performed thrice in triplicate. The data are presented as the mean \pm SD. ${ }^{\star} p<0.05,{ }^{*} p<0.01$, ${ }^{\star *}$ $p<0.005$ compared with vehicle group. d-f Representative images of F-actin immunofluorescence in B16F10, B16F1 and A375 cells. Scale bars correspond to $20 \mu \mathrm{m}$. 


\section{Figure 4}

a

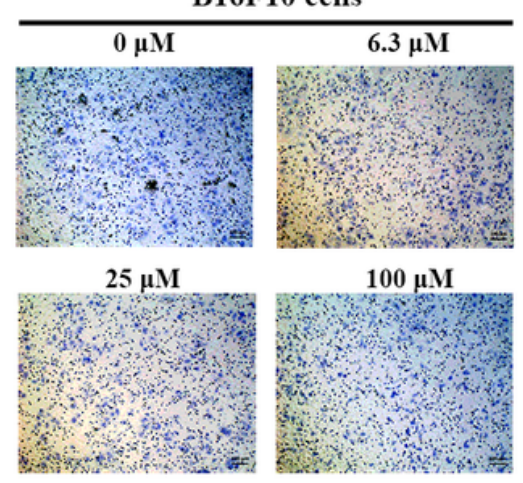

B16F10 cells

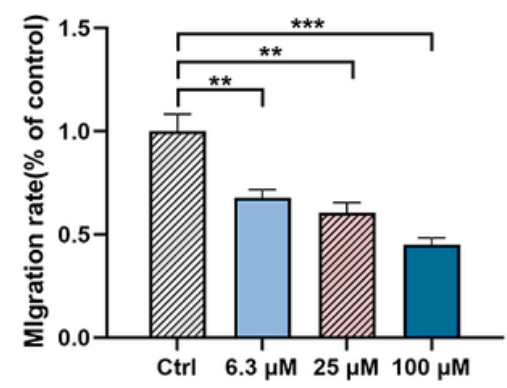

d

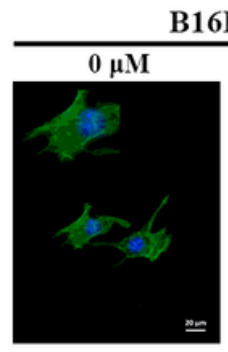

$25 \mu \mathrm{M}$

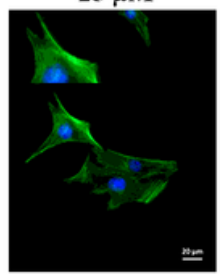

b

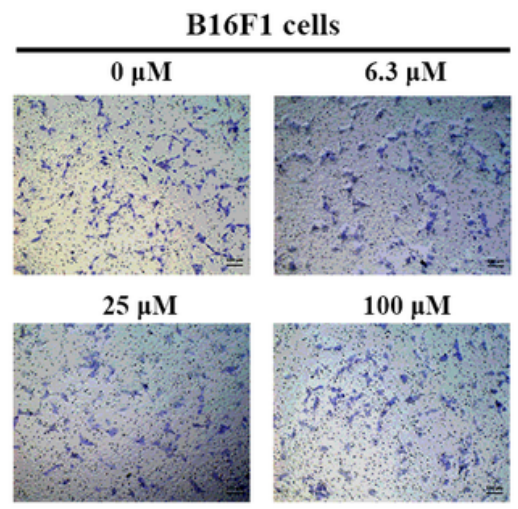

B16F1 cells

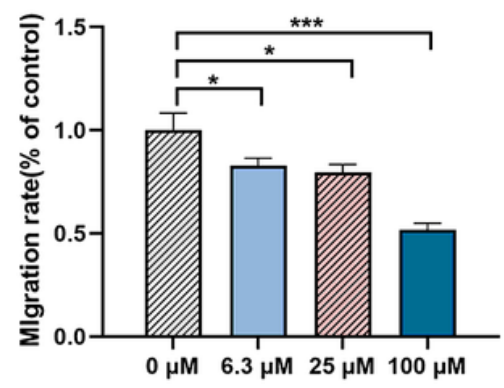

e

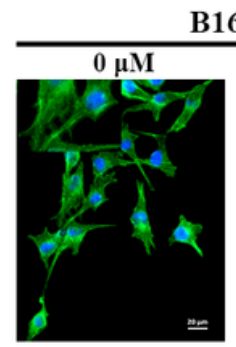

$25 \mu \mathrm{M}$

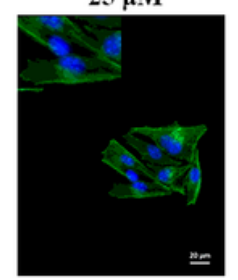

C

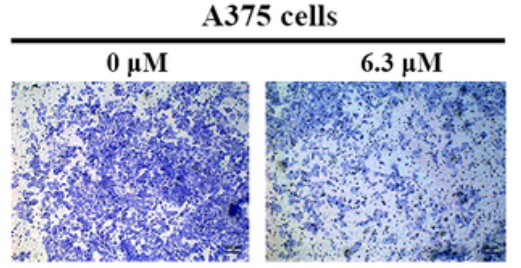

$25 \mu \mathrm{M}$

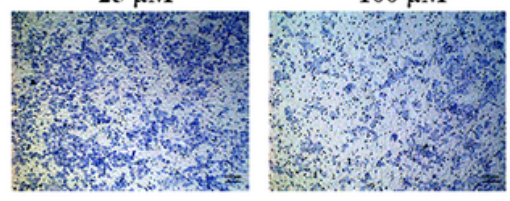

A375 cells

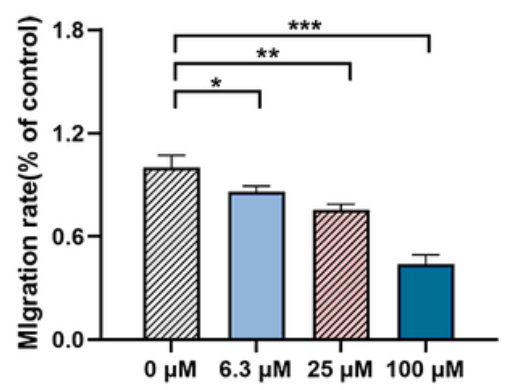

f

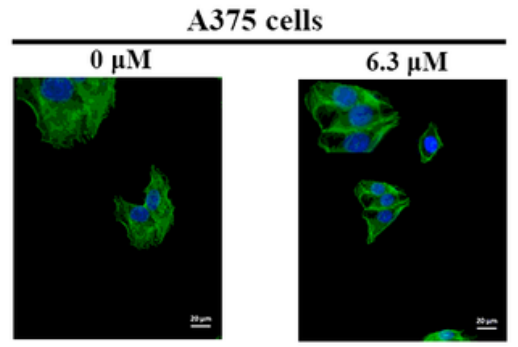

$25 \mu \mathrm{M}$

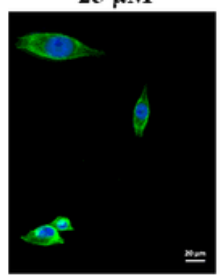

$100 \mu \mathrm{M}$

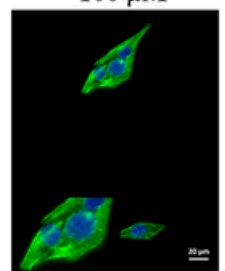

\section{Figure 4}

ADT-OH inhibits melanoma cells invasion in vitro. a-c Summary of results from the transwell invasion assay. After $12 \mathrm{~h}$ of incubation with or without ADT-OH, the cells that migrated to the lower chamber were fixed, stained, and counted using a light microscope. Four random fields per filter were scanned for the presence of cells on the lower side of the membrane. The panels of the upper figures show the images obtained by cell invasion assay in B16F10, B16F1 and A375 cells. All experiments were performed thrice in triplicate. The data are presented as the mean \pm SD. ${ }^{\star} p<0.05,{ }^{*} p<0.01$, ${ }^{\star *}$ $p<0.005$ compared with vehicle group. d-f Representative images of F-actin immunofluorescence in B16F10, B16F1 and A375 cells. Scale bars correspond to $20 \mu \mathrm{m}$. 
Figure 5

a

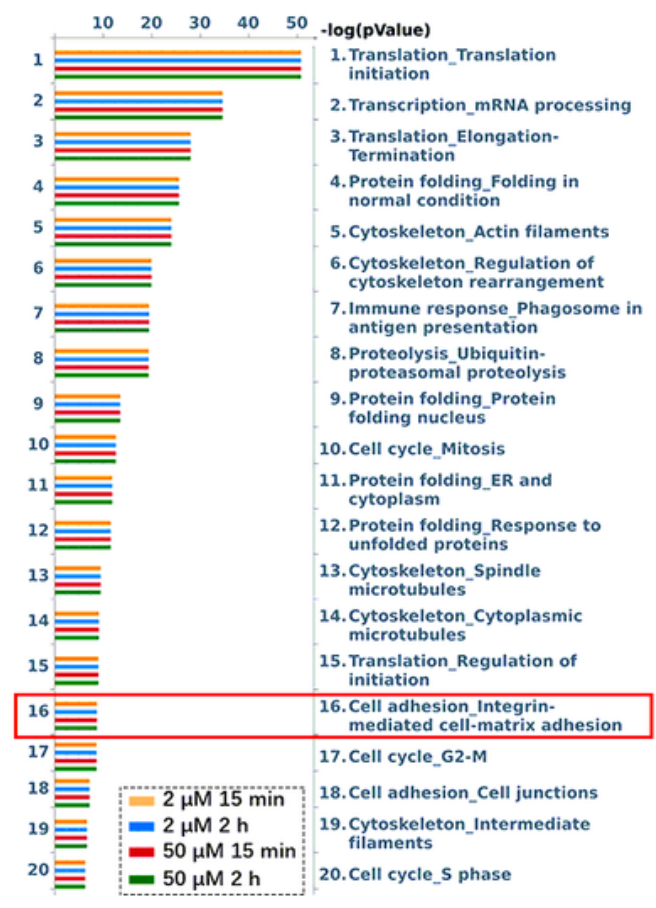

C

\begin{tabular}{|c|c|c|c|}
\hline$\square$ & Network Objects & $\begin{array}{l}=\text { of Maps containing } \\
\text { Network Object }\end{array}$ & Overall, \\
\hline$\square$ & $\underline{\text { Rac1 }}$ & 27 & 1 \\
\hline$\square$ & ERK1/2 & 23 & 2 \\
\hline$\square$ & $\mathrm{COC} 42$ & 22 & 3 \\
\hline$\square$ & RhoA & 21 & 4 \\
\hline$\square$ & c-Srs & 21 & 4 \\
\hline$\square$ & PAK1 & 20 & 5 \\
\hline$\square$ & FAK1 & 20 & 5 \\
\hline$\square$ & Paxillin & 16 & 6 \\
\hline$\square$ & $\underline{\text { Cofflin }}$ & 13 & 7 \\
\hline$\square$ & $\underline{\text { GRB2 }}$ & 12 & 8 \\
\hline$\square$ & MLCP (req) & 11 & 9 \\
\hline$\square$ & D130CAS & 11 & 9 \\
\hline$\square$ & $\underline{R O C K}$ & 11 & 9 \\
\hline$\square$ & CRK & 10 & 10 \\
\hline$\square$ & NKK(MAPK8-10) & 10 & 10 \\
\hline$\square$ & Vinculin & 10 & 10 \\
\hline$\square$ & MRLC & 10 & 10 \\
\hline$\square$ & Calmodulin & 10 & 10 \\
\hline$\square$ & D38 MAPK & 9 & 11 \\
\hline$\square$ & Fibronectin & 9 & 11 \\
\hline$\square$ & MEK $1 / 2$ & 9 & 11 \\
\hline
\end{tabular}

b

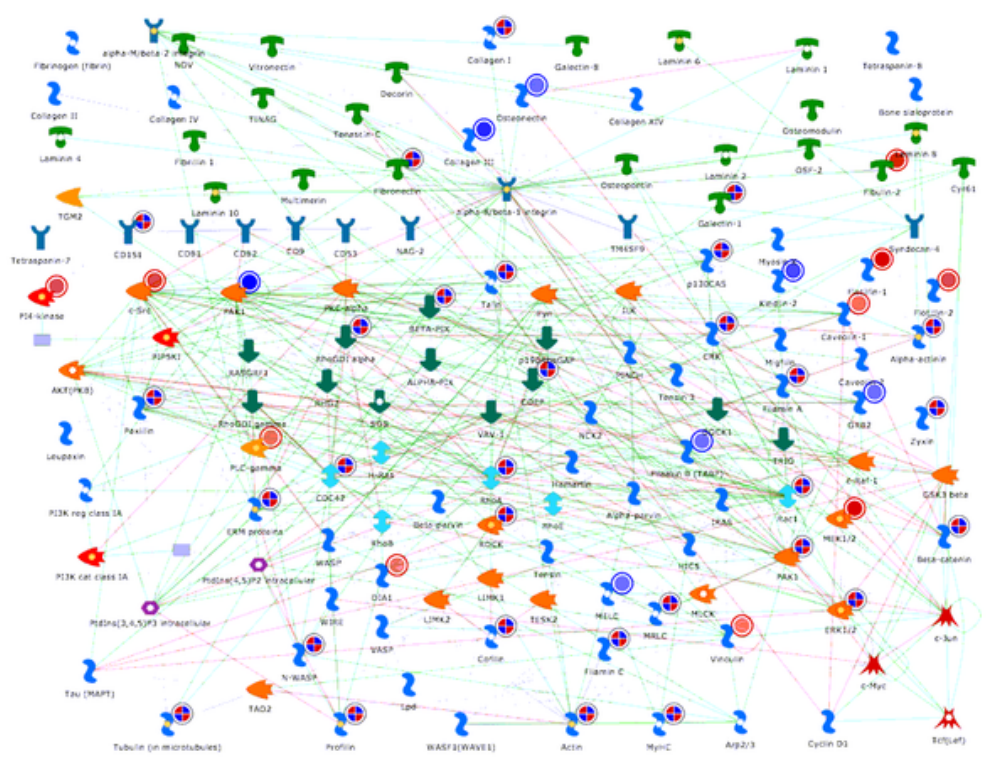

d

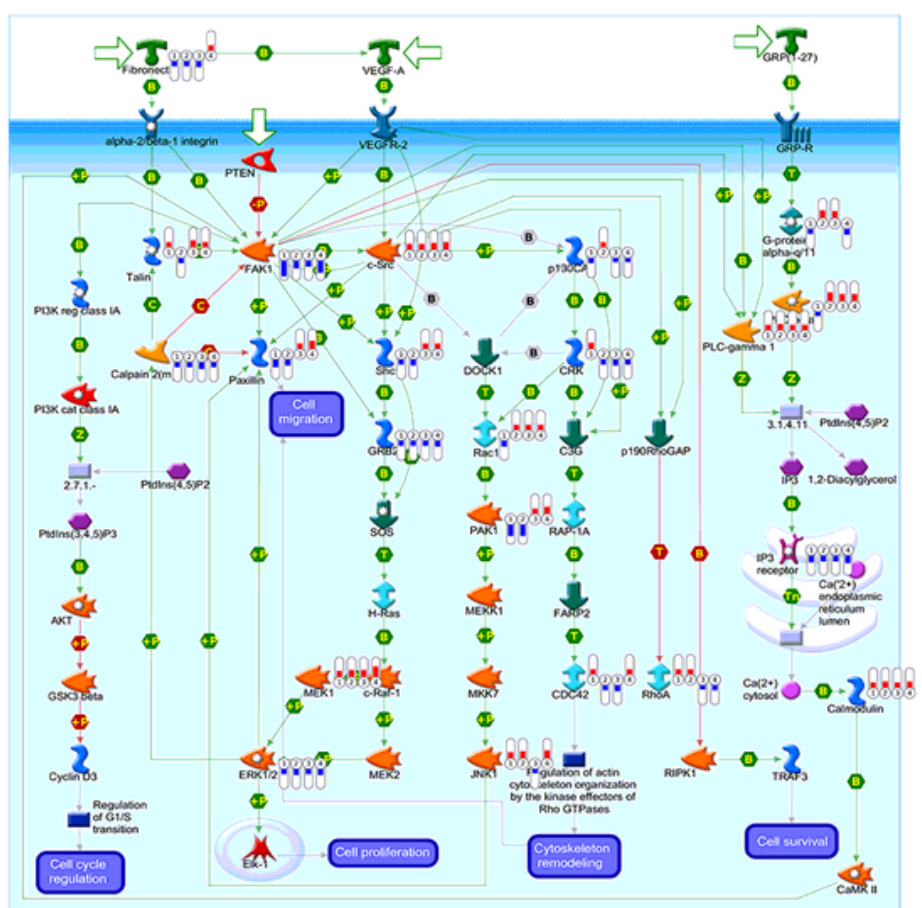

\section{Figure 5}

Proteomics analysis of proteins differentially expressed in ADT-OH-treated cells. a MetacoreTM GeneGo Pathway Maps was used to analyze the ontological categories of differentially expressed proteins in MEF cells treated with or without ADT-OH. b The protein network associated with cell adhesion and migration is differentially expressed in MEF cells treated with ADT-OH. c The network objects involved in Pathway Maps analyzed by MetacoreTM GeneGo Pathway Maps software. $d$ The GeneGO pathway shows 
changes in the expression of proteins involved in FAK/Paxillin signaling. The various proteins on the map are represented by different symbols (representing the functional categories of proteins). The symbol next to the thermometer shaded in blue or red indicates the protein identified in this study: blue indicates the protein that is down-regulated in ADT-OH treated MEF cells relative to MEF negative control cells (treated with vehicle). Red represents up-regulated protein.

\section{Figure 5}

a

$\begin{array}{lllllll}10 & 20 & 30 & 40 & 50 & -\log (p \text { Value) }\end{array}$

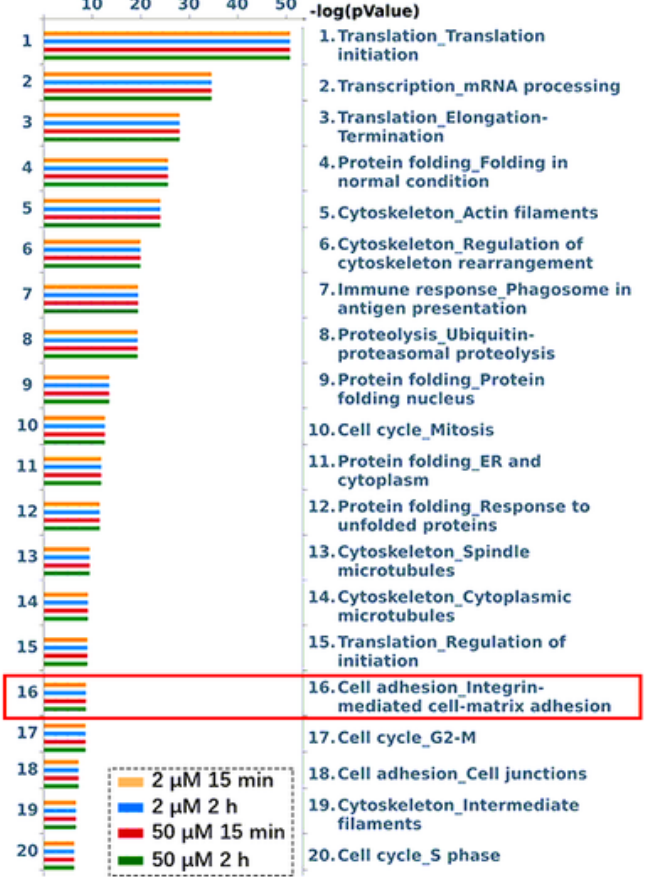

C

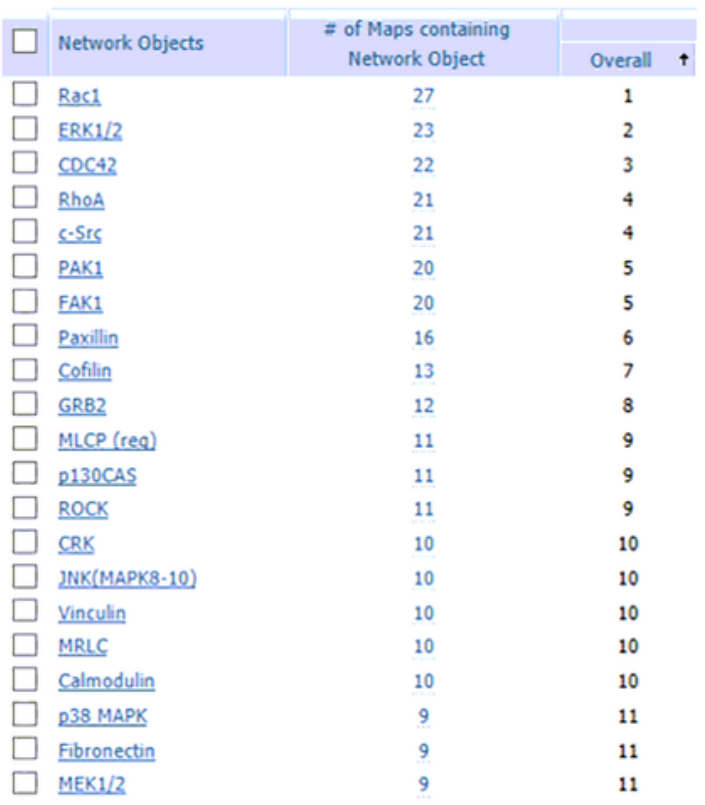

b

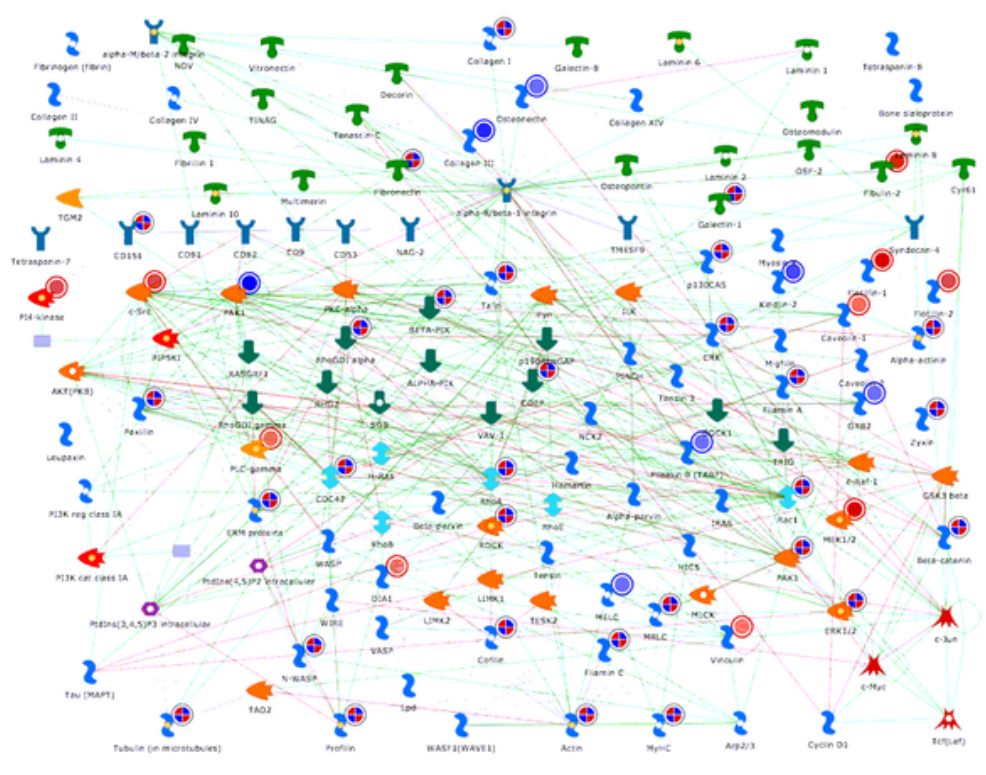

d

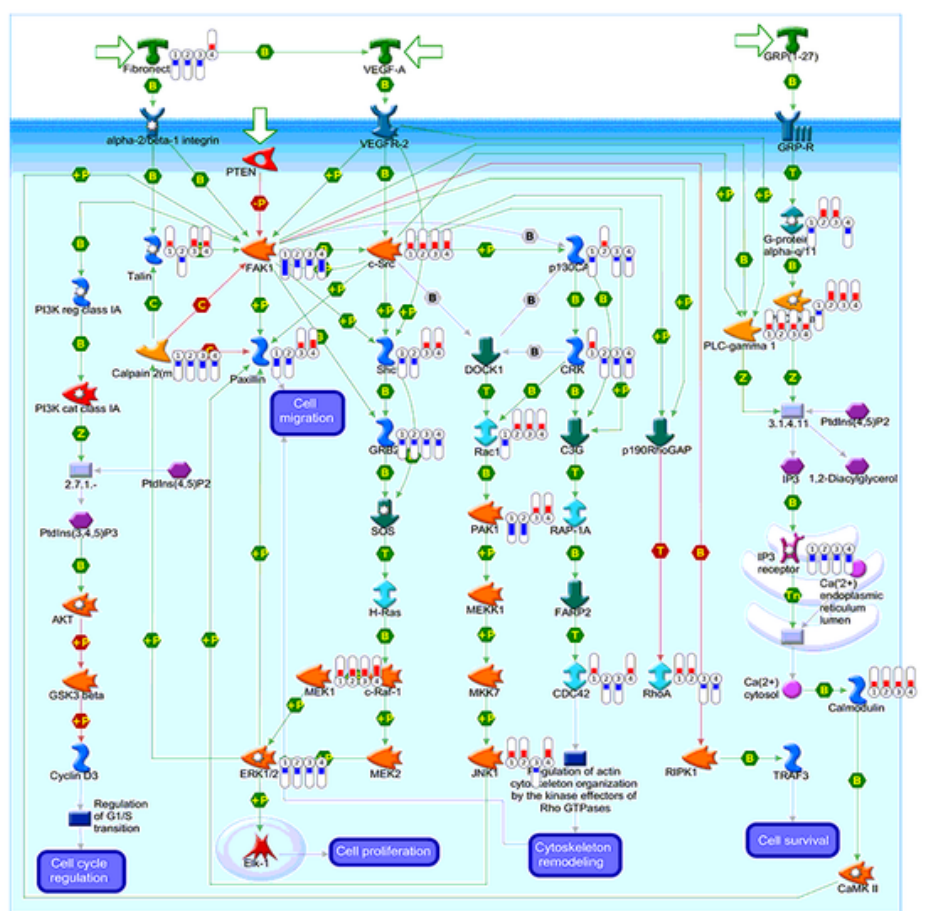

Figure 5 
Proteomics analysis of proteins differentially expressed in ADT-OH-treated cells. a MetacoreTM GeneGo Pathway Maps was used to analyze the ontological categories of differentially expressed proteins in MEF cells treated with or without ADT-OH. b The protein network associated with cell adhesion and migration is differentially expressed in MEF cells treated with ADT-OH. c The network objects involved in Pathway Maps analyzed by MetacoreTM GeneGo Pathway Maps software. $d$ The GeneGO pathway shows changes in the expression of proteins involved in FAK/Paxillin signaling. The various proteins on the map are represented by different symbols (representing the functional categories of proteins). The symbol next to the thermometer shaded in blue or red indicates the protein identified in this study: blue indicates the protein that is down-regulated in ADT-OH treated MEF cells relative to MEF negative control cells (treated with vehicle). Red represents up-regulated protein. 
Figure 5

a

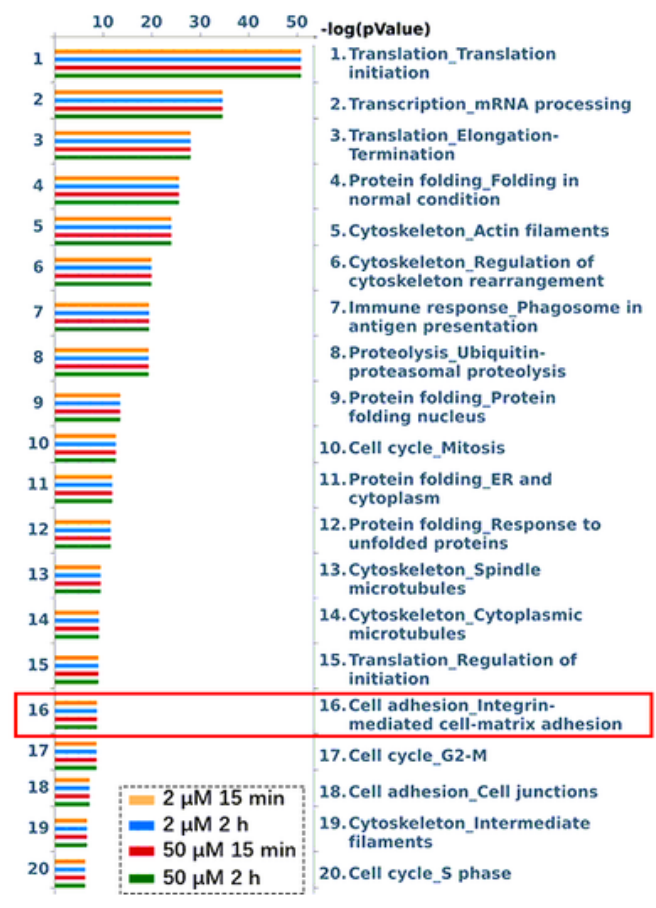

C

\begin{tabular}{|c|c|c|c|}
\hline$\square$ & Network Objects & $\begin{array}{l}=\text { of Maps containing } \\
\text { Network Object }\end{array}$ & Overall $\uparrow$ \\
\hline$\square$ & Rac1 & 27 & 1 \\
\hline$\square$ & ERK $1 / 2$ & 23 & 2 \\
\hline$\square$ & $\mathrm{COC} 42$ & 22 & 3 \\
\hline$\square$ & RhoA & 21 & 4 \\
\hline$\square$ & c.Srs & 21 & 4 \\
\hline$\square$ & PAK1 & 20 & 5 \\
\hline$\square$ & FAK1 & 20 & 5 \\
\hline$\square$ & Paxillin & 16 & 6 \\
\hline$\square$ & Coflin & 13 & 7 \\
\hline$\square$ & GRB2 & 12 & 8 \\
\hline$\square$ & MLCP (rea) & 11 & 9 \\
\hline$\square$ & p130CAS & 11 & 9 \\
\hline$\square$ & ROCK & 11 & 9 \\
\hline$\square$ & CRK & 10 & 10 \\
\hline$\square$ & JNK(MAPK8-10) & 10 & 10 \\
\hline$\square$ & Vinculin & 10 & 10 \\
\hline$\square$ & MRLC & 10 & 10 \\
\hline$\square$ & Calmodulin & 10 & 10 \\
\hline$\square$ & D38 MAPK & 9 & 11 \\
\hline$\square$ & Fibronectin & 9 & 11 \\
\hline$\square$ & MEK $1 / 2$ & 9 & 11 \\
\hline
\end{tabular}

b

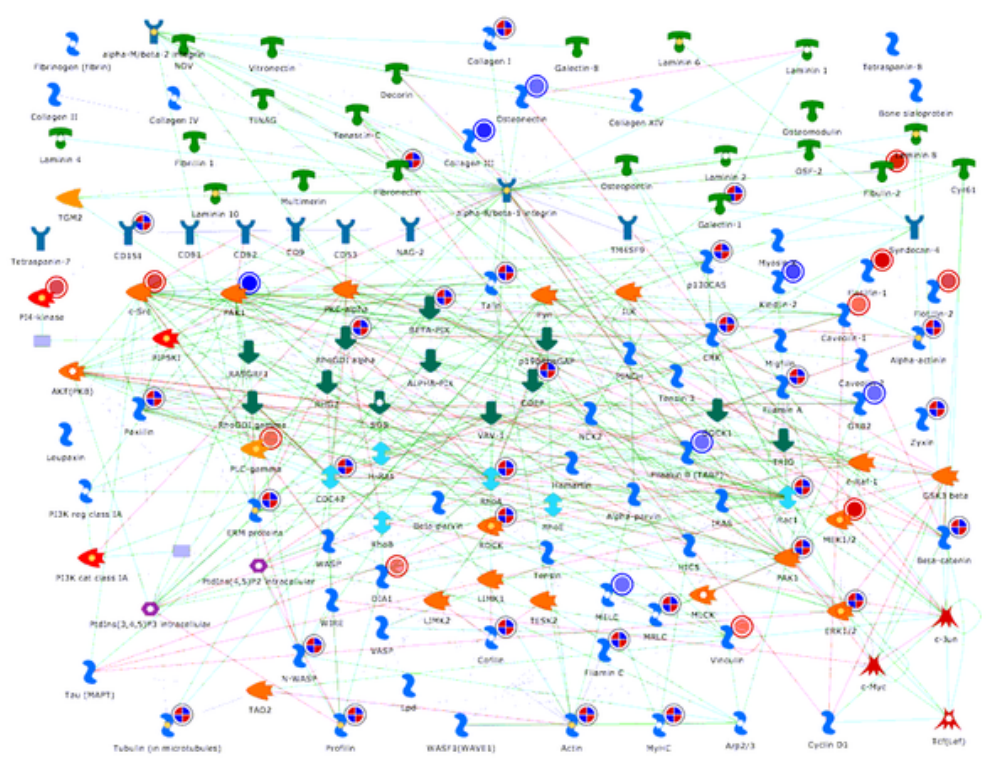

d

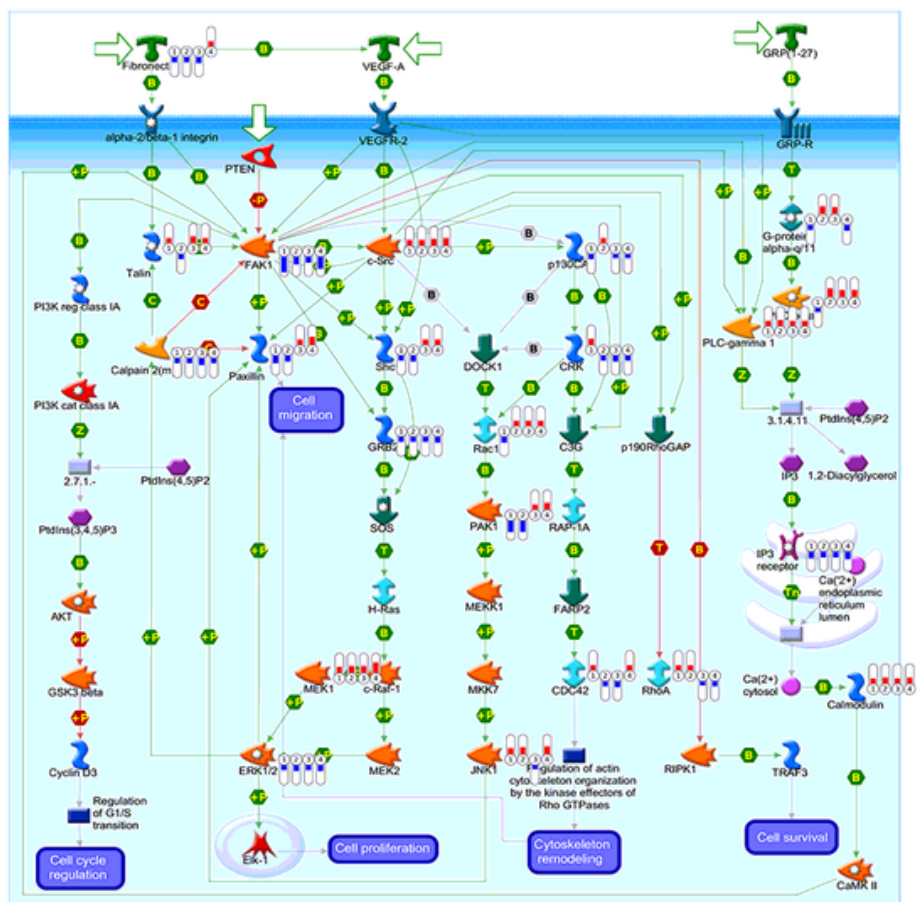

\section{Figure 5}

Proteomics analysis of proteins differentially expressed in ADT-OH-treated cells. a MetacoreTM GeneGo Pathway Maps was used to analyze the ontological categories of differentially expressed proteins in MEF cells treated with or without ADT-OH. b The protein network associated with cell adhesion and migration is differentially expressed in MEF cells treated with ADT-OH. c The network objects involved in Pathway Maps analyzed by MetacoreTM GeneGo Pathway Maps software. $d$ The GeneGO pathway shows 
changes in the expression of proteins involved in FAK/Paxillin signaling. The various proteins on the map are represented by different symbols (representing the functional categories of proteins). The symbol next to the thermometer shaded in blue or red indicates the protein identified in this study: blue indicates the protein that is down-regulated in ADT-OH treated MEF cells relative to MEF negative control cells (treated with vehicle). Red represents up-regulated protein.

\section{Figure 6}

a

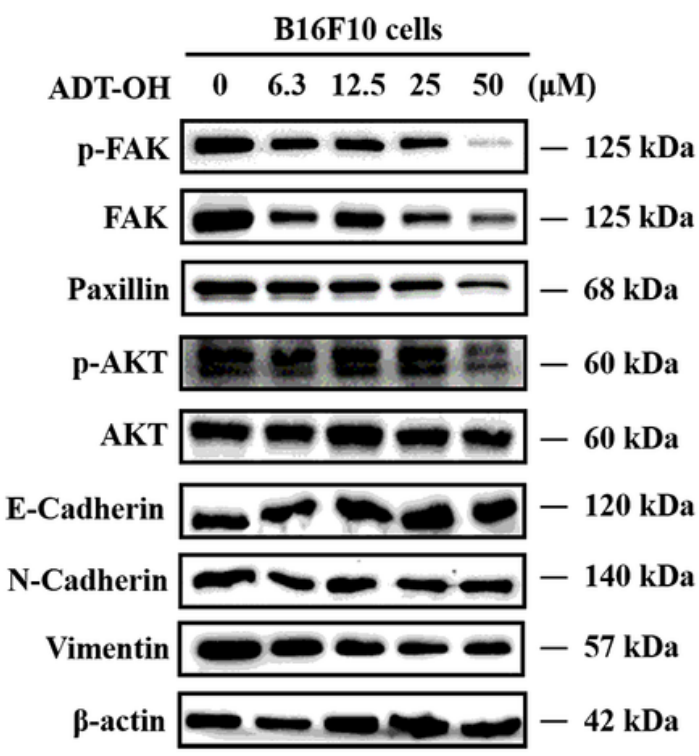

b

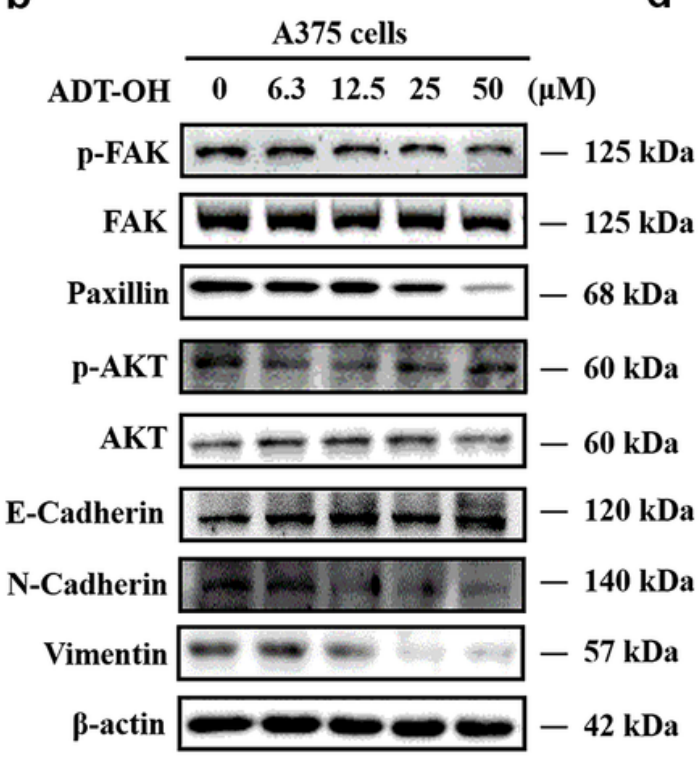

C

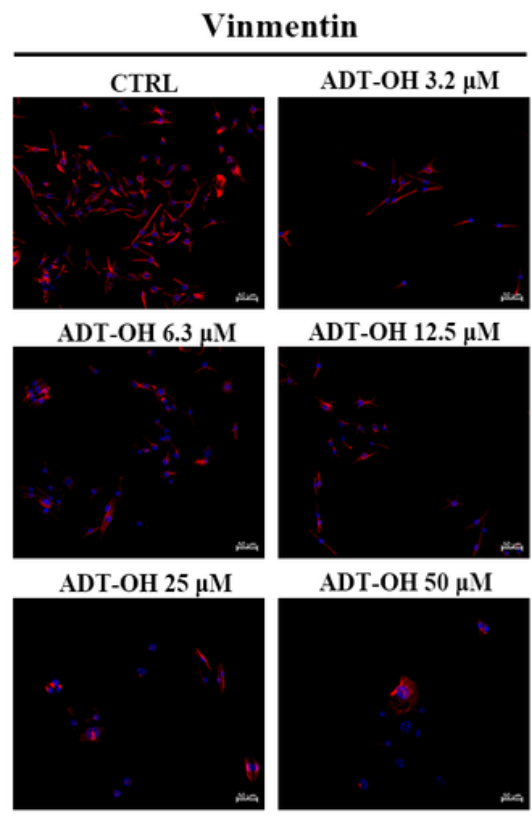

d

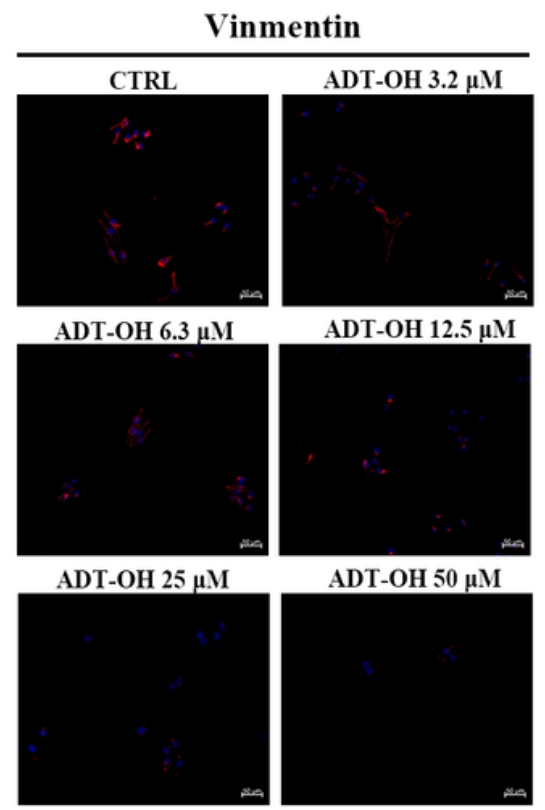

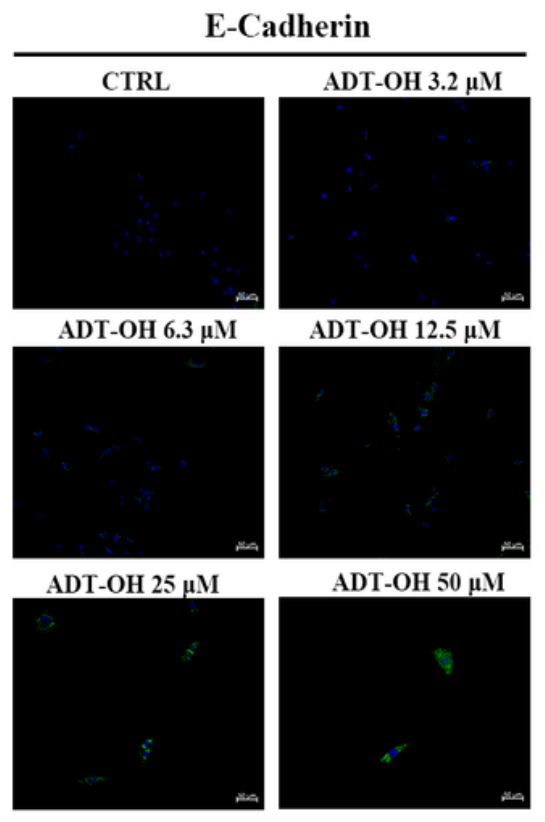

E-Cadherin

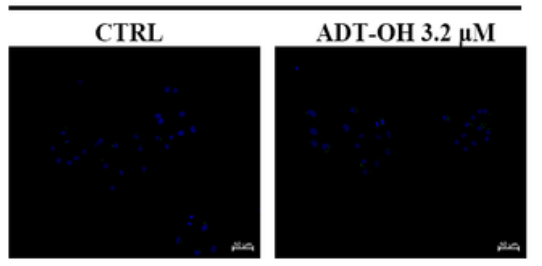

ADT-OH $6.3 \mu \mathrm{M}$

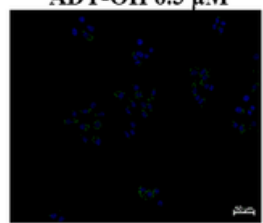

ADT-OH $25 \mu \mathrm{M}$

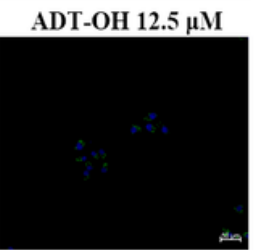

ADT-OH $50 \mu \mathrm{M}$

Figure 6

ADT-OH inhibits cell migration by regulating FAK signaling pathway. a-b Western blot analysis of pFAK, FAK, Paxillin, E-Cadherin, N-Cadherin and Vimintin in A375 and B16F10 cells treated with ADT-OH (24 h) at different concentration. c-d Representative immunofluorescence staining for Vimentin (red) and E- 
Cadherin (green) in B16F10 (c) and A375 (d) cells treated with different concentrations of ADT-OH for 24 h. Scale bars correspond to $50 \mu \mathrm{m}$.

\section{Figure 6}

a

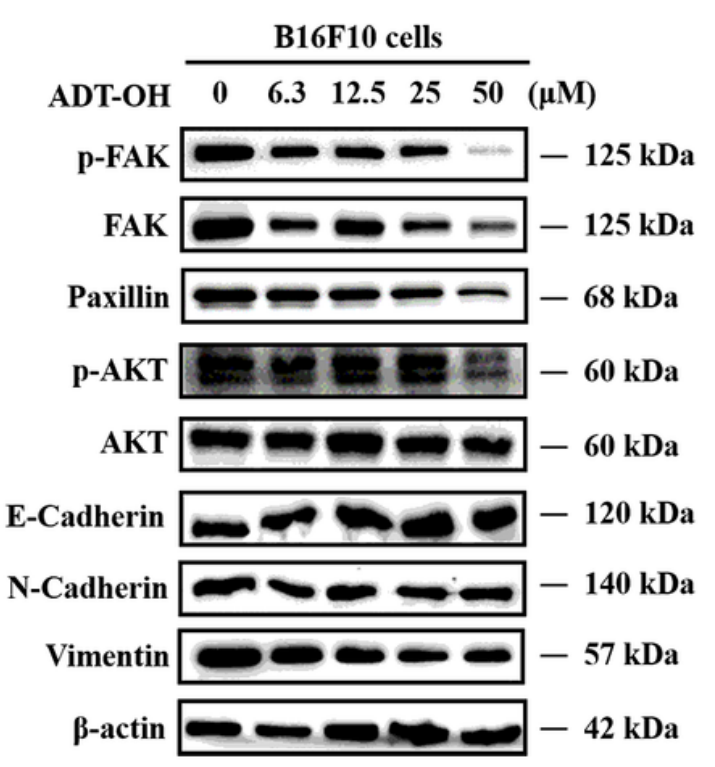

b

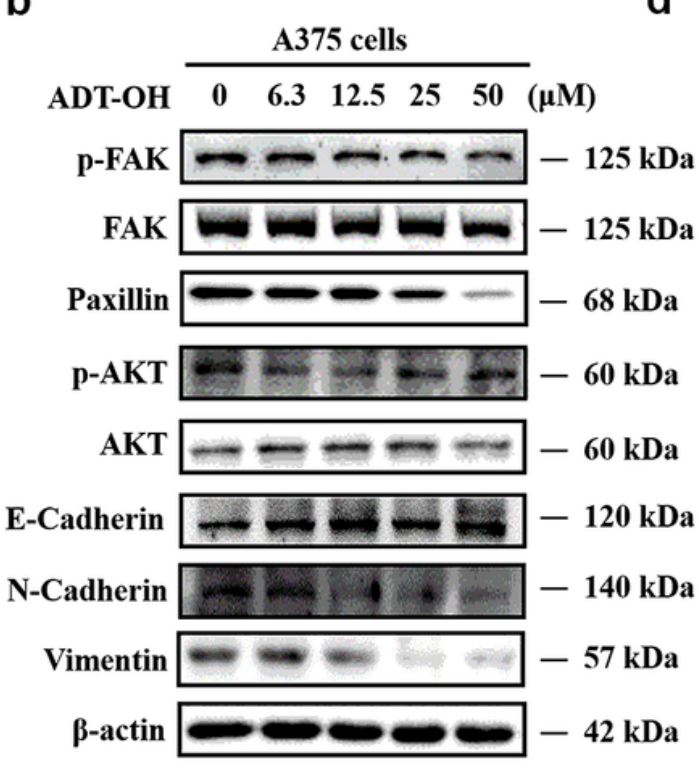

C
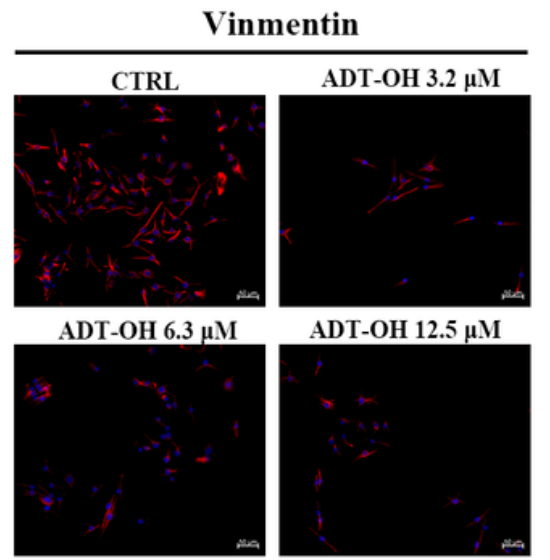

ADT-OH $25 \mu \mathrm{M}$

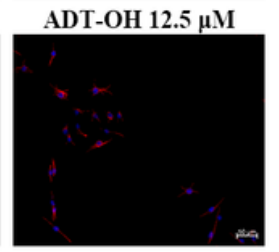

ADT-OH $50 \mu \mathrm{M}$
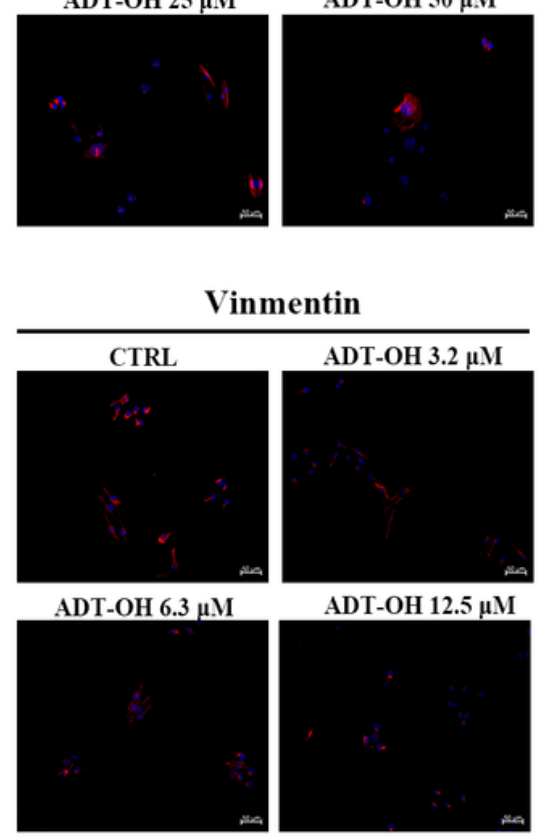

ADT-OH $25 \mu \mathrm{M}$

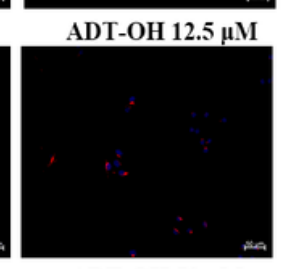

ADT-OH $50 \mu \mathrm{M}$
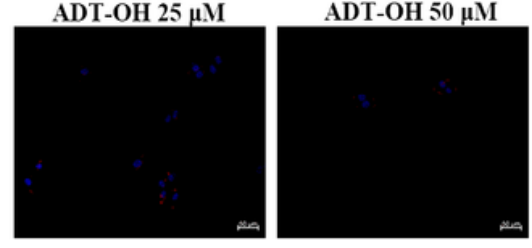

E-Cadherin

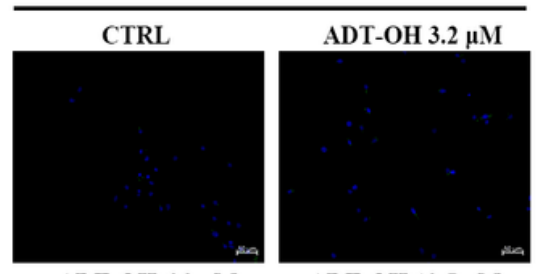

ADT-OH $6.3 \mu \mathrm{M}$

ADT-OH $12.5 \mu \mathrm{M}$
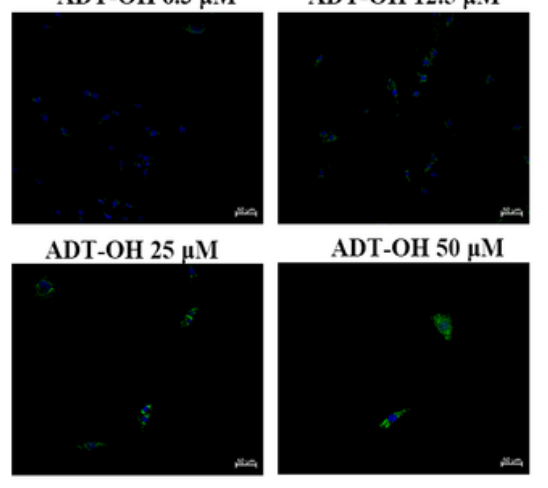

E-Cadherin

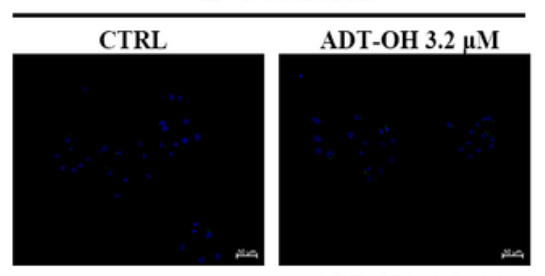

ADT-OH $6.3 \mu \mathrm{M}$

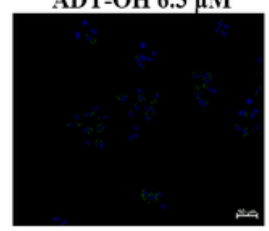

ADT-OH $12.5 \mu \mathrm{M}$

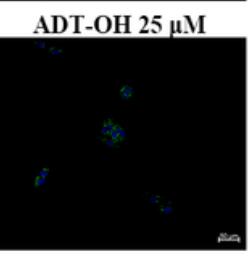

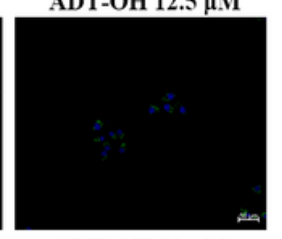

ADT-OH $50 \mu \mathrm{M}$

\section{Figure 6}

ADT-OH inhibits cell migration by regulating FAK signaling pathway. a-b Western blot analysis of pFAK, FAK, Paxillin, E-Cadherin, N-Cadherin and Vimintin in A375 and B16F10 cells treated with ADT-OH (24 h) at different concentration. c-d Representative immunofluorescence staining for Vimentin (red) and ECadherin (green) in B16F10 (c) and A375 (d) cells treated with different concentrations of ADT-OH for 24 h. Scale bars correspond to $50 \mu \mathrm{m}$. 
Figure 6 a

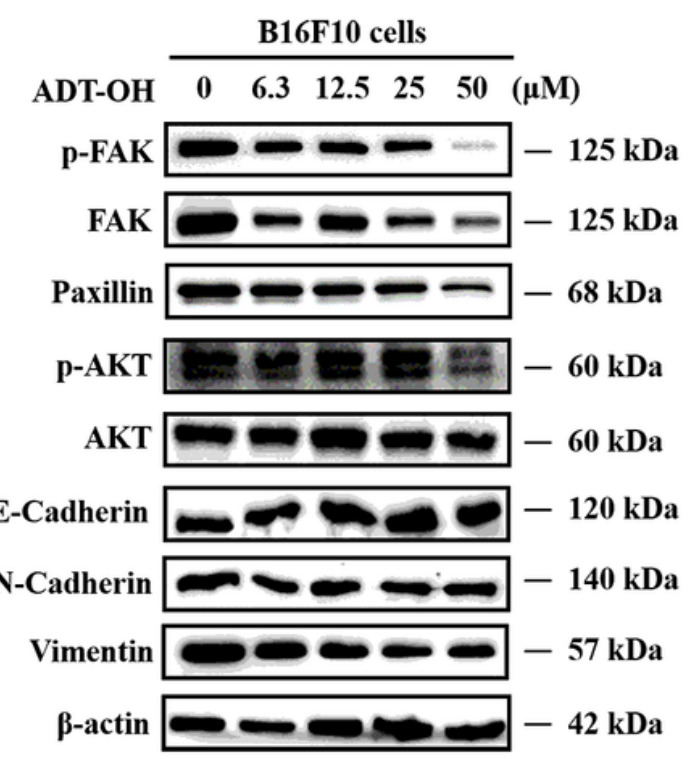

b

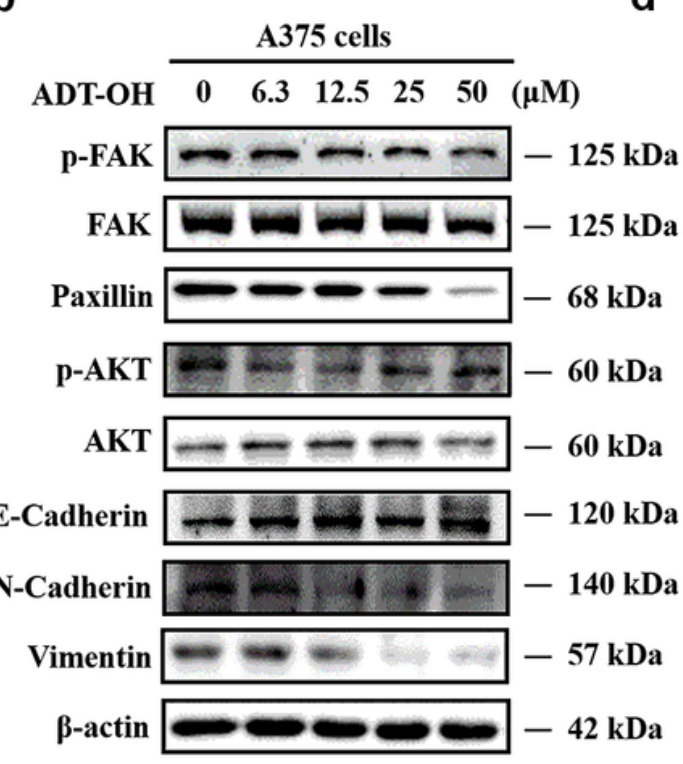

C
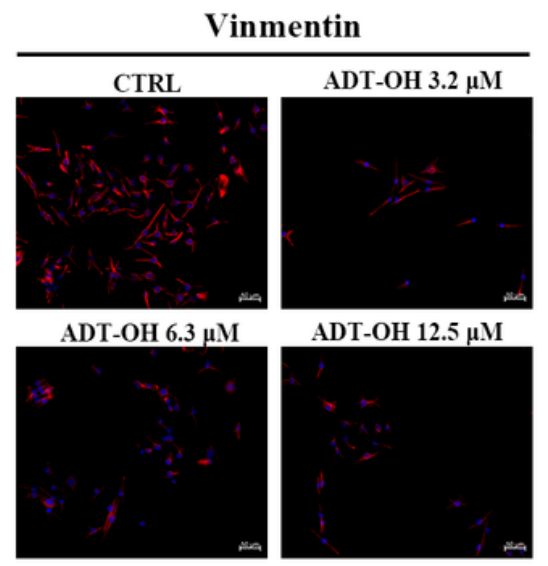

ADT-OH $12.5 \mu \mathrm{M}$

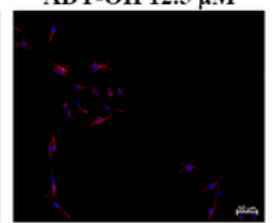

ADT-OH $50 \mu \mathrm{M}$

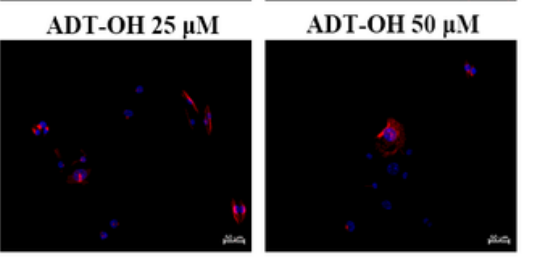

d

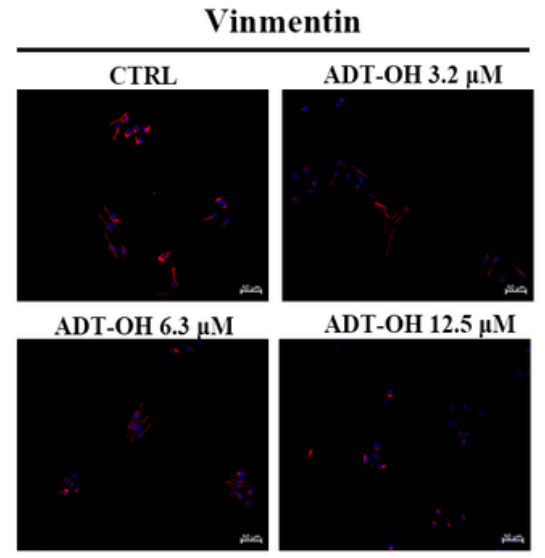

ADT-OH $25 \mu \mathrm{M}$

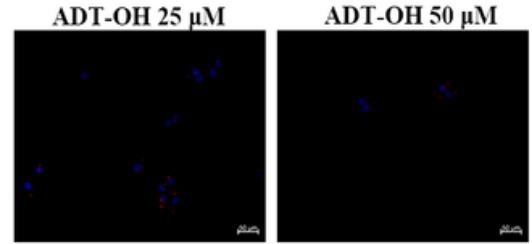

E-Cadherin

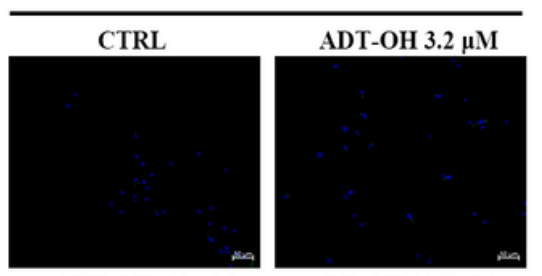

ADT-OH $6.3 \mu \mathrm{M}$

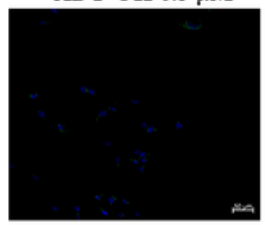

ADT-OH $12.5 \mu \mathrm{M}$

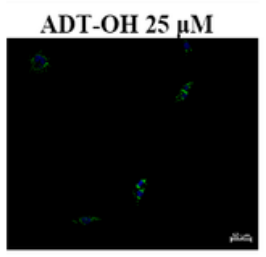

ADT-OH $50 \mu \mathrm{M}$

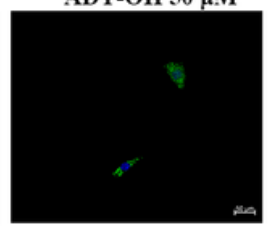

E-Cadherin

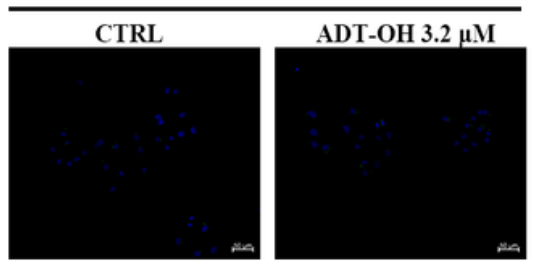

ADT-OH $6.3 \mu \mathrm{M}$

ADT-OH $12.5 \mu \mathrm{M}$

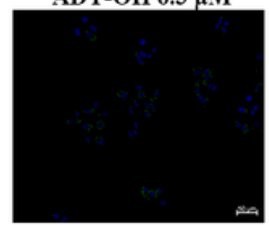

ADT-OH $25 \mu \mathrm{M}$

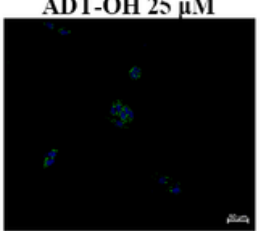

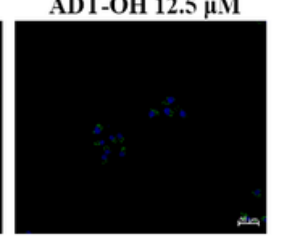

ADT-OH $50 \mu \mathrm{M}$

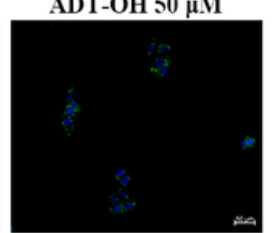

\section{Figure 6}

ADT-OH inhibits cell migration by regulating FAK signaling pathway. a-b Western blot analysis of pFAK, FAK, Paxillin, E-Cadherin, N-Cadherin and Vimintin in A375 and B16F10 cells treated with ADT-OH (24 h) at different concentration. c-d Representative immunofluorescence staining for Vimentin (red) and ECadherin (green) in B16F10 (c) and A375 (d) cells treated with different concentrations of ADT-OH for 24 h. Scale bars correspond to $50 \mu \mathrm{m}$. 


\section{Figure 7}

a

B16F10 cells

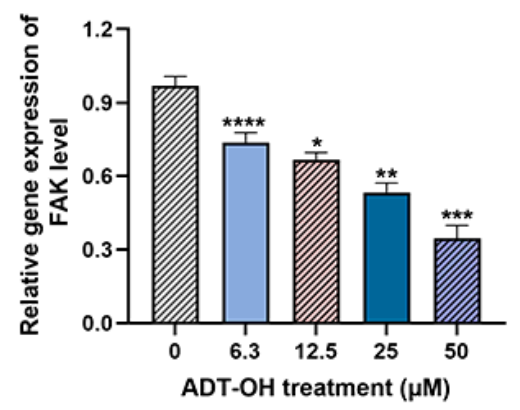

b

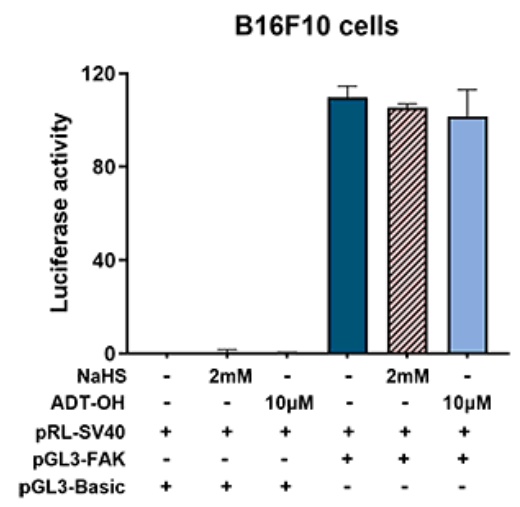

C

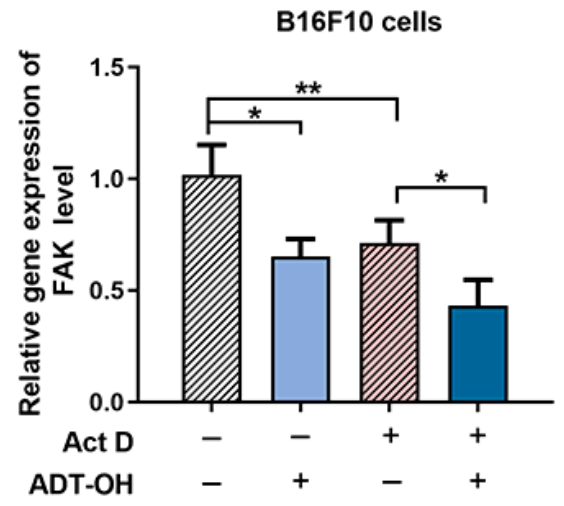

B16F1 cells

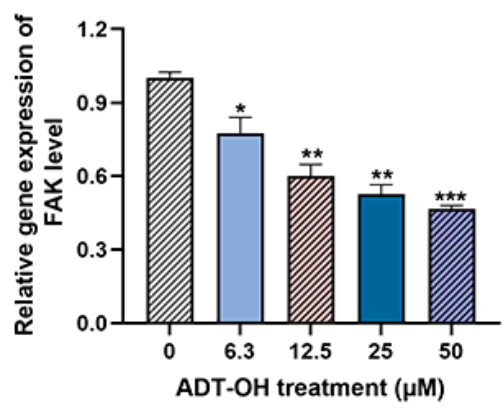

B16F1 cells
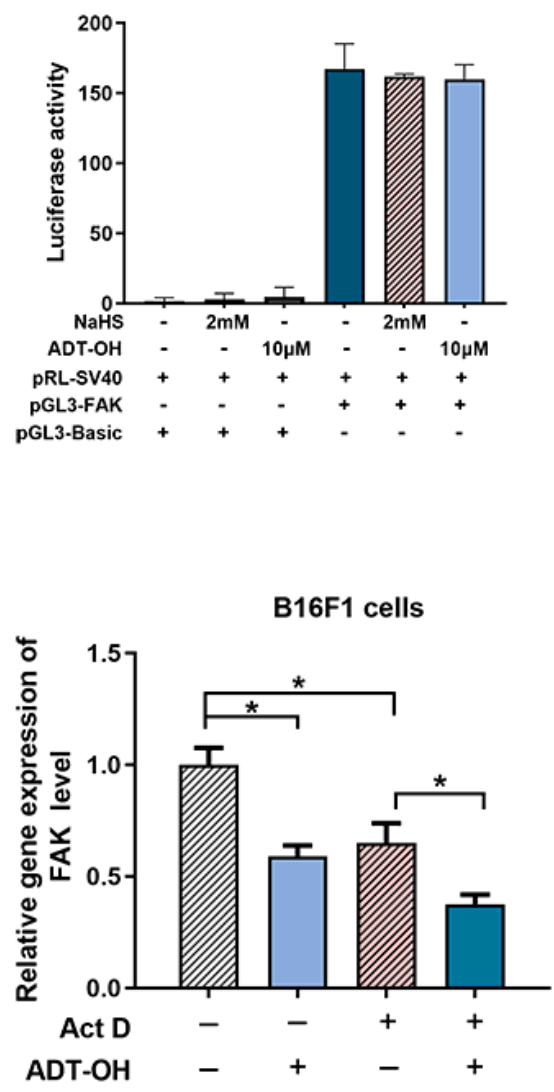

A375 cells

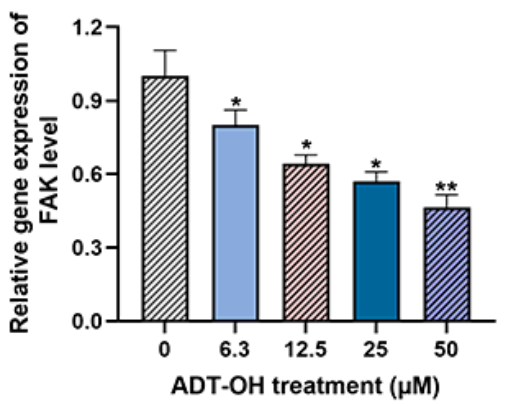

A375 cells

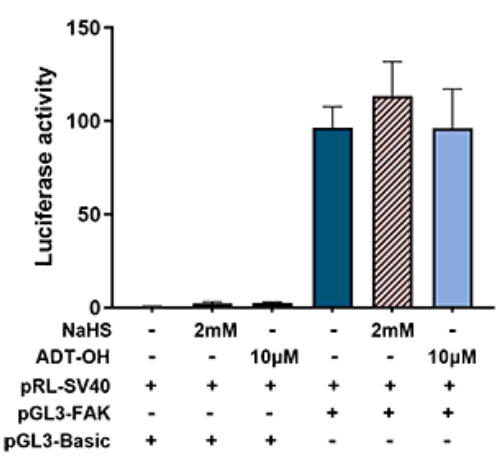

Figure 7

ADT-OH regulates the protein level of FAK mainly through decreasing the stability of FAK. a The FAK mRNA levels of B16F10, B16F1 and A375 cells were detected by qPCR analysis after ADT-OH treatment for $6 \mathrm{~h}$ respectively. b Detection of FAK promoter transcriptional activity after ADT-OH treatment with dual luciferase in B16F10, B16F1 and A375 cells. c B16F10, B16F1 and A375 cells were treated with or without Act $D \otimes 0.05 \mu \mathrm{g} / \mathrm{mL}$ and $A D T-O H(10 \mu \mathrm{M})$ for $12 \mathrm{~h}$, then the mRNA levels of FAK were detected. ${ }^{*} \mathrm{P}<0.05$, $\star \star P<0.01$. Data are expressed as mean \pm SD of three independent experiments. 


\section{Figure 7}

a

B16F10 cells

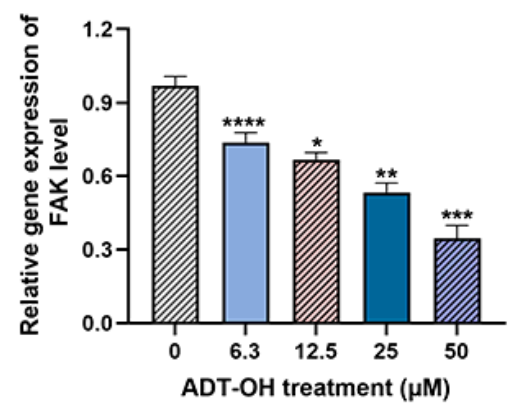

b

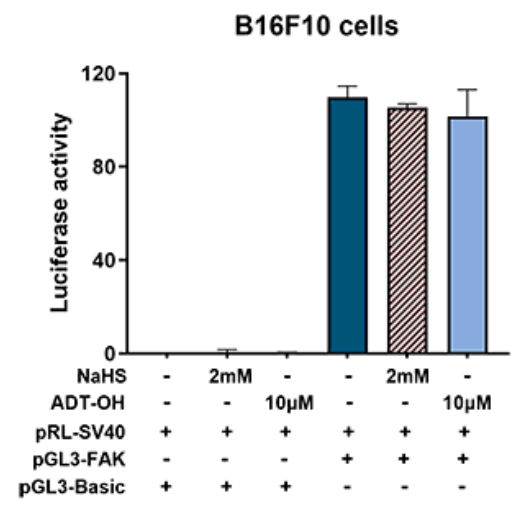

C

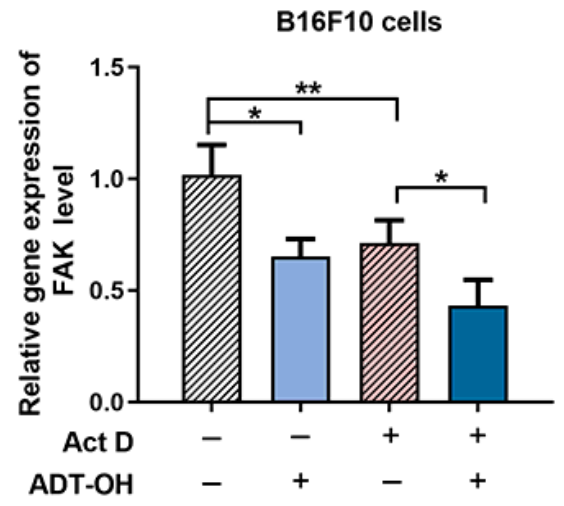

B16F1 cells

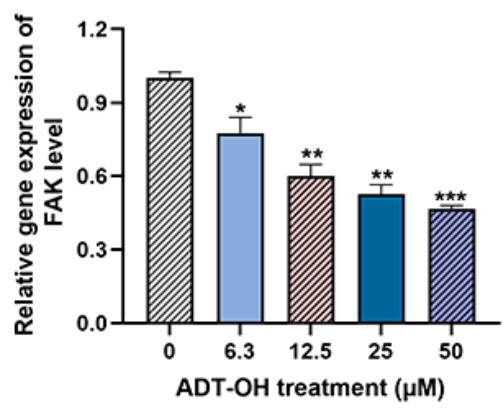

B16F1 cells
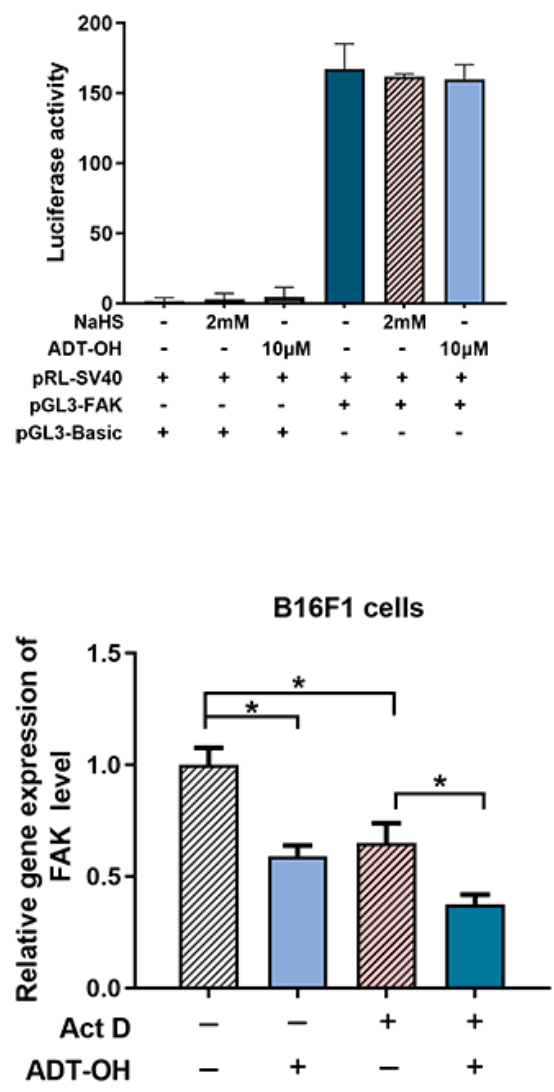

A375 cells

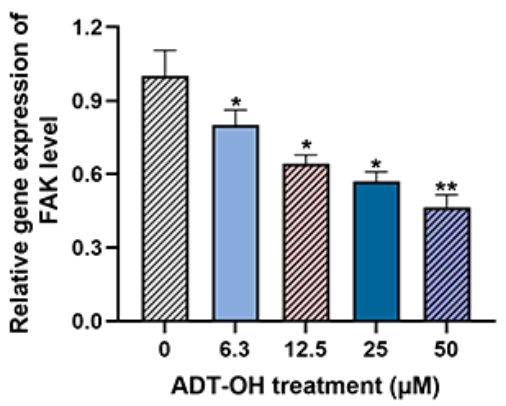

A375 cells

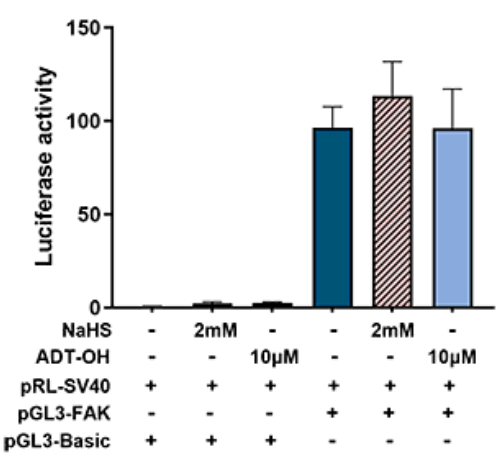

Figure 7

ADT-OH regulates the protein level of FAK mainly through decreasing the stability of FAK. a The FAK mRNA levels of B16F10, B16F1 and A375 cells were detected by qPCR analysis after ADT-OH treatment for $6 \mathrm{~h}$ respectively. b Detection of FAK promoter transcriptional activity after ADT-OH treatment with dual luciferase in B16F10, B16F1 and A375 cells. c B16F10, B16F1 and A375 cells were treated with or without Act $D \otimes 0.05 \mu \mathrm{g} / \mathrm{mL}$ and $A D T-O H(10 \mu \mathrm{M})$ for $12 \mathrm{~h}$, then the mRNA levels of FAK were detected. ${ }^{*} \mathrm{P}<0.05$, $\star \star P<0.01$. Data are expressed as mean \pm SD of three independent experiments. 


\section{Figure 7}

a

B16F10 cells

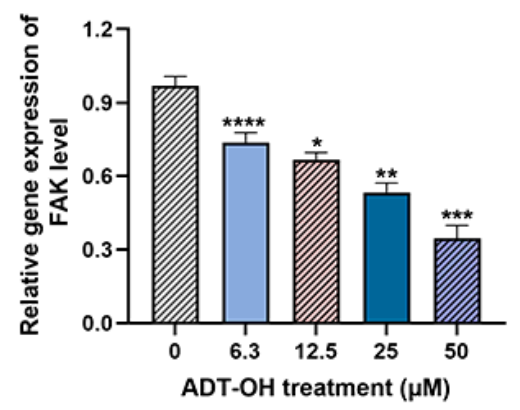

b

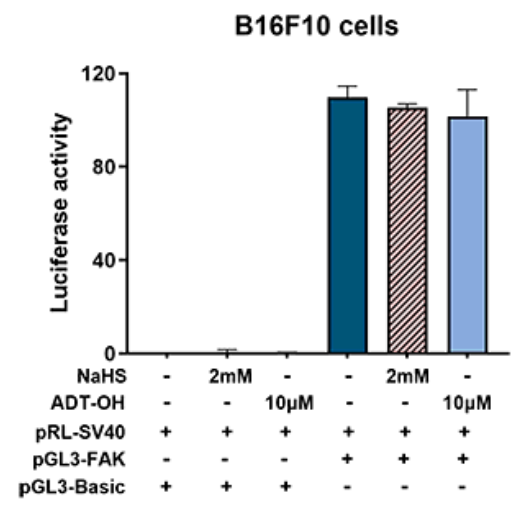

C

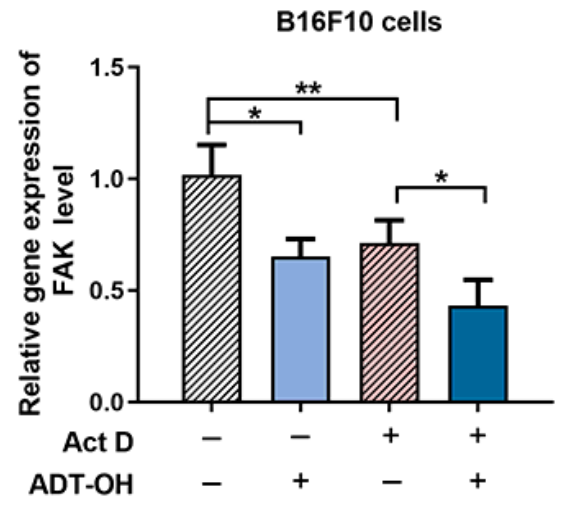

B16F1 cells

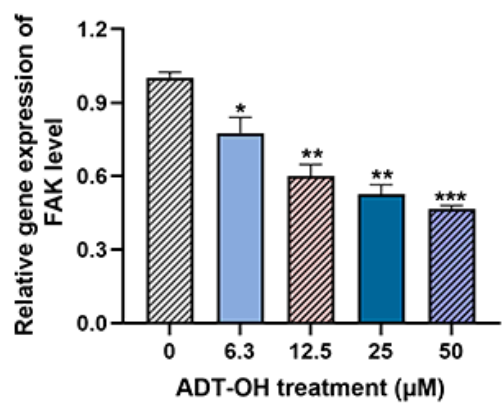

B16F1 cells
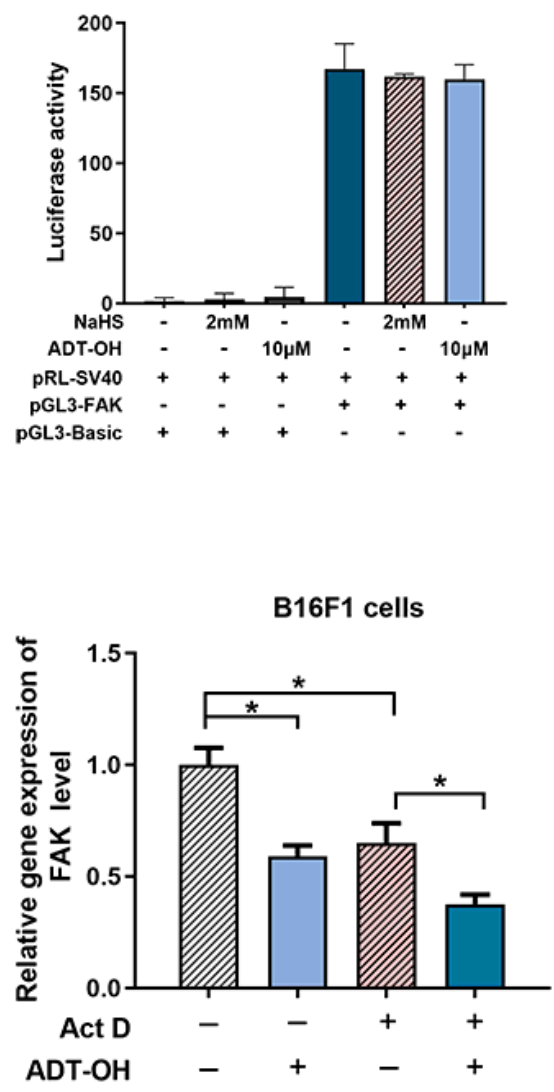

A375 cells

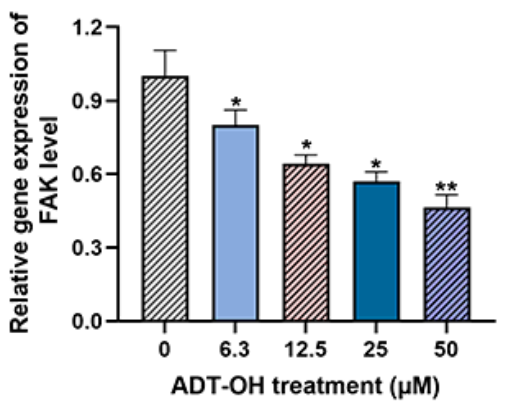

A375 cells

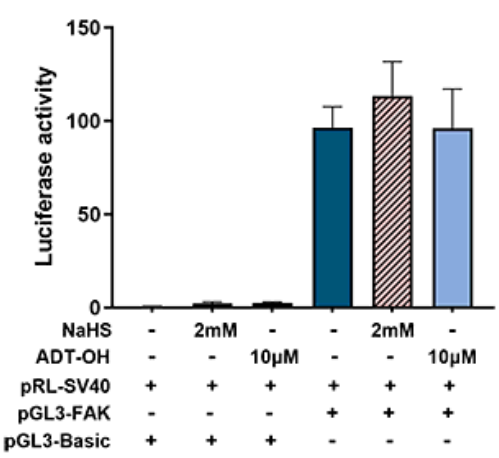

Figure 7

ADT-OH regulates the protein level of FAK mainly through decreasing the stability of FAK. a The FAK mRNA levels of B16F10, B16F1 and A375 cells were detected by qPCR analysis after ADT-OH treatment for $6 \mathrm{~h}$ respectively. b Detection of FAK promoter transcriptional activity after ADT-OH treatment with dual luciferase in B16F10, B16F1 and A375 cells. c B16F10, B16F1 and A375 cells were treated with or without Act $D \otimes 0.05 \mu \mathrm{g} / \mathrm{mL}$ and $A D T-O H(10 \mu \mathrm{M})$ for $12 \mathrm{~h}$, then the mRNA levels of FAK were detected. ${ }^{*} \mathrm{P}<0.05$, $\star \star P<0.01$. Data are expressed as mean \pm SD of three independent experiments. 
Figure 8

a

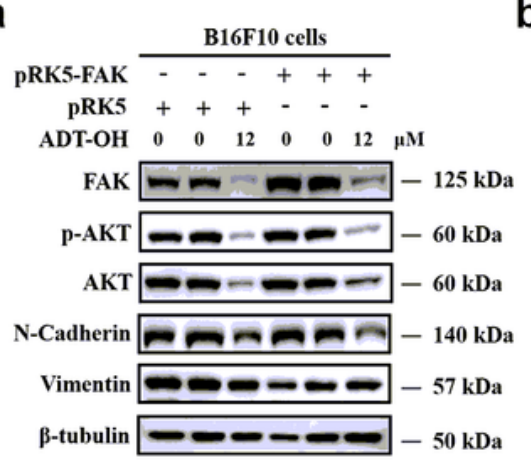

b
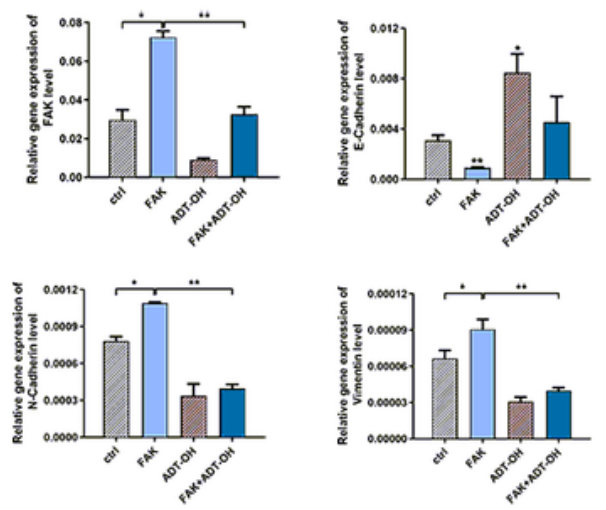

C
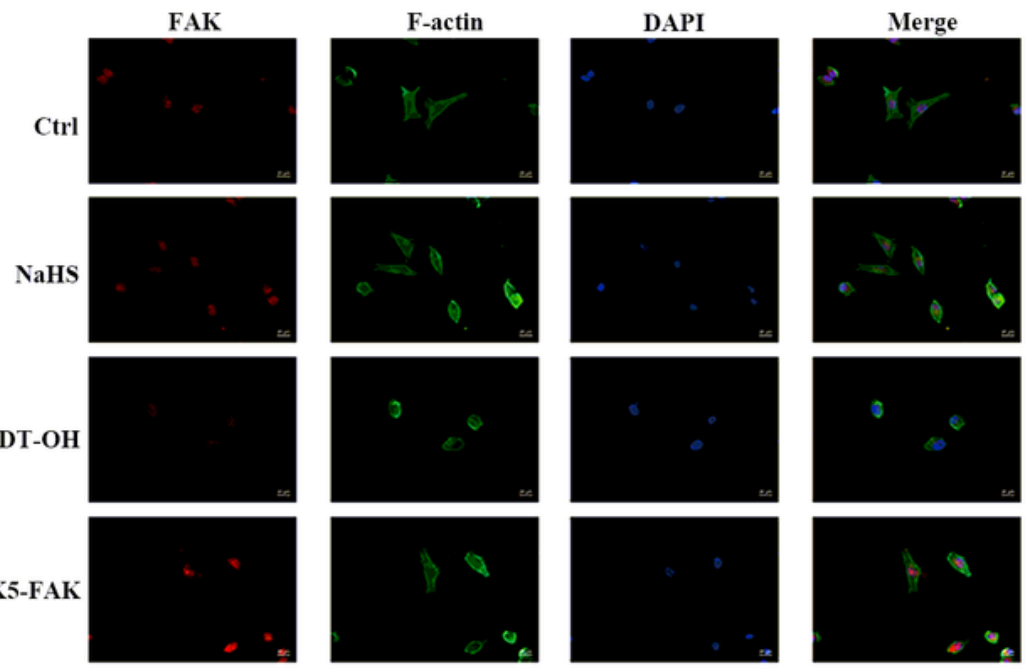

pRK5-FAK
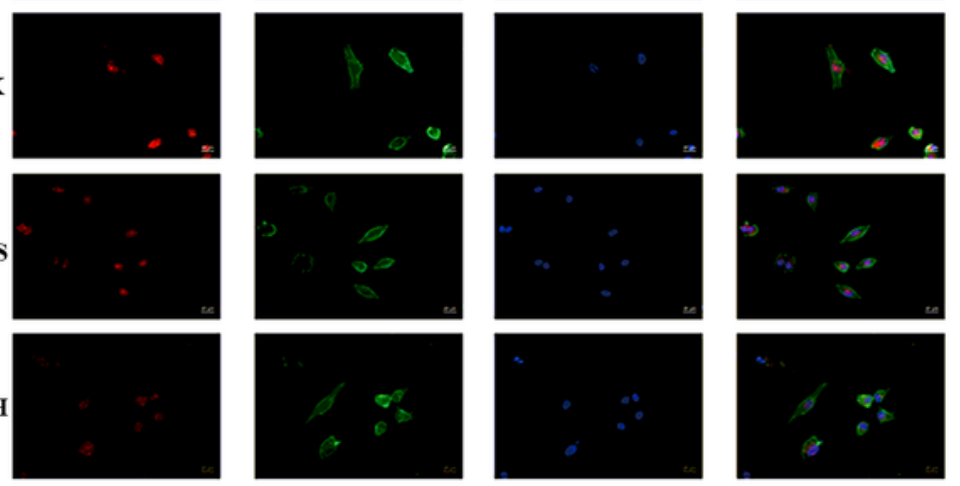

d
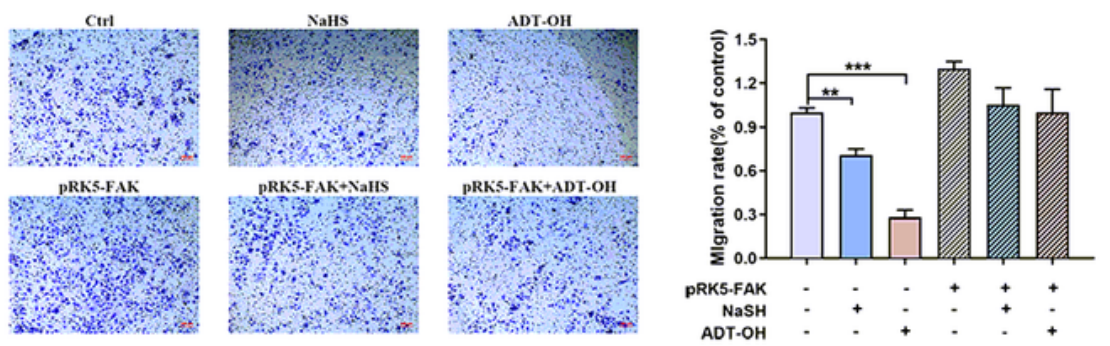

\section{Figure 8}

FAK overexpression reverses the effects of ADT-OH on cell migration. a B16F10 cells were transfected with pRK5-FAK or pRK5 plasmid for $24 \mathrm{~h}$ and then exposed to NaHS $(2 \mathrm{mM})$ or ADT-OH (12 $\mu \mathrm{M})$ for $24 \mathrm{~h}$. The cell lysates were performed by western blot with indicated antibodies. $b$ The mRNA levels of FAK, Ecadherin, N-cadherin and Vimentin in B16F10 cells under different treatment conditions were examined by RT-qPCR. c After transfected with pRK5-FAK or pRK5 plasmid, B16F10 cells were exposed to NaHS (2 
$\mathrm{mM}$ ) or ADT-OH (12 $\mu \mathrm{M})$ for $24 \mathrm{~h}$. Immunofluorescence staining for FAK and F-actin was performed and representative images are shown. $d$ Transwell assay. B16F10 cells were transfected with pRK5-FAK or pRK5 plasmid and then treated with NaHS $(2 \mathrm{mM})$ or ADT-OH $(12 \mu \mathrm{M})$. After $24 \mathrm{~h}$, the cells that migrated to the inferior membrane were stained and counted in 5 fields at a magnification of $\times 100 . n=5$, bar $=100$ $\mu \mathrm{m}$. The experiments were carried out in triplicate and representative data are shown. ${ }^{*} p<0.05,{ }^{* \star} p<$ 0.01 .

\section{Figure 8}

a

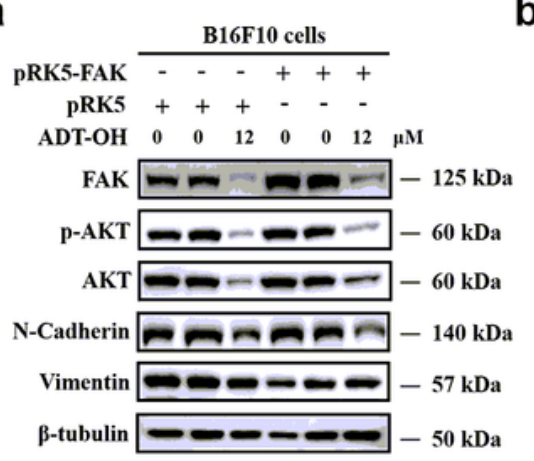

b
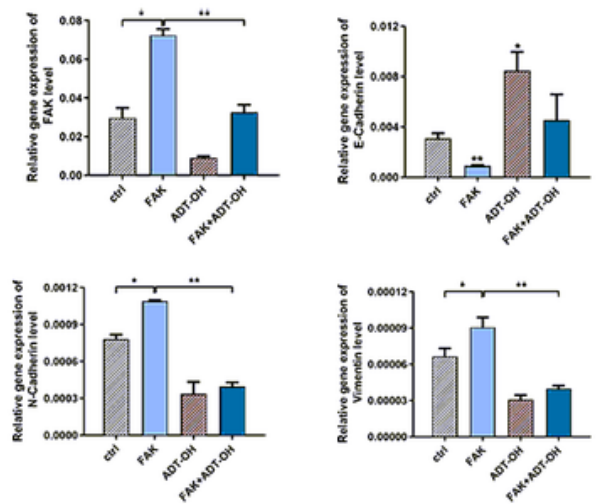

C
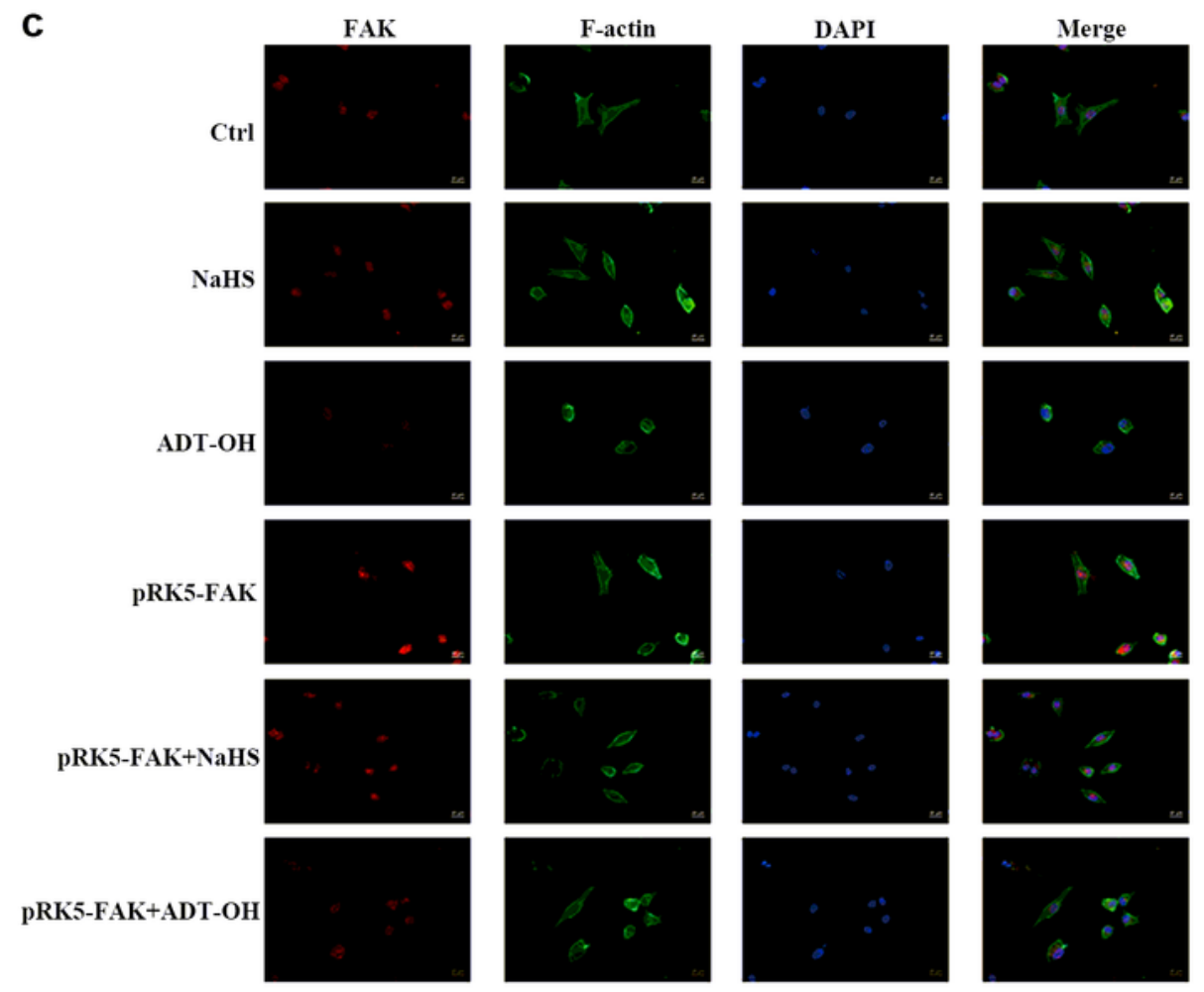

d
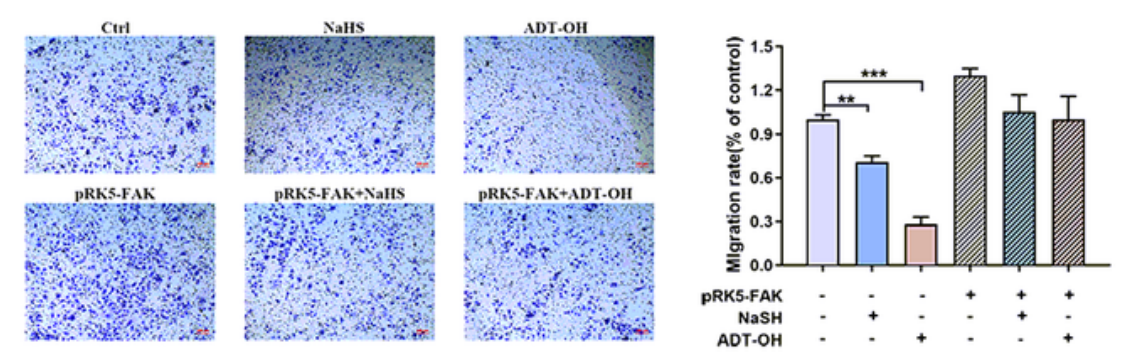

Figure 8 
FAK overexpression reverses the effects of ADT-OH on cell migration. a B16F10 cells were transfected with pRK5-FAK or pRK5 plasmid for $24 \mathrm{~h}$ and then exposed to NaHS (2 mM) or ADT-OH (12 $\mu \mathrm{M})$ for $24 \mathrm{~h}$. The cell lysates were performed by western blot with indicated antibodies. b The mRNA levels of FAK, Ecadherin, N-cadherin and Vimentin in B16F10 cells under different treatment conditions were examined by RT-qPCR. c After transfected with pRK5-FAK or pRK5 plasmid, B16F10 cells were exposed to NaHS (2 $\mathrm{mM})$ or ADT-OH $(12 \mu \mathrm{M})$ for $24 \mathrm{~h}$. Immunofluorescence staining for FAK and F-actin was performed and representative images are shown. $d$ Transwell assay. B16F10 cells were transfected with pRK5-FAK or pRK5 plasmid and then treated with NaHS $(2 \mathrm{mM})$ or ADT-OH $(12 \mu \mathrm{M})$. After $24 \mathrm{~h}$, the cells that migrated to the inferior membrane were stained and counted in 5 fields at a magnification of $\times 100 . n=5$, bar $=100$ $\mu \mathrm{m}$. The experiments were carried out in triplicate and representative data are shown. ${ }^{*} p<0.05,{ }^{* *} p<$ 0.01 . 
Figure 8

a

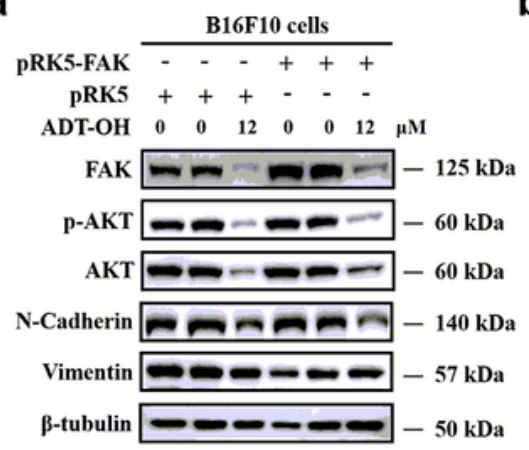

b
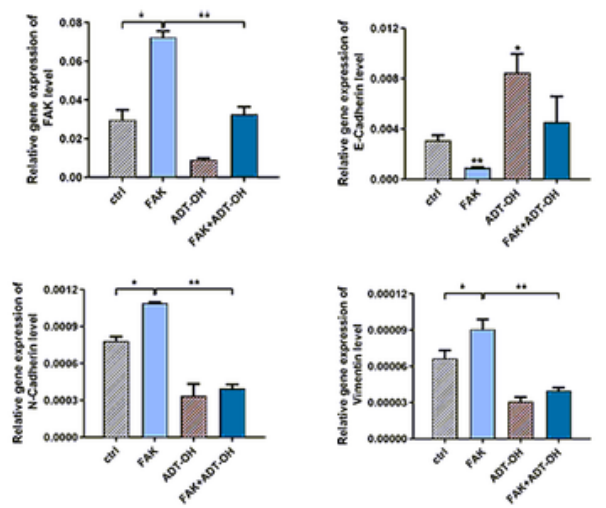

C
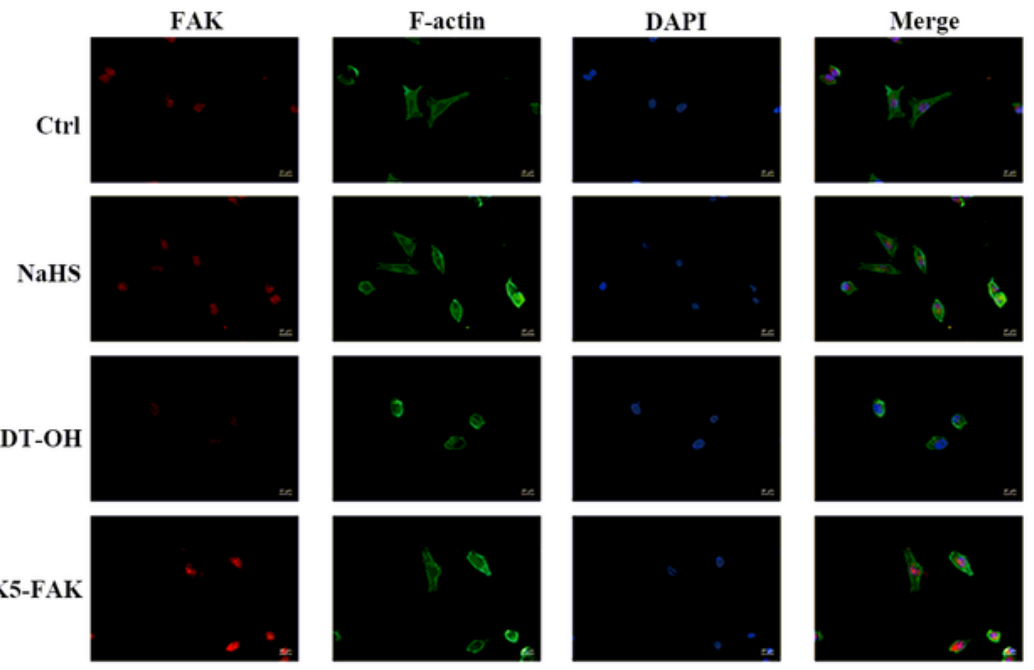

pRK5-FAK
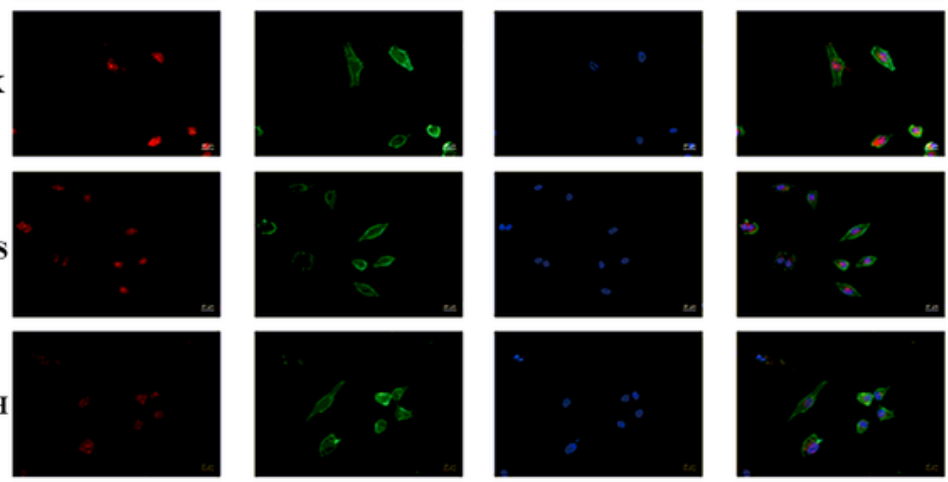

d
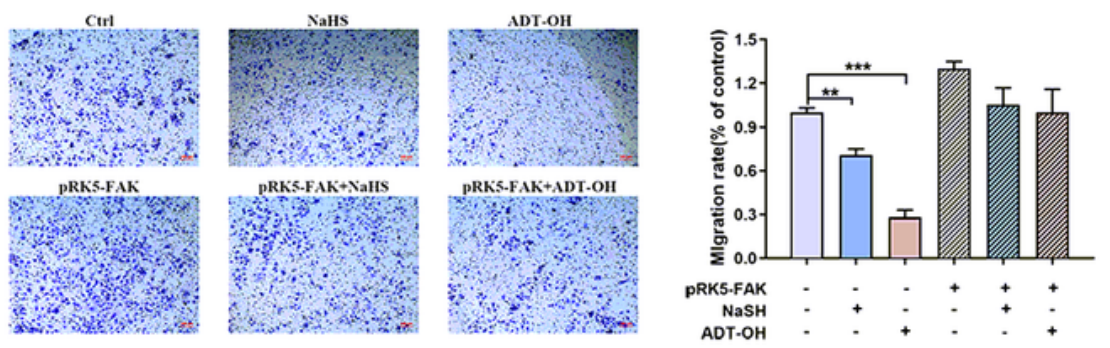

\section{Figure 8}

FAK overexpression reverses the effects of ADT-OH on cell migration. a B16F10 cells were transfected with pRK5-FAK or pRK5 plasmid for $24 \mathrm{~h}$ and then exposed to NaHS $(2 \mathrm{mM})$ or ADT-OH $(12 \mu \mathrm{M})$ for $24 \mathrm{~h}$. The cell lysates were performed by western blot with indicated antibodies. $b$ The mRNA levels of FAK, Ecadherin, N-cadherin and Vimentin in B16F10 cells under different treatment conditions were examined by RT-qPCR. c After transfected with pRK5-FAK or pRK5 plasmid, B16F10 cells were exposed to NaHS (2 
$\mathrm{mM}$ ) or ADT-OH (12 $\mu \mathrm{M})$ for $24 \mathrm{~h}$. Immunofluorescence staining for FAK and F-actin was performed and representative images are shown. $d$ Transwell assay. B16F10 cells were transfected with pRK5-FAK or pRK5 plasmid and then treated with NaHS $(2 \mathrm{mM})$ or ADT-OH $(12 \mu \mathrm{M})$. After $24 \mathrm{~h}$, the cells that migrated to the inferior membrane were stained and counted in 5 fields at a magnification of $\times 100 . n=5$, bar $=100$ $\mu \mathrm{m}$. The experiments were carried out in triplicate and representative data are shown. ${ }^{\star} p<0.05,{ }^{* \star} p<$ 0.01 .

\section{Supplementary Files}

This is a list of supplementary files associated with this preprint. Click to download.

- AdditionalFile1.docx

- AdditionalFile1.docx

- AdditionalFile1.docx

- AdditionalFile2.pptx

- AdditionalFile2.pptx

- AdditionalFile2.pptx

- AdditionalFile3.xlsx

- AdditionalFile3.xlsx

- AdditionalFile3.xlsx 